Cochrane Database of Systematic Reviews

\title{
Prophylactic platelet transfusions prior to surgery for people with a
} low platelet count (Review)

Estcourt LJ, Malouf R, Doree C, Trivella M, Hopewell S, Birchall J

Estcourt LJ, Malouf R, Doree C, Trivella M, Hopewell S, Birchall J.

Prophylactic platelet transfusions prior to surgery for people with a low platelet count.

Cochrane Database of Systematic Reviews 2018, Issue 9. Art. No.: CD012779.

DOI: 10.1002/14651858.CD012779.pub2.

www.cochranelibrary.com 
TABLE OF CONTENTS

ABSTRAC

PLAIN LANGUAGE SUMMARY

SUMMARY OF FINDINGS

BACKGROUND

OBJECTIVES

METHODS

RESULTS

Figure 1.

DISCUSSION

Figure 2.

AUTHORS' CONCLUSIONS

ACKNOWLEDGEMENTS

REFERENCES

CHARACTERISTICS OF STUDIES

DATA AND ANALYSES

Analysis 1.1. Comparison 1 Prophylactic platelet transfusion prior to surgery versus no prophylactic platelet transfusion prior to surgery, Outcome 1 All-cause mortality within 30 days of surgery.

Analysis 1.2. Comparison 1 Prophylactic platelet transfusion prior to surgery versus no prophylactic platelet transfusion prior to surgery, Outcome 2 Number of participants with major procedure-related bleeding within 7 days of surgery.

Analysis 1.3. Comparison 1 Prophylactic platelet transfusion prior to surgery versus no prophylactic platelet transfusion prior to surgery, Outcome 3 Number of participants with minor procedure-related bleeding within 7 days of surgery.

Analysis 1.4. Comparison 1 Prophylactic platelet transfusion prior to surgery versus no prophylactic platelet transfusion prior to surgery, Outcome 4 Proportion of participants requiring additional interventions to stop bleeding within 7 days of surgery. .

Analysis 2.1. Comparison 2 Prophylactic platelet transfusion prior to surgery versus alternative treatments, Outcome 1 Number of participants with minor procedure-related bleeding within 7 days of surgery.

Analysis 2.2. Comparison 2 Prophylactic platelet transfusion prior to surgery versus alternative treatments, Outcome 2 Proportion of participants requiring additional interventions to stop bleeding within 7 days of surgery.

Analysis 2.3. Comparison 2 Prophylactic platelet transfusion prior to surgery versus alternative treatments, Outcome 3 Serious adverse events (transfusion related adverse effects within 24 hours of the transfusion).

APPENDICES

CONTRIBUTIONS OF AUTHORS

DECLARATIONS OF INTEREST

SOURCES OF SUPPORT

DIFFERENCES BETWEEN PROTOCOL AND REVIEW

INDEX TERMS 
[Intervention Review]

\section{Prophylactic platelet transfusions prior to surgery for people with a low platelet count}

Lise J Estcourt¹, Reem Malouf², Carolyn Doree ${ }^{3}$, Marialena Trivella4 ${ }^{4}$, Sally Hopewell ${ }^{5}$, Janet Birchall 6

1Haematology/Transfusion Medicine, NHS Blood and Transplant, Oxford, UK. 2National Perinatal Epidemiology Unit (NPEU), University of Oxford, Oxford, UK. ${ }^{3}$ Systematic Review Initiative, NHS Blood and Transplant, Oxford, UK. ${ }^{4}$ Centre for Statistics in Medicine, University of Oxford, Oxford, UK. ${ }^{5}$ Nuffield Department of Orthopaedics, Rheumatology and Musculoskeletal Sciences (NDORMS), University of Oxford, Oxford, UK. 6 Haematology/Transfusion Medicine, NHS Blood and Transplant, Bristol and North Bristol NHS Trust, Bristol, UK

Contact: Lise J Estcourt, Haematology/Transfusion Medicine, NHS Blood and Transplant, Level 2, John Radcliffe Hospital, Headington, Oxford, OX3 9BQ, UK. lise.estcourt@nhsbt.nhs.uk, lise.estcourt@ndcls.ox.ac.uk.

Editorial group: Cochrane Haematological Malignancies Group.

Publication status and date: New, published in Issue 9, 2018.

Citation: Estcourt LJ, Malouf R, Doree C, Trivella M, Hopewell S, Birchall J. Prophylactic platelet transfusions prior to surgery for people with a low platelet count. Cochrane Database of Systematic Reviews 2018, Issue 9. Art. No.: CD012779. DOI: 10.1002/14651858.CD012779.pub2.

Copyright @ 2018 The Cochrane Collaboration. Published by John Wiley \& Sons, Ltd.

\section{A B S T R A C T}

\section{Background}

People with thrombocytopenia often require a surgical procedure. A low platelet count is a relative contraindication to surgery due to the risk of bleeding. Platelet transfusions are used in clinical practice to prevent and treat bleeding in people with thrombocytopenia. Current practice in many countries is to correct thrombocytopenia with platelet transfusions prior to surgery. Alternatives to platelet transfusion are also used prior surgery.

\section{Objectives}

To determine the clinical effectiveness and safety of prophylactic platelet transfusions prior to surgery for people with a low platelet count.

\section{Search methods}

We searched the following major data bases: Cochrane Central Register of Controlled Trials (CENTRAL; 2017, Issue 2), PubMed (epublications only), Ovid MEDLINE, Ovid Embase, the Transfusion Evidence Library and ongoing trial databases to 11 December 2017.

\section{Selection criteria}

We included all randomised controlled trials (RCTs), as well as non-RCTs and controlled before-and-after studies (CBAs), that met Cochrane EPOC (Effective Practice and Organisation of Care) criteria, that involved the transfusion of platelets prior to surgery (any dose, at any time, single or multiple) in people with low platelet counts. We excluded studies on people with a low platelet count who were actively bleeding.

\section{Data collection and analysis}

We used standard methodological procedures expected by Cochrane for data collection. We were only able to combine data for two outcomes and we presented the rest of the findings in a narrative form.

\section{Main results}

We identified five RCTs, all conducted in adults; there were no eligible non-randomised studies. Three completed trials enrolled 180 adults and two ongoing trials aim to include 627 participants. The completed trials were conducted between 2005 and 2009 . The two ongoing trials are scheduled to complete recruitment by October 2019. One trial compared prophylactic platelet transfusions to no transfusion in people with thrombocytopenia in an intensive care unit (ICU). Two small trials, 108 participants, compared prophylactic platelet transfusions to 
other alternative treatments in people with liver disease. One trial compared desmopressin to fresh frozen plasma or one unit of platelet transfusion or both prior to surgery. The second trial compared platelet transfusion prior to surgery with two types of thrombopoietin mimetics: romiplostim and eltrombopag. None of the included trials were free from methodological bias. No included trials compared different platelet count thresholds for administering a prophylactic platelet transfusion prior to surgery. None of the included trials reported on all the review outcomes and the overall quality per reported outcome was very low.

None of the three completed trials reported: all-cause mortality at 90 days post surgery; mortality secondary to bleeding, thromboembolism or infection; number of red cell or platelet transfusions per participant; length of hospital stay; or quality of life.

None of the trials included children or people who needed major surgery or emergency surgical procedures.

\section{Platelet transfusion versus no platelet transfusion (1 trial, 72 participants)}

We were very uncertain whether giving a platelet transfusion prior to surgery had any effect on all-cause mortality within 30 days ( 1 trial, 72 participants; risk ratio (RR) $0.78,95 \%$ confidence interval (CI) 0.41 to 1.45 ; very-low quality evidence). We were very uncertain whether giving a platelet transfusion prior to surgery had any effect on the risk of major (1 trial, 64 participants; RR 1.60, 95\% CI 0.29 to 8.92; very lowquality evidence), or minor bleeding (1 trial, 64 participants; RR 1.29, 95\% Cl 0.90 to 1.85; very-low quality evidence). No serious adverse events occurred in either study arm (1 trial, 72 participants, very low-quality evidence).

\section{Platelet transfusion versus alternative to platelet transfusion (2 trials, 108 participants)}

We were very uncertain whether giving a platelet transfusion prior to surgery compared to an alternative has any effect on the risk of major ( 2 trials, 108 participants; no events; very low-quality evidence), or minor bleeding (desmopressin: 1 trial, 36 participants; RR 0.89, 95\% $\mathrm{Cl} 0.06$ to 13.23; very-low quality evidence: thrombopoietin mimetics: 1 trial, 65 participants; no events; very-low quality evidence). We were very uncertain whether there was a difference in transfusion-related adverse effects between the platelet transfused group and the alternative treatment group (desmopressin: 1 trial, 36 participants; RR 2.70, 95\% Cl 0.12 to 62.17; very-low quality evidence).

\section{Authors' conclusions}

Findings of this review were based on three small trials involving minor surgery in adults with thrombocytopenia. We found insufficient evidence to recommend the administration of preprocedure prophylactic platelet transfusions in this situation with a lack of evidence that transfusion resulted in a reduction in postoperative bleeding or all-cause mortality. The small number of trials meeting the inclusion criteria and the limitation in reported outcomes across the trials precluded meta-analysis for most outcomes. Further adequately powered trials, in people of all ages, of prophylactic platelet transfusions compared with no transfusion, other alternative treatments, and considering different platelet thresholds prior to planned and emergency surgical procedures are required. Future trials should include major surgery and report on bleeding, adverse effects, mortality (as a long-term outcome) after surgery, duration of hospital stay and quality of life measures.

\section{PLAIN LANGUAGE SUMMARY}

\section{Platelet transfusion before surgery for people with low platelet counts}

\section{Review question}

We aimed to assess the safety and clinical effectiveness of administrating platelet transfusions to people with a low platelet count who require surgery. We included three comparisons: giving platelet transfusion versus no platelet transfusion; giving platelet transfusion versus an alternative treatment (medicines that reduce the risk of bleeding or increase the platelet count) or giving platelet transfusions when the platelet count is below a set number (low platelet count e.g. $20 \times 10^{9} / \mathrm{L}$ versus slightly higher e.g. $50 \times 10^{9} / \mathrm{L}$ ).

Our target population was people with a low platelet count of any age who required surgery. We excluded studies on people with a low platelet count who were actively bleeding.

\section{Key messages}

There was not enough evidence to help guide the use of platelet transfusions prior to surgery in people with a low platelet count. There is no evidence for infants and children or prior to a major operation.

\section{What was studied in this review?}

Platelets are tiny cells in the blood that form clots to help stop bleeding. If a person with a low platelet counts requires surgery they are at increased risk of bleeding during and after surgery. A number of strategies are used to reduce the risk of bleeding, these include: giving platelet transfusions (injecting platelets into the bloodstream) to increase the platelet count, giving medicines to increase the platelet count and giving medicines that reduce the risk of bleeding. The current strategies are not based on good evidence, but based on individual clinical experience and expertise. 


\section{What are the main results of this review?}

We found five randomised controlled trials (clinical studies where people are randomly put into one of two or more treatment groups) eligible for inclusion in this review. Two of these studies are still in progress. The three completed trials were small, with a combined total of 180 people. All were in adults who required minor surgery or an invasive procedure (a procedure that is carried out through the skin or a body cavity or anatomical opening). Two trials were in adults with liver disease and one trial was in adults in the intensive care unit. One trial compared platelet transfusion to no transfusion. One trial compared platelet transfusion to drugs that increased the platelet count. One trial compared platelet transfusion to a drug that decreased the risk of bleeding. We did not find any studies that compared the use of platelet transfusions using different platelet count levels as a guide for platelet transfusion.

There was not enough evidence to determine whether platelet transfusions affected the risk of death due to any cause, minor or major procedure-related bleeding, or the risk of a serious side effect. The only available evidence was of very-low quality because: the estimates were very imprecise, the studies were at risk of bias (participants and doctors knew which treatment they were receiving) and the evidence only applied to adults with liver disease requiring a dental procedure or liver biopsy (sample of the liver taken for analysis), or adults in intensive care units requiring insertion of a tube to help breathing (tracheotomy).

None of the studies reported: death due to any cause at 90 days after surgery; death due to bleeding, infection or a blood clot; number of red cell (cells that carry oxygen in the blood) or platelet transfusions each participant received; length of hospital stay or quality of life.

None of the trials included children or people who needed major surgery or emergency surgical procedures.

\section{How up to date is this evidence?}

We searched for studies published up to December 2017. 
SUMMARY OF FINDINGS

Summary of findings for the main comparison. Prophylactic platelet transfusion prior to surgery versus no prophylactic platelet transfusion prior to surgery

Prophylactic platelet transfusion prior to surgery versus no prophylactic platelet transfusion prior to surgery

Patient or population: people with a low platelet count

Setting: surgery

Intervention: platelet transfusion

Comparison: no platelet transfusion

\begin{tabular}{|c|c|c|c|c|c|c|}
\hline \multirow[t]{2}{*}{ Outcomes } & \multicolumn{2}{|c|}{$\begin{array}{l}\text { Anticipated absolute effects* }(95 \% \\
\mathrm{CI})\end{array}$} & \multirow[t]{2}{*}{$\begin{array}{l}\text { Relative effect } \\
(95 \% \mathrm{CI})\end{array}$} & \multirow{2}{*}{$\begin{array}{l}\text { № of partici- } \\
\text { pants } \\
\text { (studies) }\end{array}$} & \multirow{2}{*}{$\begin{array}{l}\text { Quality of the } \\
\text { evidence } \\
\text { (GRADE) }\end{array}$} & \multirow[t]{2}{*}{ Comments } \\
\hline & $\begin{array}{l}\text { Risk with no } \\
\text { platelet trans- } \\
\text { fusion }\end{array}$ & $\begin{array}{l}\text { Risk with } \\
\text { platelet transfu- } \\
\text { sion }\end{array}$ & & & & \\
\hline All-cause mortality within $\mathbf{3 0}$ days of surgery & \multicolumn{2}{|l|}{ Study population } & $\begin{array}{l}\mathbf{R R} \mathbf{0 . 7 8} \\
(0.41 \text { to } 1.45)\end{array}$ & $\begin{array}{l}72 \\
(1 \mathrm{RCT})\end{array}$ & $\begin{array}{l}\oplus \ominus \odot \ominus \\
\text { Very low }{ }^{a, b}\end{array}$ & - \\
\hline $\begin{array}{l}\text { Mortality secondary to bleeding within } 30 \text { days of } \\
\text { surgery - not reported }\end{array}$ & - & - & - & - & - & - \\
\hline $\begin{array}{l}\text { Mortality secondary to thromboembolism within } \\
\mathbf{3 0} \text { days of surgery - not reported }\end{array}$ & - & - & - & - & - & - \\
\hline $\begin{array}{l}\text { Mortality secondary to infection within } 30 \text { days of } \\
\text { surgery - not reported }\end{array}$ & - & - & - & - & - & - \\
\hline \multirow{2}{*}{$\begin{array}{l}\text { Number of participants with major bleeding with- } \\
\text { in } 7 \text { days of surgery (surgical site bleeding requiring } \\
\text { a second intervention or reoperation or surgical site } \\
\text { bleeding that causes a haematoma or haemarthrosis } \\
\text { of sufficient size to delay mobilisation or wound heal- } \\
\text { ing) }\end{array}$} & \multicolumn{2}{|l|}{ Study population } & \multirow{2}{*}{$\begin{array}{l}\text { RR } 1.60 \\
(0.29 \text { to } 8.92)\end{array}$} & \multirow{2}{*}{$\begin{array}{l}64 \\
(1 \mathrm{RCT})\end{array}$} & \multirow{2}{*}{$\begin{array}{l}\oplus \odot \odot \ominus \\
\text { Very low } b, c\end{array}$} & \multirow[t]{2}{*}{-} \\
\hline & 61 per 1000 & $\begin{array}{l}97 \text { per } 1000 \\
(18 \text { to } 541)\end{array}$ & & & & \\
\hline $\begin{array}{l}\text { The number of participants with minor proce- } \\
\text { dure-related bleeding within } 7 \text { days of surgery }\end{array}$ & Study population & & $\begin{array}{l}\text { RR } 1.29 \\
(0.90 \text { to } 1.85)\end{array}$ & $\begin{array}{l}64 \\
(1 \mathrm{RCT})\end{array}$ & $\begin{array}{l}\oplus \ominus \ominus \ominus \\
\text { Very lowa,c,d }\end{array}$ & - \\
\hline
\end{tabular}




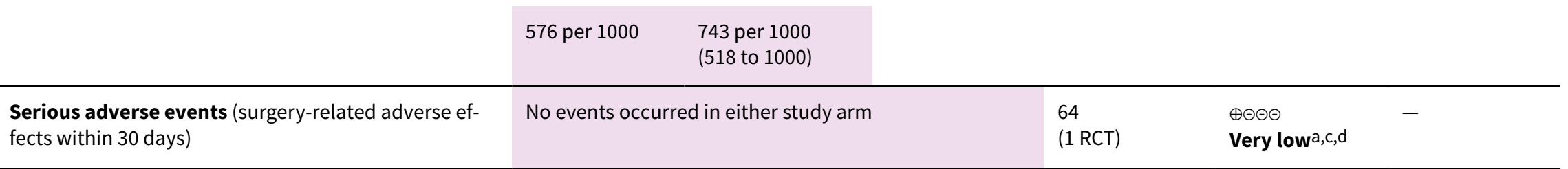

${ }^{*}$ The risk in the intervention group (and its $95 \%$ confidence interval) is based on the assumed risk in the comparison group and the relative effect of the intervention (and its $95 \% \mathrm{Cl}$ ).

Cl: confidence interval; $\mathbf{R C T}$ : randomised controlled trial; RR: risk ratio.

\section{GRADE Working Group grades of evidence}

High quality: we are very confident that the true effect lies close to that of the estimate of the effect.

Moderate quality: we are moderately confident in the effect estimate: the true effect is likely to be close to the estimate of the effect, but there is a possibility that it is substantially different.

Low quality: our confidence in the effect estimate is limited: the true effect may be substantially different from the estimate of the effect.

Very low quality: we have very little confidence in the effect estimate: the true effect is likely to be substantially different from the estimate of effect.

aOnly adults in the intensive care unit were included in this trial (downgraded one level for indirectness).

$b$ The confidence intervals included a serious risk of harm or benefit (downgraded two levels for imprecision).

cThis is a subjective outcome and the trial was unblinded (downgraded one level for risk of bias).

$d$ The confidence intervals included a risk of harm or benefit (downgraded one level for imprecision).

\section{Summary of findings 2. Prophylactic platelet transfusion prior to surgery versus alternative treatments}

\section{Prophylactic platelet transfusion prior to surgery versus alternative treatments}

Patient or population: people with a low platelet count

Setting: surgery

Intervention: platelet transfusion

Comparison: desmopressin

\begin{tabular}{|c|c|c|c|c|c|c|}
\hline \multirow[t]{2}{*}{ Outcomes } & \multicolumn{2}{|c|}{$\begin{array}{l}\text { Anticipated absolute effects* } \\
(95 \% \mathrm{Cl})\end{array}$} & \multirow[t]{2}{*}{$\begin{array}{l}\text { Relative effect } \\
(95 \% \mathrm{CI})\end{array}$} & \multirow{2}{*}{$\begin{array}{l}\text { № of partici- } \\
\text { pants } \\
\text { (studies) }\end{array}$} & \multirow{2}{*}{$\begin{array}{l}\text { Quality of the } \\
\text { evidence } \\
\text { (GRADE) }\end{array}$} & \multirow[t]{2}{*}{ Comments } \\
\hline & $\begin{array}{l}\text { Risk with } \\
\text { desmopressin }\end{array}$ & $\begin{array}{l}\text { Risk with } \\
\text { platelet trans- } \\
\text { fusion }\end{array}$ & & & & \\
\hline
\end{tabular}




\begin{tabular}{|c|c|c|c|c|c|c|}
\hline $\begin{array}{l}\text { All-cause mortality within } \mathbf{3 0} \text { days of surgery - not re- } \\
\text { ported }\end{array}$ & - & - & - & - & - & - \\
\hline $\begin{array}{l}\text { Mortality secondary to bleeding within } 30 \text { days of } \\
\text { surgery - not reported }\end{array}$ & - & - & - & - & - & - \\
\hline $\begin{array}{l}\text { Mortality secondary to thromboembolism within } 30 \\
\text { days of surgery - not reported }\end{array}$ & - & - & - & - & - & - \\
\hline $\begin{array}{l}\text { Mortality secondary to infection within } 30 \text { days of } \\
\text { surgery - not reported }\end{array}$ & - & - & - & - & - & - \\
\hline $\begin{array}{l}\text { Number of participants with major bleeding with- } \\
\text { in } 7 \text { days of surgery (bleeding that required } \geq 2 \text { units } \\
\text { of whole blood/red blood cells within } 24 \text { hours of the } \\
\text { bleeding) }\end{array}$ & \multicolumn{3}{|c|}{ No events in either study arm } & $\begin{array}{l}36 \\
(1 \mathrm{RCT})\end{array}$ & $\begin{array}{l}\oplus \ominus \odot \odot \\
\text { Very lowa,b,c }\end{array}$ & - \\
\hline Number of participants with minor procedure-relat- & \multicolumn{2}{|c|}{ Study population } & \multirow{2}{*}{$\begin{array}{l}\text { RR } 0.89 \\
(0.06 \text { to } 13.23)\end{array}$} & \multirow{2}{*}{$\begin{array}{l}36 \\
(1 \mathrm{RCT})\end{array}$} & \multirow{2}{*}{$\begin{array}{l}\oplus \ominus \Theta \ominus \\
\text { Very lowa,b,c }\end{array}$} & \multirow[t]{2}{*}{-} \\
\hline 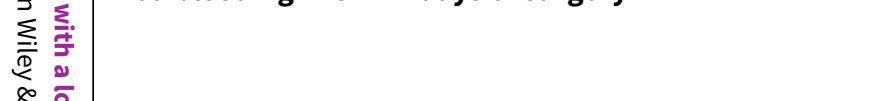 & 59 per 1000 & $\begin{array}{l}52 \text { per } 1000 \\
(4 \text { to } 778)\end{array}$ & & & & \\
\hline \multirow{2}{*}{$\begin{array}{l}\text { Serious adverse events (transfusion-related adverse } \\
\text { effects within } 24 \text { hours of the transfusion) }\end{array}$} & \multicolumn{2}{|c|}{ Study population } & \multirow{2}{*}{$\begin{array}{l}\text { RR } 2.70 \\
(0.12 \text { to } 62.17)\end{array}$} & \multirow{2}{*}{$\begin{array}{l}36 \\
(1 \mathrm{RCT})\end{array}$} & \multirow{2}{*}{$\begin{array}{l}\oplus \ominus \ominus \ominus \\
\text { Very lowa,b,c }\end{array}$} & \multirow[t]{2}{*}{-} \\
\hline & 0 per 1000 & $\begin{array}{l}0 \text { per } 1000 \\
(0 \text { to } 0)\end{array}$ & & & & \\
\hline
\end{tabular}

${ }^{*}$ The risk in the intervention group (and its $95 \%$ confidence interval) is based on the assumed risk in the comparison group and the relative effect of the intervention (and its $95 \% \mathrm{Cl}$ ).

CI: confidence interval; $\mathbf{R C T}$ : randomised controlled trial; RR: risk ratio.

\section{GRADE Working Group grades of evidence}

High quality: we are very confident that the true effect lies close to that of the estimate of the effect.

Moderate quality: we are moderately confident in the effect estimate: the true effect is likely to be close to the estimate of the effect, but there is a possibility that it is substantially different.

Low quality: our confidence in the effect estimate is limited: the true effect may be substantially different from the estimate of the effect.

Very low quality: we have very little confidence in the effect estimate: the true effect is likely to be substantially different from the estimate of effect.

aOpen-label trial (downgraded one level for risk of bias).

bStudy only included adults with chronic liver disease (downgraded one level for indirectness).

cConfidence intervals included a serious risk or benefit or treatment (downgraded one level for imprecision, as already downgraded one level for indirectness and risk of bias). 


\begin{tabular}{|c|c|c|c|c|c|c|}
\hline \multicolumn{7}{|c|}{ Different platelet count thresholds for administering a prophylactic platelet transfusion prior to surgery } \\
\hline \multicolumn{7}{|l|}{ Patient or population: people with a low platelet count } \\
\hline \multicolumn{7}{|l|}{ Setting: surgery } \\
\hline \multicolumn{7}{|l|}{ Intervention: platelet transfusion } \\
\hline \multicolumn{7}{|l|}{ Comparison: TPO mimetic } \\
\hline \multirow[t]{2}{*}{ Outcomes } & \multicolumn{2}{|c|}{$\begin{array}{l}\text { Anticipated absolute effects* } \\
(95 \% \mathrm{Cl})\end{array}$} & \multirow[t]{2}{*}{$\begin{array}{l}\text { Relative effect } \\
(95 \% \mathrm{Cl})\end{array}$} & \multirow{2}{*}{$\begin{array}{l}\text { № of partici- } \\
\text { pants } \\
\text { (studies) }\end{array}$} & \multirow{2}{*}{$\begin{array}{l}\text { Quality of the } \\
\text { evidence } \\
\text { (GRADE) }\end{array}$} & \multirow[t]{2}{*}{ Comments } \\
\hline & $\begin{array}{l}\text { Risk with TPO } \\
\text { mimetic }\end{array}$ & $\begin{array}{l}\text { Risk with } \\
\text { platelet trans- } \\
\text { fusion }\end{array}$ & & & & \\
\hline $\begin{array}{l}\text { All-cause mortality within } \mathbf{3 0} \text { days of surgery - not re- } \\
\text { ported }\end{array}$ & - & - & - & - & - & - \\
\hline $\begin{array}{l}\text { Mortality secondary to bleeding within } 30 \text { days of } \\
\text { surgery - not reported }\end{array}$ & - & - & - & - & - & - \\
\hline $\begin{array}{l}\text { Mortality secondary to thromboembolism within } 30 \\
\text { days of surgery - not reported }\end{array}$ & - & - & - & - & - & - \\
\hline $\begin{array}{l}\text { Mortality secondary to infection within } 30 \text { days of } \\
\text { surgery - not reported }\end{array}$ & - & - & - & - & - & - \\
\hline $\begin{array}{l}\text { Number of participants with major bleeding within } 7 \\
\text { days of surgery }\end{array}$ & \multicolumn{3}{|c|}{ No bleeding in any of the study arms } & $\begin{array}{l}65 \\
(1 \mathrm{RCT})\end{array}$ & $\begin{array}{l}\oplus \ominus \ominus \ominus \\
\text { Very lowa,b }\end{array}$ & - \\
\hline $\begin{array}{l}\text { Number of participants with minor procedure-relat- } \\
\text { ed bleeding within } 7 \text { days of surgery }\end{array}$ & \multicolumn{3}{|c|}{ No bleeding occurred in any of the study arms } & $\begin{array}{l}65 \\
(1 \mathrm{RCT})\end{array}$ & $\begin{array}{l}\oplus \ominus \ominus \ominus \\
\text { Very lowa,b }\end{array}$ & - \\
\hline Serious adverse events - not reported & - & - & - & - & - & - \\
\hline
\end{tabular}

${ }^{\star}$ The risk in the intervention group (and its $95 \%$ confidence interval) is based on the assumed risk in the comparison group and the relative effect of the intervention (and its $95 \% \mathrm{Cl})$.

Cl: confidence interval; RCT: randomised controlled trial; RR: risk ratio; TPO: thrombopoietin.

\section{GRADE Working Group grades of evidence}

High quality: we are very confident that the true effect lies close to that of the estimate of the effect. 
Moderate quality: we are moderately confident in the effect estimate: the true effect is likely to be close to the estimate of the effect, but there is a possibility that it is substantially different.

Low quality: our confidence in the effect estimate is limited: the true effect may be substantially different from the estimate of the effect.

Very low quality: we have very little confidence in the effect estimate: the true effect is likely to be substantially different from the estimate of effect.

aStudy only included adults with chronic liver disease (downgraded one level for indirectness)

$b_{\text {No }}$ events occurred (downgraded two levels for imprecision). 


\section{B A C K G R O U N D}

\section{Description of the condition}

Platelets are an essential component in the formation of a blood clot (BCSH 2003). A low platelet count can lead to a range of bleeding symptoms such as bruising, nosebleeds and, rarely, lifethreatening or fatal bleeding.

Thrombocytopenia is defined as a platelet count less than 150 $\times 10^{9} / \mathrm{L}$ (BCSH 2003). When this is dilutional, associated with an expanded blood volume, the drop is mild and rarely clinically significant. Severe thrombocytopenia is defined as a platelet count less than $50 \times 109 / \mathrm{L}$ (BCSH 2003). Thrombocytopenia can be caused by: reduced platelet production in the bone marrow often as a result of chemotherapy or a haematological malignancy (blood cancer) (Leguit 2010; Weinzierl 2013); increased platelet consumption as occurs in bleeding or disseminated intravascular coagulation (Levi 2009); increased platelet destruction such as immune thrombocytopenia (ITP) (Neunert 2013; Pacheco 2011; Provan 2010); or a combination of these conditions.

Mild, dilutional thrombocytopenia is common in pregnancy $(7 \%$ to $12 \%$ of pregnancies), but severe thrombocytopenia is much less common ( $0.05 \%$ to $1 \%$ of pregnancies) and is a sign of complications (Burrows 1990; Nisha 2012; Sainio 2000). A platelet count less than $150 \times 10^{9} / \mathrm{L}$ is very common in people with chronic liver disease (up to 76\%) (Afdhal 2008), and people who are critically ill (up to 68\%) (Hui 2011). One large UK study of people admitted to the intensive care unit (ICU) reported that $9 \%$ developed severe thrombocytopenia (Stanworth 2013). Thrombocytopenia is also frequent in people with haematological malignancies (Leguit 2010; Weinzierl 2013), and most platelet transfusions are used in people with haematological disorders (Cameron 2007; Greeno 2007; Pendry 2011).

People with thrombocytopenia often require a surgical procedure. A low platelet count is a relative contraindication to surgery due to the risk of bleeding (Estcourt 2017a; Kaufman 2015; NICE 2015). Platelet transfusions are one of a number of interventions used in modern clinical practice to prevent and treat bleeding in people with thrombocytopenia.

\section{Description of the intervention}

Platelet concentrates are the second most frequently used blood component (Bolton-Maggs 2016). Approximately 2.2 million platelet units are transfused annually in the USA (Whitaker 2013). Seventy-four per cent of platelet transfusions are given prophylactically to non-bleeding people with thrombocytopenia and $15 \%$ are given to prevent bleeding prior to surgery or a procedure in people with haematological malignancies. In many cases, platelet transfusions are given when the platelet counts are higher than the recommended triggers (Estcourt 2012; Greeno 2007).

Unlike other blood components, platelets must be kept on a shaker at room temperature, limiting the shelf life of platelet units to five to seven days. This makes it difficult for hospitals to manage their platelet stock (Fuller 2011).

Current practice in many countries is to correct thrombocytopenia with platelet transfusions prior to surgery. Guidelines often recommend a platelet count threshold of $50 \times 109 / \mathrm{L}$ prior to major surgery and $100 \times 109 / \mathrm{L}$ prior to surgery involving the brain or eyes (Estcourt 2017a; Kaufman 2015; NICE 2015). Guidelines often do not go into further detail about risks for different types of surgery. Some low-risk surgery may not require platelet transfusions at all, other procedures may be higher risk and the risk may also be dependent on patient comorbidities.

Platelet transfusions are not risk-free. In 2014, 34\% of all transfusion-related adverse events reported to the UK national reporting system (Serious Hazards of Transfusion (SHOT)) were due to platelet components. The most common adverse events due to platelet components were febrile and allergic reactions (Birchall 2015). Although most of these reactions are not lifethreatening, they can be extremely distressing for the person and time consuming for health professionals to investigate and exclude a more serious cause. Rarer, but more serious sequelae, include: anaphylaxis (life-threatening allergic reaction), transfusion-transmitted infections (TTI) and transfusion-related acute lung injury (TRALI) (Blumberg 2010; Chapman 2015; Kaufman 2015; Slichter 2007; Vlaar 2013). Platelet units are stored at room temperature on a shaker, which increases the risk of bacterial growth (1:2000 to 1:3000) (Jacobs 2011). In 2015, there were four near-miss incidents (three in platelets) reported, between 2011 and 2015 and a total of 37/44 bacterial transfusion-transmissions to individual recipients (34 incidents) were caused by the transfusion of platelets (Bolton-Maggs 2016).

One prospective multicentre cohort study concluded that in critically ill people, transfusion of platelets, but not of red blood cells and plasma, is an independent risk factor for acquiring a nosocomial infection (Engele 2016).

Alternative agents that could replace or reduce platelet transfusions may be more effective than platelet transfusions at controlling bleeding and will have a different adverse effect profile. Alternatives include artificial platelet substitutes, cryosupernatant, recombinant factor VIIa ( $r F V I I a)$, fibrinogen, recombinant factor XIII ( $\mathrm{FFXIII),} \mathrm{thrombopoietin} \mathrm{(TPO)} \mathrm{mimetics} \mathrm{and} \mathrm{antifibrinolytic} \mathrm{drugs.}$

\section{How the intervention might work}

\section{Platelet transfusions}

The premise for preprocedure intervention with platelet transfusion is as follows: thrombocytopenia increases the risk of bleeding, platelet transfusion corrects thrombocytopenia, a higher platelet count prevents bleeding and overall there is benefit to the patient. However, this presumption is over simplistic.

In one small randomised controlled trial (RCT) of 23 participants with thrombocytopenia who required 35 procedures and 84 teeth removed, bleeding complications were minimal without blood product support (Perdigão 2012).

One study including 1720 participants with thrombocytopenia undergoing coronary artery bypass graft (CABG) surgery pooled individual patient data from one pilot study and six RCTs. Platelet transfusion compared with no platelet transfusion was associated with a significant increase in mortality among people undergoing CABG surgery (odds ratio (OR) 4.76, 95\% confidence interval (CI) 1.65 to $13.73 ; \mathrm{P}=0.009$ ). Although the authors used propensity score analysis, it was unclear if the increased mortality was due 
to platelet transfusion or because people who were more unwell received platelet transfusions (Spiess 2004).

\section{Alternatives to platelet transfusions}

Alternatives to platelet transfusion simulate the effects of platelets (artificial platelet substitutes), stimulate additional fibrin formation (cryosupernatant, rFVIla and fibrinogen), promote von Willebrand factor release and platelet function (desmopressin), increase platelet production (TPO mimetics), strengthen clot structure (rFXIII) or decrease clot breakdown (antifibrinolytics). These agents aim to promote haemostasis without the adverse effects associated with platelet transfusions. Their main adverse effect is excessive clotting and thrombosis.

In this review, we excluded trials that assessed the use of: rFVIla; fibrinogen concentrate; rFXIII; prothrombin complex concentrate and desmopressin as these are the subject of other Cochrane Reviews that compared these interventions to an active comparator in people requiring a surgical procedure (Desborough 2017; Fabes 2013; Simpson 2012).

\section{Artificial platelet substitutes}

Artificial platelet substitutes such as microspheres of human albumin coated with fibrinogen, lyophilised platelets, infusible plasma membranes and liposomes with inserted platelet receptors aim to reproduce the active components of platelets without associated adverse events (Desborough 2016). Artificial platelets are not yet in routine clinical use, so their costs and adverse events are at present unclear.

\section{Cryosupernatant}

Cryosupernatant is a source of clotting factors and can be administered intravenously. It is a blood component and is associated with a small risk of transfusion reactions and TTIs.

\section{Thrombopoietin mimetics}

TPO is made by the liver and is the key regulator of bone marrow platelet production. TPO mimetics have been used in several disease states to promote both an increase in the cells that produce platelets (megakaryopoiesis) and the production of platelets themselves (thrombopoiesis) (Kuter 2014). The two main TPO mimetics in current use are romiplostim (weekly injection) and eltrombopag (daily oral tablet), both of which are recommended by the National Institute for Health and Care Excellence (NICE) for use in adults with ITP who have severe disease and a high risk of bleeding (NICE 2011; NICE 2013). While a systematic review found that these agents improved platelet counts, there was no evidence that they reduced the risk of significant bleeding for people with ITP (Zeng 2011). TPO mimetics are more expensive than platelet transfusions (Joint Formulary Committee 2016). Interleukin 6 and interleukin 11 may also act as stimulants of thrombopoiesis (Gordon 1995; Kurzrock 2011; Tsimberidou 2005). They are not in routine clinical use, so their costs are unclear at present.

\section{Antifibrinolytic drugs}

Fibrinolysis is the process by which blood clots are broken down after they have been formed. Antifibrinolytic drugs block this process, resulting in greater clot strength. The three most commonly used antifibrinolytic drugs are tranexamic acid, aprotinin and epsilon-aminocaproic acid. Other Cochrane systematic reviews have assessed these agents in people undergoing surgical procedures (Henry 2011; McNicol 2016), or in people with haematological disorders (Estcourt 2016a).

\section{Why it is important to do this review}

People with a low platelet count often require surgery. Current guidelines are mainly based on expert opinion rather than good evidence and frequently do not go into detail about the risks for different types of surgery or define a specific platelet count threshold. Some low-risk surgery, for example dental extraction, may not require platelet transfusions at all. Platelet transfusions may cause immediate- or longer-term harm and delay the start of life-saving treatments. Alternatives to platelets may be more effective and safer. Therefore, there is a need to assess the likely benefit of platelet transfusion and their alternatives, in different procedures, against known risks.

In this review we aimed to answer the following questions.

- Do people require prophylactic platelet transfusion prior to certain types of surgery?

- If platelet transfusions are required, which platelet count threshold should be used to trigger the transfusion of prophylactic platelets prior to surgery?

- Are prophylactic platelet transfusions superior to other alternative treatments?

\section{OB JECTIVES}

To determine the clinical effectiveness and safety of prophylactic platelet transfusions prior to surgery for people with a low platelet count.

\section{METHODS}

\section{Criteria for considering studies for this review}

\section{Types of studies}

We included RCTs, non-randomised controlled trials (non-RCTs) and controlled before-and-after studies (CBAs), irrespective of language or publication status. We excluded uncontrolled studies, cross-sectional studies and case-control studies.

We only included cluster-RCTs, non-randomised cluster trials, and CBAs with at least two intervention sites and two control sites. In studies with only one intervention or control site, the intervention (or comparison) is completely confounded by study site making it difficult to attribute any observed differences to the intervention rather than to other site-specific variables.

Our plan was that if there were sufficient data to answer this review's questions using only data from RCTs we would only report data from RCTs.

\section{Types of participants}

People of all ages with a low platelet count who were due to have surgery including invasive procedures.

We excluded studies on people with a low platelet count who were actively bleeding because they would receive platelet transfusions as part of the treatment of bleeding. 


\section{Types of interventions}

We compared three types of platelet transfusion regimens.

- Comparison 1: prophylactic platelet transfusion prior to surgery versus no prophylactic platelet transfusion prior to surgery (placebo or no treatment).

- Comparison 2: prophylactic platelet transfusion prior to surgery versus alternative treatments (cryosupernatant, antifibrinolytics, TPO mimetics). In this review, we excluded trials that assess the use of rFVIIa; fibrinogen concentrate, rFXIII, prothrombin complex concentrate and desmopressin as these are the subject of other Cochrane Reviews that compared these interventions to an active comparator in people requiring a surgical procedure (Carless 2004; Fabes 2013; Simpson 2012).

- Comparison 3: different platelet count thresholds for administering a prophylactic platelet transfusion prior to surgery.

We recorded type of platelet component and dose of platelet component received.

\section{Types of outcome measures}

\section{Primary outcomes}

- Mortality (all-causes, secondary to bleeding, secondary to thromboembolism and secondary to infection) within 30 days and 90 days of surgery.

- Number of participants with major procedure-related bleeding within seven days of surgery, defined as:

- surgical site bleeding requiring a second intervention or reoperation or surgical site bleeding that causes a haematoma or haemarthrosis of sufficient size to delay mobilisation or wound healing;

- bleeding of sufficient size to cause delayed wound healing, or wound infection or surgical site bleeding that was unexpected and prolonged or caused haemodynamic instability (as defined by the study) that was associated with a $20 \mathrm{~g} / \mathrm{L}$ drop in haemoglobin $(\mathrm{Hb})$;

- bleeding that required two or more units of whole blood/red cells within 24 hours of the bleeding;

- bleeding defined by the study with no further details.

\section{Secondary outcomes}

- Number of participants with minor procedure-related bleeding within seven days of surgery (e.g. haematoma, prolonged bleeding at surgical site that did not fulfil the definition for major bleeding).

- Number of platelet transfusions per participant and number of platelet components per participant.

- Number of red cell transfusions per participant and number of red cell components per participant.

- Proportion of participants requiring additional interventions to stop bleeding (surgical; medical, e.g. tranexamic acid; other blood products, e.g. fresh frozen plasma (FFP), cryoprecipitate, fibrinogen) within seven days of surgery.

- Quality of life assessment using validated tools.

- Serious adverse events due to:

- transfusion (transfusion reactions, TRALI, transfusion-related infection, transfusion-associated circulatory overload, transfusion-related dyspnoea) within 24 hours of the transfusion;

- surgery (e.g. delayed wound healing, infection) within 30 days after the operation.

- Length of hospital stay and length of ICU stay.

- Venous and arterial thromboembolism (including deep vein thrombosis, pulmonary embolism, stroke, myocardial infarction).

\section{Search methods for identification of studies}

The Systematic Review Initiative's Information Specialist (CD) developed the search strategies in collaboration with the Cochrane Haematological Malignancies Group.

\section{Electronic searches}

We searched the following databases.

\section{Bibliographic databases}

- Cochrane Central Register of Controlled Trials (CENTRAL, the Cochrane Library, 2017, Issue 12) (Appendix 1).

- MEDLINE (OvidSP, Epub Ahead of Print, In-Process and other Non-Indexed Citations, and 1946 to 11 December 2017) (Appendix 2).

- PubMed (for e-publications ahead or print only) (www.ncbi.nlm.nih.gov/pubmed) (Appendix 3).

- Embase (OvidSP, 1974 to 11 December 2017) (Appendix 4).

- CINAHL (EBSCOHost, 1937 to 11 December 2017) (Appendix 5).

- Transfusion Evidence Library (www.transfusionevidencelibrary.com; 1950 to 11 December 2017 - this included a search of grey literature) (Appendix 6).

- LILACS (1982 to present) (lilacs.bvsalud.org/en/) (Appendix 7).

- Web of Science: Conference Proceedings Citation Index-Science (CPCl-S) (Thomson Reuters, 1990 to 11 December 2017) (Appendix 8).

\section{Online databases of ongoing trials}

We searched for ongoing studies to 11 December 2017 in the following databases:

- ClinicalTrials.gov (clinicaltrials.gov) (Appendix 9);

- World Health Organization (WHO) International Clinical Trials Registry Search Platform (ICTRP) (apps.who.int/trialsearch/ AdvSearch.aspx) (Appendix 10).

We combined searches in MEDLINE and Embase with the recommended Cochrane RCT search filters (Lefebvre 2011), systematic review filters based on those of the Scottish Intercollegiate Guidelines Network (SIGN) (www.sign.ac.uk/ methodology/filters.html), and CBA study filters based on those used in reviews of the Cochrane Effective Practice and Organisation of Care Group (EPOC 2015) (epoc.cochrane.org/). Searches in CINAHL were combined with the SIGN systematic review and RCT filter and an EPOC-based filter. We did not limit searches by language, year of publication or publication type.

Once we identified studies for inclusion, we searched MEDLINE (OvidSP) for errata or retraction statements for the reports of these studies. 


\section{Searching other resources}

We handsearched the reference lists of included studies and any relevant systematic reviews to identify further relevant studies. We made contact with lead authors of relevant studies to identify any unpublished material, missing data or information regarding ongoing studies.

\section{Data collection and analysis}

We summarised data in accordance with standard Cochrane methodologies. We planned to analyse data from different study designs separately.

\section{Selection of studies}

We selected studies with reference to the methods outlined in the Cochrane Handbook for Systematic Reviews of Interventions (Higgins 2011a). The Systematic Review Initiative's Information Specialist (CD) initially screened all search hits for relevance against the eligibility criteria and discarded those that were clearly irrelevant. Thereafter, two review authors (LE, RM) independently screened all the remaining references for relevance against the full eligibility criteria. We retrieved full-text papers for all references for which a decision on eligibility could not be made from only screening the title and abstract. If necessary, we requested additional information from study authors to assess the eligibility for inclusion of individual studies. The two review authors discussed the results of study selection and resolved any discrepancies between themselves, without the need for a third review author (MT). We reported the results of study selection using a PRISMA flow diagram (Moher 2009). We also recorded the reasons for excluding studies based on full-text assessment and added those to the Characteristics of excluded studies table.

We collated multiple reports of one study so that the study, and not the report, was the unit of analysis

\section{Data extraction and management}

Two review authors (RM, LE) independently extracted data as recommended by the Cochrane Handbook for Systematic Reviews of Interventions (Higgins 2011a), using standardised forms available in Covidence software (Covidence 2016). We planned to pilot two different data extraction forms for included RCTs and non-RCTs separately, however we included only RCTs in this review. The two review authors came to consensus agreements without the need for a third review author (MT). The review authors were not be blinded to names of authors, institutions, journals or the study outcomes. They extracted the following information for each study.

\section{Randomised controlled trials}

- Source: study ID, report ID, review author ID, date of extraction, ID of author checking extracted data, citation of paper, contact author's details.

- General study information: publication type, study objectives, funding source, conflict of interest declared, other relevant study publication reviewed.

- Study details and methods: location, country, clinical setting, number of centres, study design, total study duration, recruitment dates, length of follow-up, power calculation, primary analysis (and definition), stopping rules, method of sequence generation, allocation concealment, blinding (of clinicians, participants and outcome assessors) and any concerns regarding bias.

- Characteristics of interventions: number of study arms, description of experimental arm, description of control arm, type of platelet component (e.g. apheresis or pooled), dose of platelet component, thresholds of platelets transfusions, type of surgery.

- Characteristics of participants: age, gender, primary diagnosis, surgery types procedure (minor, major, surgery to sensitive areas as ocular surgery or neurosurgery), platelet count, coagulation abnormalities, anticoagulant medications, antiplatelet medications.

- Participant flow: total number screened for inclusion, total number recruited, total number excluded, total number allocated to each study arm, total number analysed (for review outcomes), number of allocated participants who received planned treatment, number of dropouts with reasons (percentage in each arm), protocol violations, missing data.

- Method of data analyses.

- Outcomes: mortality (all-causes, secondary to bleeding, secondary to thromboembolism and secondary to infection) within 30 days and 90 days of surgery; number of participants with major procedure-related bleeding within seven days of surgery; number of participants with minor procedurerelated bleeding within seven days of surgery; number of platelet transfusions per participant and number of platelet components per participant; number of red cell transfusions per participant and number of red cell components per participant; proportion of participants requiring additional interventions to stop bleeding within seven days of surgery; quality of life assessment using validated tools; serious adverse events due to transfusion (within 24 hours of the transfusion) or surgery (within 30 days after the operation); length of hospital stay and length of ICU stay, venous and arterial thromboembolism.

\section{Non-randomised controlled trials}

There were no non-RCTs eligible for inclusion in this review.

In future updates of this review, we plan to extract all the data collected for RCTs and additional information on the following.

- Study design.

- Method of selecting participants: sample source, sample size, participants eligibility criteria, number of participants at each follow-up point, and the source of study control group and baseline differences between the two groups.

- Confounding factors: baseline confounding factors and cointerventions that might lead potentially to bias are identified in the study and relevant confounding factors and cointerventions that could introduce bias after the starting of platelets transfusions; the comparability of groups on confounding factors.

- Method of assigning the intervention.

- Cointervention status: this is in order to document if any other cointerventions are considered in the study.

- Method of data analysis: methods used to control for confounding and on multiple effect estimates (both unadjusted and adjusted estimates) as recommended in theCochrane Handbook of Systematic Reviews of Interventions (Reeves 2011). 


\section{Assessment of risk of bias in included studies}

\section{Randomised controlled trials}

We assessed the risk of bias for all included RCTs using the Cochrane 'Risk of bias' tool according to the Cochrane Handbook for Systematic Reviews of Interventions (Higgins 2011b). Two review authors (LE, RM) independently assessed each element of potential bias listed below as 'high', 'low' or 'unclear' risk of bias. We reported a brief description of the judgement statements upon which the review authors assessed potential bias in the Characteristics of included studies table. We ensured that a consensus on the degree of risk of bias was met through comparison of the review authors' statements and, where necessary, through consultation with a third review author $(\mathrm{SH})$. We used Cochrane's tool for assessing risk of bias, that included the following domains.

- Selection bias: we described for each included study if and how the allocation sequence was generated and if allocation was adequately concealed prior to assignment. We described the method used to conceal the allocation sequence in detail and determine if intervention allocation could have been foreseen in advance of, or during, recruitment, or changed after assignment.

- Performance bias: we described for each included study, where possible, if the study participants and personnel were adequately blinded from knowledge of which intervention a participant received. We judged studies as low risk of bias if they were blinded, or if judged that lack of blinding could not have had affected the results.

- Detection bias: was blinding of the outcome assessors effective in preventing systematic differences in the way in which the outcomes were determined?

- Incomplete outcome data: we described for each included study the attrition bias due to amount, nature or handling of incomplete outcome data. We also tried to evaluate whether intention-to-treat analysis were performed or could had been performed from published information.

- Selective outcome reporting or reporting bias: we described for each included study the possibility of selective outcome reporting bias.

- Other bias: was the study apparently free of other problems that could put it at risk of bias?

We summarised the risk of bias for each key outcome for each included study. We judged studies with at least one domain of high risk at high risk of bias overall.

\section{Non-randomised controlled trials}

There were no non-RCTs eligible for inclusion in this review.

In future updates of this review, we plan to use the ROBINS-I tool to rate the quality of non-randomised controlled trials (non-RCTs) and CBAs (Sterne 2016). This tool is based on the Cochrane 'Risk of bias' tool for rating the quality of RCTs (Higgins 2011c). The tool covers seven domains and the quality of evidence is rated 'low,' 'moderate,' 'serious,' 'critical or no information,' and the response options were 'yes,' 'probably yes,' 'no,' 'probably no' and 'no information' (see Appendix 2 for a copy of the tool) and uses signalling questions for the assessment of:

- bias due to confounding;

- bias in the selection of participants;
- bias in measurement of interventions;

- bias due to departure from intended interventions;

- bias due to missing data;

- bias in measurement of outcomes;

- bias in the selection of the reported result.

For 'low risk of bias,' the study was judged at low risk of bias on all the tool seven domains.

For 'moderate risk of bias,' the study was judged at low-tomoderate risk of bias on all tool seven domains.

For 'serious risk of bias ' the study is judged to be at serious risk of bias in at least one of the tool seven domains.

For 'critical risk of bias,' the study was judged at critical risk of bias in at least one domain of the tool seven domains.

For 'no information on bias,' when information in one or more key risk of bias domains were lacking.

Two review authors independently assessed each domain of potential bias listed and also tabulated a brief description of the judgement statements upon which they assessed potential bias in the Characteristics of included studies table. We ensured that a consensus on the degree of risk of bias was met through comparison of the review authors' statements and where necessary, through consultation with a third review author. We highlighted the highest quality evidence for each outcome.

We prespecified the following main potential confounding factors.

- Primary diagnosis of participant (e.g. liver disease, critical illness, pregnancy).

- Age: variability in the age of participants included, for example, paediatric (under 16 years) versus adult (older than 16 years) versus older adult (older than 60 years).

- Gender: male to female ratio.

- Previous severe bleeding (e.g. WHO grade 3 or 4 or equivalent).

\section{Measures of treatment effect}

\section{Randomised controlled trials}

For dichotomous outcomes, we recorded the number of events and the total number of participants in both the treatment and control groups.

For continuous outcomes, we recorded the mean, standard deviation and total number of participants in both the treatment and control groups. For continuous outcomes using the same scale, we performed analyses using the mean difference (MD) with $95 \%$ $\mathrm{Cls}$. If continuous outcomes were reported using different scales, we used standardised mean difference (SMD).

None of the studies reported hazard ratios (HR) and no HRs could be estimated using the available data. In future updates of this review, if available, we plan to extract and report HRs for time-to-eventdata (mortality or time in hospital) data. If HRs are not available, we will make every effort to estimate as accurately as possible the HR using the available data and a purpose-built method based on the Parmar and Tierney approach (Parmar 1998; Tierney 2007). If sufficient studies provide HRs, we plan to use HRs in favour of RRs or MDs in a meta-analysis, but for completeness, we will also perform 
a separate meta-analysis of data from studies providing only RRs or MDs for the same outcome.

For dichotomous outcomes, we reported the pooled risk ratio (RR) with a $95 \% \mathrm{Cl}$ (Deeks 2011). No outcomes required an analysis using the Peto's odds ratio (OR). In future updates of this review, where the number of observed events is small (less than $5 \%$ of sample per group), and where trials have balanced treatment groups, we plan to report the Peto's OR with 95\% Cl (Deeks 2011).

There were no cluster-randomised trials. In future updates of this review, for cluster-randomised trials, we will extract and report direct estimates of the effect measure (e.g. RR with a 95\% Cl) from an analysis that accounts for the clustered design. We will obtain statistical advice to ensure the analysis is appropriate. If appropriate analyses are not available, we will make every effort to approximate the analysis following the recommendations in the Cochrane Handbook for Systematic Reviews of Interventions (Higgins 2011d).

If data allowed, we undertook quantitative assessments using Review Manager 5 (Review Manager 2014).

\section{Non-randomised studies}

There were no non-randomised studies eligible for inclusion in this review.

In future updates of this review, for dichotomous outcomes, if available we will extract and report the RR with a $95 \% \mathrm{Cl}$ from statistical analyses adjusting for baseline differences (such as Poisson regressions or logistic regressions) or the ratio of risk ratios (i.e. the risk ratio postintervention/risk ratio preintervention). For continuous variables, if available we will extract and report the absolute change from a statistical analysis adjusting for baseline differences (such as regression models, mixed models or hierarchical models), or the relative change adjusted for baseline differences in the outcome measures (i.e. the absolute postintervention difference between the intervention and control groups, as well as the absolute preintervention difference between the intervention and control groups/the postintervention level in the control group) (EPOC 2015). If data allows, we will undertake quantitative assessments using Review Manager 5 (Review Manager 2014).

\section{All studies}

Where appropriate, we planned to report the number needed to treat for an additional beneficial outcome (NNTB) and harmful outcome (NNTH) with $95 \%$ Cls.

If we could not report the available data in any of the formats described above, we performed a narrative report, and if appropriate, we presented the data in tables.

\section{Unit of analysis issues}

There were no unit of analysis issues in this review.

In future updates of this review if any unit of analysis issues arise, we will treat these in accordance with the advice given in the Cochrane Handbook for Systematic Reviews of Interventions (Higgins 2011c). If participants are randomised more than once, we plan to contact the authors of the study to provide us with data associated with the initial randomisation. For studies with multiple treatment groups, we excluded subgroups that were considered irrelevant to the analysis. We tabulated all subgroups in the Characteristics of included studies table. When appropriate, we combined groups to create a single pair-wise comparison. If this was not possible, we selected the most appropriate pair of interventions and excluded the others (Higgins 2011c).

\section{Dealing with missing data}

Where we identified data to be missing or unclear in published literature, we contacted study authors directly. We contacted the authors of all three completed studies for additional information, but no additional information was provided (Basu 2012; Stanca 2010; Veelo 2012).

\section{Assessment of heterogeneity}

We planned to analyse the data in RCTs, non-RCTs, and CBA studies separately. However, we only identified three RCTs for inclusion in this review.

We did not perform any meta-analyses and, therefore, could not assess heterogeneity of the included RCTs (Deeks 2011).

In future updates of this review, if the clinical and methodological characteristics of individual studies are sufficiently homogeneous, we will combine the data and perform a meta-analysis. We will assess the extent of heterogeneity by both visual inspection of forest plots and utilising statistical methods. We will assess statistical heterogeneity of treatment effects between studies using a $\mathrm{Chi}^{2}$ test with a significance level at $\mathrm{P}$ less than 0.1 . We will use the 12 statistic to quantify the degree of potential heterogeneity and classify it as low if the 12 statistic is $50 \%$ or less, moderate if the $\mathrm{I}^{2}$ statistic is $50 \%$ to $80 \%$ or considerable if the $\mathrm{I}^{2}$ statistic is greater than $80 \%$. We will use the random-effects model for low-tomoderate heterogeneity. If statistical heterogeneity is considerable, we will not report the overall summary statistic. We will assess potential causes of heterogeneity by sensitivity and subgroup analyses (Deeks 2011).

\section{Assessment of reporting biases}

We did not perform a formal assessment of publication bias because we did not perform any meta-analyses (Sterne 2011).

\section{Data synthesis}

We did not perform any meta-analyses.

In future updates of this review, If studies are sufficiently homogenous in their study design, we will conduct a meta-analysis according to the recommendations of Cochrane (Deeks 2011). We will not conduct meta-analyses that include both RCTs and nonRCTs. We will conduct separate meta-analyses for each comparison. Different thresholds within the comparisons will only be grouped together if they were considered to be clinically similar.

\section{Randomised controlled trials}

For RCTs where meta-analysis is feasible, we will use the randomeffects model for pooling the data. For binary outcomes, we will base the estimation of the between-study variance on the MantelHaenszel estimator. We will use the inverse-variance method for continuous outcomes, outcomes that include data from clusterRCTs, or outcomes where HRs are available. If there is heterogeneity 
above $80 \%$, and we identify a cause for the heterogeneity, we will explore this with subgroup analyses. If we cannot find a cause for the heterogeneity, then we will not perform a meta-analysis, but comment on the results as a narrative with the results from all studies presented in tables.

\section{Non-randomised studies}

We identified no non-RCTs for inclusion in this review. In future updates, if meta-analysis is feasible for non-RCTs or CBA studies, we will analyse non-RCTs and CBA studies separately. We will only analyse outcomes with adjusted effect estimates if these are adjusted for the same factors using the inverse-variance method as recommended in the Cochrane Handbook of Systematic Reviews of Interventions (Reeves 2011).

\section{All studies}

We used the random-effects model for all analyses as we anticipated that true effects were related but were not the same for included studies. If we could not perform a meta-analysis, we commented on the results as a narrative with the results from all studies presented in tables.

\section{'Summary of findings' tables}

We used the GRADE tool (study limitations, consistency of effect, imprecision, indirectness and publication bias) to assess the quality of evidence for each outcome. We presented 'Summary of findings' tables as suggested in the Cochrane Handbook for Systematic Reviews of Interventions (Schünemann 2011a; Schünemann 2011b).

We applied the GRADE approach to rate the quality of the evidence as 'high,' 'moderate,' 'low' or 'very low' using the five GRADE considerations.

- Risk of bias: serious or very serious.

- Inconsistency: serious or very serious.

- Indirectness: serious or very serious.

- Imprecision: serious or very serious.

- Publication bias: likely or very likely.

The outcomes we included were listed below in order of most relevant endpoints for participants.

- All-cause mortality.

- Mortality secondary to bleeding.

- Mortality secondary to thromboembolism.

- Mortality secondary to infection.

- Number of participants with major procedure-related bleeding within seven days of surgery.
- Number of participants with minor procedure-related bleeding within seven days of surgery.

- Serious adverse events due to platelet transfusions.

\section{Subgroup analysis and investigation of heterogeneity}

There were insufficient data to perform any subgroup analyses. In future updates of this review, we plan to perform subgroup analyses for each of the following outcomes in order to assess the effect on heterogeneity.

- Age of participant (neonate, infant, child, adult).

- Type of surgery: minor or major (cardiac, eye, neurosurgery, dental, orthopaedic, liver, obstetric, gynaecological, plastic, gastrointestinal).

- Underlying cause of thrombocytopenia (bone marrow failure due to disease or treatment, increased destruction of platelets or increased consumption of platelets).

- Dose of platelet component

- Coexisting coagulopathy.

- Coexisting platelet dysfunction (inherited or acquired).

\section{Sensitivity analysis}

We planned to assess the robustness of the results by performing the following sensitivity analyses when possible; however, no metaanalyses were performed.

- Including studies with a 'low risk of bias' (e.g. RCTs with methods assessed as low risk for random sequence generation and concealment of treatment allocation).

- Including studies with less than a $20 \%$ dropout.

\section{RES U LTS}

\section{Description of studies}

See Characteristics of included studies; Characteristics of excluded studies; and Characteristics of ongoing studies tables for more details.

\section{Results of the search}

The search (conducted on 11 December 2017) identified 10,564 potentially relevant records (Figure 1). There were 8091 records after we removed duplicates. One reference was identified from other sources. We excluded 8032 references on the basis of the abstract and checked the eligibility of 60 full-text papers. We identified five RCTs eligible for inclusion in this review, three completed RCTs (Basu 2012; Stanca 2010; Veelo 2012) and two ongoing RCTs (NTR5653; Rocha 2017). 
Figure 1. Study flow diagram.

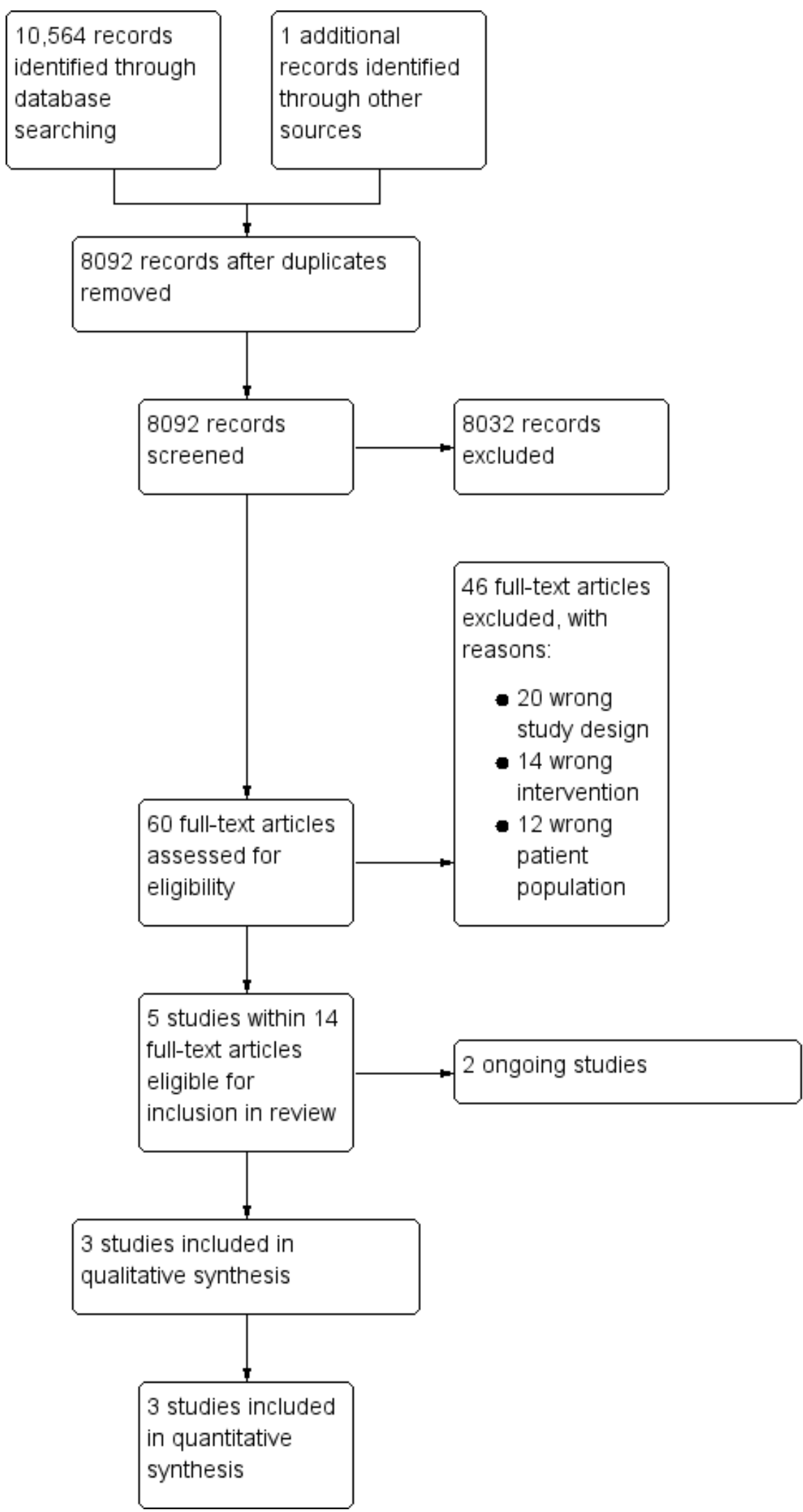




\section{Included studies}

See Characteristics of included studies table for full details of the included studies.

Of the three completed RCTs, two trials were published in full (Stanca 2010; Veelo 2012), and one was only available as an abstract (Basu 2012).

\section{Study design and setting}

All included trials were single-centre parallel-group RCTs. Two trials were conducted in the USA (Basu 2012; Stanca 2010), and one was conducted in the Netherlands (Veelo 2012).

\section{Trials comparing platelet transfusions with no transfusion before the surgical procedure}

One trial (72 participants) compared platelet transfusion to no platelet transfusion before a surgical procedure (Veelo 2012). It included people requiring mechanical ventilation who had mild coagulation disorders (defined as prothrombin time (PT) 14.7 seconds to 20.0 seconds, or platelet count $40 \times 10^{9} / \mathrm{L}$ to $100 \times$ $109 / \mathrm{L}$, or active treatment with aspirin (acetylsalicylic acid), or any combination) who required a percutaneous dilational tracheotomy (PDT). Eight participants did not undergo the tracheotomy after randomisation. About $60 \%$ of all participants had a prolonged PT and just over a third had a low platelet count and another third had received aspirin. There was more than one coagulation disorder was present in about $20 \%$ of the participants.

\section{Study interventions}

Veelo 2012 randomised participants into two groups. Group A received one unit of FFP if the PT was between 14.7 seconds and 18 seconds and two units of FFP when the PT was between 18 seconds and 20 seconds, as well as five units of buffy coat prepared platelets if they had a low platelet count or had received aspirin. Group $B$ received neither plasma nor platelets; however, in the event of bleeding during or after the procedure, immediate transfusion of FFP or platelets was available.

\section{Study outcomes}

The primary outcomes were volume of blood loss during the PDT procedure, severity of intratracheal bleeding and time until no blood was visible in tracheal aspirates. Veelo 2012 assessed bleeding during and within the first 12 hours after the PDT procedure. Bleeding was defined as "minor" for blood loss of less than $100 \mathrm{~g}$ from the site of the procedure that could be controlled by applying local pressure and did not require the transfusion of red blood cells. "Major" bleeding was defined as the presence of blood in the airways which required repeated suction or emergency surgery or red blood cell transfusion, or both.

\section{Trials comparing platelet transfusion to alternative treatments before the surgical procedure}

Two trials (108 participants) compared platelet transfusions to different alternative treatments (Basu 2012; Stanca 2010). Both included adults with liver disease, and excluded people with bleeding disorders, hepatocellular carcinoma and treatment with antiplatelet medications. Participants in Basu 2012 had severe thrombocytopenia (no further details). Stanca 2010 included people with moderate coagulopathy (defined as platelet count of
$30 \times 10 \mathrm{~g} / \mathrm{L}$ to $50 \times 10 \mathrm{9} / \mathrm{L})$ (22 participants), or an international normalised ratio (INR) of 2.0 to 3.0 , or both.

In Basu 2012, the procedure was percutaneous liver biopsy, and in Stanca 2010, the procedure was dental extractions.

\section{Study interventions}

Basu 2012 randomly assigned participants to three groups: group $A$ received seven units of platelets the night before the procedure; group $B$ received romiplostim $500 \mu \mathrm{g}$ subcutaneously given once two weeks before the procedure and group $C$ received eltrombopag $57 \mathrm{mg}$ per day by mouth for two weeks before the procedure.

Stanca 2010 randomised participants were to two groups: group A received intranasal desmopressin (one spray in each nostril, total of $300 \mu \mathrm{g}$ ) and group B received FFP $10 \mathrm{~mL} / \mathrm{kg}$ if the INR was 2.0 to 3.0 or one single unit of donor platelets when the platelet count was between $30 \times 10^{9} / \mathrm{L}$ and $50 \times 10^{9} / \mathrm{L}$.

\section{Study outcomes}

Basu 2012 reported on the incidence of bleeding and haematoma after the procedure, and adverse effects and cost effectiveness. Stanca 2010 reported incidence of bleeding and adverse effects at 24 hours to 48 hours after dental extraction, and a cost comparison between the two interventions.

\section{Excluded studies}

We excluded 46 studies for the following reasons:

- wrong study design: 20 studies (Abdelfatah 2016; Al-Zaabi 2014; Barrera 1996; Cai 2014; Chantarangkul 2013; Chen 2011; Embrey 2006; Fayed 2014; Hibbert 2013; Khair 2015; Napolitano 2017; NCT02200419; NCT02987712; NCT03011827; NCT00549484; Park 2016; Pereboom 2009; Perek 2016; Ray 1997; Tripodi 2013);

- wrong intervention: 14 studies (Afdhal 2012; De Pietri 2016; EudraCT 2007-005851-40; Karkouti 2016; Kultufan 2006; NCT00678587; NCT01919840; NCT02042898; NCT02352181; NCT02990273; Perl 2016; Pietri 2014; Tripodi 2013; Smart 2017);

- wrong patient population: 12 studies (Backos 1999; Harding 1975; Hess 2015; Holcomb 2015; NCT00521664; NCT01291290; NCT01402739; NCT02074436; NCT03022253; Simon 1982; Simon 1984; Tanaka 2014).

\section{Ongoing studies}

We found two ongoing clinical trials (NTR5653; Rocha 2017). See Characteristics of ongoing studies for further details.

\section{NTR5653}

This multicentre RCT is currently enrolling participants and aims to complete recruitment by October 2019 (NTR5653). The study is being conducted in the Netherlands and plans to enrol 462 adults on the ICU with a platelet count of $50 \times 10^{9} / \mathrm{L}$ or less who require insertion of a central venous catheter. Participants will be randomised to receive or not receive a platelet transfusion.

\section{Rocha 2017}

The POCKET trial (point-of-care versus standard coagulation tests versus restrictive strategy to guide transfusion in chronic liver failure patients requiring central venous line) is a single-centre, double-blind RCT that is currently enrolling participants and aims 
to complete recruitment by December 2018 (Rocha 2017). The study is being conducted in Brazil and plans to enrol 165 adults with chronic liver disease, randomised to receive transfusion of FFP, platelets or cryoprecipitate, or any combination guided by the use of standard tests of coagulation (INR greater than 1.5, activated partial thromboplastin time (aPPT) greater than 50 seconds or platelet count less than $50 \times 109 / \mathrm{L}$ ) versus thromboelastometry (ROTEM) versus standard tests of coagulation with a restrictive threshold (INR greater than 5, platelets less than $25 \times 10^{9} / \mathrm{L}$ ) prior to central venous catheterisation.

\section{Risk of bias in included studies}

\section{Allocation}

\section{Sequence generation}

We rated two trials at low risk of bias for sequence generation because they used a computer-generated technique (Stanca 2010; Veelo 2012).

We rated Basu 2012 at unclear risk of bias because it was only available as an abstract and there were no further details available.

\section{Allocation concealment}

We rated two trials at low risk of bias for allocation concealment as both trials used opaque sealed envelopes to allocate the treatment to participants (Stanca 2010; Veelo 2012).

We rated Basu 2012 at unclear risk of bias due to lack of relevant information in the published abstract.

\section{Blinding}

We rated Basu 2012 at low risk of performance and detection bias because it was described as a double-blind trial with no further information available.

We rated two trials at high risk of bias for both performance and detection bias because they were both open-label trials (Stanca 2010; Veelo 2012).

\section{Incomplete outcome data}

We rated one trial at low risk of attrition bias because all participants who received platelet transfusions were included in the analysis (Veelo 2012).

We rated two trials at unclear risk of attrition bias (Basu 2012; Stanca 2010). In Basu 2012, the trial was only published as an abstract, and they did not report the number of participants who were randomised and included in the analyses. Stanca 2010 did not include all randomised participants in the analysis of outcome data. The study enrolled 43 participants, but the analysis included only 36 participants (19\% dropout). The reasons for excluding these participants were clearly provided: two participants assigned to the blood transfusion group withdrew their consent; five participants were not included in the analysis because their blood results prior to the procedure showed they no longer met the trial eligibility criteria. Although this was a significant dropout, it was unclear what effect this would have on the study's findings, as most of the exclusions were because participants were no longer eligible.

\section{Selective reporting}

We rated two trials at unclear risk of selective reporting (Basu 2012; Stanca 2010). Basu 2012 was only available as an abstract, and there was no trial registration. The only outcome listed on the trial registration (NCT00816127) for Stanca 2010 was: "Necessity of rescue blood transfusion in patients who received DDAVP [desmopressin] or blood transfusion prior to dental extraction." There were no other secondary outcomes listed. Although this outcome was reported, there was no protocol available to assess if other outcomes were planned.

We rated Veelo 2012 at "high" risk of selective reporting, because not all the outcomes stated in the trial registration (ISRCTN31808827) were reported in the published paper such as the amount of blood products used during and after the procedure (not reported for intervention group). Some other outcomes were classified as the trial's primary outcome measures in the trial registration (ISRCTN31808827), but were reported as secondary outcomes in the published paper for example the volume of blood loss during the surgical procedure, the intensity of intra-tracheal bleeding, time until no blood was visible in tracheal aspirates.

\section{Other potential sources of bias}

We rated Stanca 2010 at low risk of other potential sources of bias, because baseline characteristics were balanced for the two groups, and there were no obvious sources of bias.

We rated two trials at unclear risk of other potential sources of bias (Basu 2012; Veelo 2012). Basu 2012 did not report adequate baseline information for the three study groups. The Veelo 2012 trial was stopped early due to increased resistance to recruitment and low rate of bleeding in either trial arm, planned recruitment was 152 participants but only 64 participants were included in the analysis.

\section{Effects of interventions}

See: Summary of findings for the main comparison Prophylactic platelet transfusion prior to surgery versus no prophylactic platelet transfusion prior to surgery; Summary of findings 2 Prophylactic platelet transfusion prior to surgery versus alternative treatments; Summary of findings 3 Different platelet count thresholds for administering a prophylactic platelet transfusion prior to surgery

\section{Prophylactic platelet transfusion prior to surgery versus no prophylactic platelet transfusion prior to surgery}

Only one trial compared prophylactic platelet transfusions versus no prophylactic platelet transfusions (Veelo 2012) (Summary of findings for the main comparison).

\section{Primary outcomes}

Mortality

\section{All-cause mortality within $\mathbf{3 0}$ days of the surgery}

There was no evidence of a difference in the risk of death due to any cause between participants having their coagulopathy corrected (platelets, plasma, or both) and participants who did not (1 trial, 72 participants; RR $0.78,95 \% \mathrm{Cl} 0.41$ to 1.45 ; very-low quality evidence; Analysis 1.1). 
Mortality secondary to bleeding; mortality secondary to thromboembolism and mortality secondary to infection (within $\mathbf{3 0}$ days of surgery)

The trial did not report these outcomes.

All-cause mortality; mortality secondary to bleeding; mortality secondary to thromboembolism and mortality secondary to infection (within 90 days of the surgery)

The trial did not report these outcomes.

Number of participants with major procedure-related bleeding within seven days of surgery

Veelo 2012 defined major bleeding as the presence of blood in the airways requiring repeated suction post procedure, emergency surgery, transfusion of packed red cells, or a combination of these.

There was no evidence of a difference on the incidence of procedure-related bleeding between participants having their coagulopathy corrected (platelets, plasma, or both) and participants who did not (1 trial, 72 participants; RR 1.60, 95\% Cl 0.29 to 8.92 ; very-low quality evidence; Analysis 1.2).

\section{Secondary outcomes}

Number of participants with minor procedure-related bleeding within seven days of surgery

Veelo 2012 defined minor bleeding as blood loss less than 100 $\mathrm{g}$ that could be controlled with the application of local pressure and did not require re-exploration or transfusion of packed red cells. There was no evidence of a difference in the risk of minor bleeding during or for 12 hours after the procedure for participants having their coagulopathy corrected (platelets, plasma, or both) and participants who did not (1 trial, 64 participants; RR 1.29, 95\% $\mathrm{Cl} 0.90$ to 1.85 ; Analysis 1.3 ).

Number of platelet transfusions per participant and number of platelet components per participant

Twenty-three participants received a platelet transfusion (five buffy coat units) prior to the procedure in the intervention arm and no participants received a platelet transfusion in the comparator arm. It was not clear whether any participant in the intervention arm received a platelet transfusion during or after the procedure.

Number of red cell transfusions per participant and number of red cell components per participant

No participants in either treatment arm received a red cell transfusion during or after the procedure ( 1 trial, 64 participants; no events).

Proportion of participants requiring additional interventions to stop bleeding (surgical; medical, e.g. tranexamic acid; other blood products, e.g. fresh frozen plasma, cryoprecipitate, fibrinogen) within seven days of surgery

There was no evidence of a difference in the risk of requiring additional procedures to stop bleeding between participants having their coagulopathy corrected (platelets, plasma or both) and participants who did not ( 1 trial, 64 participants; RR 0.35, 95\% $\mathrm{Cl} 0.01$ to 8.38; Analysis 1.4). Bleeding occurred directly after skin incision and before opening the airway in one participant in the "no correction" group who was on active aspirin treatment, this was treated with suturing and application of local compression.

\section{Quality of life assessment}

The trial did not report this outcome.

\section{Serious adverse events}

Serious adverse events due to transfusion

The trial did not report this outcome.

\section{Serious adverse events due to surgery}

No participants in either treatment arm developed a serious adverse event due to the procedure ( 1 trial, 64 participants; no events; very-low quality evidence).

\section{Length of hospital stay and length of intensive care unit stay}

The trial did not report length of hospital stay.

There was no evidence of a difference in the length of ICU stay (median: 15 days (range 8 to 29) with coagulopathy correction versus median 21 days (range 14 to 26 ); $P=0.21$ (analysis by study authors)).

Venous and arterial thromboembolism (including deep vein thrombosis, pulmonary embolism, stroke, myocardial infarction)

The trial did not report these outcomes.

\section{Prophylactic platelet transfusion prior to surgery versus alternative treatments}

Two trials compared platelet transfusions to other alternative treatments before surgery (Basu 2012; Stanca 2010). Stanca 2010 compared platelet transfusion or plasma transfusion or both to internasal desmopressin, whereas Basu 2012 compared platelet transfusion to TPO mimetics (romiplostim and eltrombopag) (Summary of findings 2; Summary of findings 3).

\section{Primary outcomes}

\section{Mortality}

All-cause mortality; mortality secondary to bleeding; mortality secondary to thromboembolism and mortality secondary to infection (within $\mathbf{3 0}$ days of the surgery)

The trials did not report mortality within 30 days.

All-cause mortality; mortality secondary to bleeding; mortality secondary to thromboembolism and mortality secondary to infection (within 90 days of the surgery)

The trials did not report mortality within 90 days.

Number of participants with major procedure-related bleeding within seven days of surgery

\section{Platelet transfusion versus desmopressin}

No participants had major procedure-related bleeding (1 trial, 36 participants; no events; very-low quality evidence).

\section{Platelet transfusion versus thrombopoietin mimetic}

No participants had major procedure-related bleeding (1 trial, 65 participants; no events; very-low quality evidence). 


\section{Secondary outcomes}

Number of participants with minor procedure-related bleeding within seven days of surgery

\section{Platelet transfusion versus desmopressin}

There was no evidence of a difference in minor procedure-related bleeding ( 1 trial, 36 participants, 0.89 , 95\% Cl 0.06 to 13.23; verylow quality evidence; Analysis 2.1).

Platelet transfusion versus thrombopoietin mimetic

No participants had minor procedure-related bleeding (1 trial, 65 participants; no events; very-low quality evidence).

Number of platelet transfusions per participant and number of platelet components per participant

The trials did not report these outcomes.

Number of red cell transfusions per participant and number of red cell components per participant

\section{Platelet transfusion versus desmopressin}

In Stanca 2010, no participants required red cells transfusions to treat bleeding post dental extraction (1 trial, 36 participants; no events).

\section{Platelet transfusion versus thrombopoietin mimetic}

In Basu 2012, no participants required red cells transfusions to treat bleeding post liver biopsy (1 trial, 65 participants; no events).

Proportion of participants requiring additional interventions to stop bleeding

\section{Platelet transfusion versus desmopressin}

In Stanca 2010, four participants reused desmopressin at home, the amount of bleeding prior to repeat use of desmopressin administration was not measured, in comparison only one participant in the transfusion group had bleeding after the procedure and required an additional transfusion. There was no evidence of a difference between the two groups for this outcome (1 trial, 36 participants; RR $0.22,95 \%$ Cl 0.03 to 1.81 ; Analysis 2.2).

\section{Platelet transfusion versus thrombopoietin mimetic}

In Basu 2012, no bleeding occurred in either study arm, therefore no treatments were required to stop bleeding ( 1 trial, 65 participants; no events).

\section{Quality of life assessment}

The trials did not report this outcome.

\section{Serious adverse events within $\mathbf{3 0}$ days after the operation}

\section{Platelet transfusion versus desmopressin}

There was no evidence of a difference in the risk of serious adverse reaction related to transfusion (1 trial, 36 participants; RR 2.70, 95\% $\mathrm{Cl} 0.12$ to 62.17 , very-low quality evidence; Analysis 2.3).

The trials did not report serious adverse events related to surgery.

\section{Platelet transfusion versus thrombopoietin mimetic}

The trials did not report serious adverse events related to surgery or transfusion.

\section{Length of hospital stay and length of intensive care unit stay}

The trials did not report these outcomes.

Venous and arterial thromboembolism (including deep vein thrombosis, pulmonary embolism, stroke, myocardial infarction)

The trials did not report these outcomes.

Different platelet count thresholds for administering a prophylactic platelet transfusion prior to surgery

We found no trials comparing different platelet count thresholds for platelet transfusion.

\section{DISCUSSION}

\section{Summary of main results}

The aim of this review was to assess the efficacy and safety of prophylactic platelet transfusions in people with low platelet counts prior to surgery (including invasive procedures).

We included three completed trials in this review; two trials are still ongoing but not yet recruiting participants. All three completed trials were small single-centre RCTs (180 participants in total) (Basu 2012; Stanca 2010; Veelo 2012). The ongoing trials are a multicentre RCT and a single-centre RCT that plan to recruit more than 600 adults (Characteristics of ongoing studies table), which is greater than the combined number of participants included in the three completed trials. All three trials were conducted between 2005 and 2009. Two trials included people with chronic liver disorders (Basu 2012; Stanca 2010), whereas one trial was set in an ICU involving people with various morbidities (Veelo 2012).

None of the included trials included children, major surgical procedures or emergency surgery.

\section{Prophylactic platelet transfusion prior to surgery versus no prophylactic platelet transfusion prior to surgery}

One small trial in people in ICU requiring a tracheotomy (72 randomised, 64 had a tracheotomy) compared platelet transfusions versus no platelet transfusion before the surgical procedure (Veelo 2012).

- No cases of death reported within 30 days of the surgery.

- We were very uncertain whether there was a difference in the risk of major bleeding between the two groups during or after the surgical procedure.

- We were very uncertain whether there was a difference in the risk of minor bleeding between the two groups during or after the surgical procedure.

- We were very uncertain whether there was a difference in number of participants who required additional surgical interventions to stop bleeding.

- None of the participants had procedure-related serious adverse events.

- We were very uncertain whether there was a difference in the duration of ICU stay.

The trial did not report quality of life or length of hospital stay. 
Prophylactic platelet transfusion prior to surgery versus alternative treatments

Two small trials in people with liver disease compared platelet transfusion versus alternative treatments before the surgical procedure (Basu 2012; Stanca 2010). Basu 2012 (65 participants) compared platelet transfusion to two types of TPO analogue (romiplostim, eltrombopag) in people requiring a liver biopsy. Stanca 2010 compared platelet transfusion to desmopressin in people requiring dental procedures.

- We were very uncertain whether there was a difference in the risk of major bleeding between the two groups during or after the surgical procedure.

- We were very uncertain whether there was a difference in the risk of minor bleeding between the two groups during or after the surgical procedure.

- We were very uncertain whether there was a difference in the number of participants who required blood transfusions to stop bleeding after surgery.

- We were very uncertain whether there was a difference in the number of participant who had transfusion-related serious adverse events.

Neither trial reported mortality, quality of life or length of hospital stay.

\section{Different platelet count thresholds for administering a prophylactic platelet transfusion prior to surgery}

We found no trials that compared different platelet count thresholds.

\section{Overall completeness and applicability of evidence}

The conclusions which can be drawn following this systematic review were very limited due to the inclusion of only three small RCTs (180 randomised). There was insufficient evidence to determine the effect of platelet transfusion prior to surgery on the primary outcomes of all-cause mortality or major procedurerelated bleeding. There were insufficient data to determine the effect on minor procedure-related bleeding or any other secondary outcome.

There are two ongoing RCTs (anticipated to recruit 627 participants), which are scheduled to complete recruitment by October 2019 (NTR5653; Rocha 2017). One is comparing platelet transfusion versus no platelet transfusion prior to central line insertion (462 participants) (NTR5653), the other trial is comparing a restrictive versus liberal versus thrombelastography- based transfusion algorithm (165 participants) prior to central line insertion (Rocha 2017).

The available evidence for the effectiveness and safety of prophylactic platelet transfusions only related to adults, and most of the evidence was for people with chronic liver disease. None of the included or ongoing trials included children, major surgical procedures or emergency surgery.

This review excluded studies that compared a platelet count threshold versus thromboelastography-based transfusion algorithm, or different thromboelastography-based transfusion algorithms, and several studies that were excluded at the full-text stage assessed this comparison (see Characteristics of excluded studies table), including one completed study in people with liver disease (De Pietri 2016). Thromboelastography has been suggested as an alternative to the platelet count to assess the need for a platelet transfusion by assessing the speed and strength of blood clot formation in vitro (Bolliger 2012).

\section{Quality of the evidence}

Overall, the quality of evidence was rated according to the GRADE methodology as very low across difference outcomes due to high risk of bias (unblinded studies); imprecision of the estimates, and indirectness (only adults with liver disease or adults in the ICU were included in the studies) (Summary of findings for the main comparison; Summary of findings 2; Summary of findings 3).

We assessed the GRADE quality of evidence as very low for:

- all-cause mortality;

- number of participants with major procedure-related bleeding within seven days of surgery;

- number of participants with minor procedure-related bleeding within seven days of surgery;

- serious adverse events.

We could not assess the quality of the evidence for: mortality secondary to bleeding, mortality secondary to thromboembolism and mortality secondary to infection because none of the trials reported these outcomes.

All three included trials in this review were RCTs; however, none of the trials were free from methodological bias. See Figure 2 for the visual summary of the risk of bias assessment on each domain. Two trials were at risk of performance and detection bias, this was due to the nature of the intervention "platelet transfusion" (Stanca 2010; Veelo 2012). Most 'Risk of bias' tool domains of one of the included trial were at unclear risk of bias as the trial was only available as an abstract (Basu 2012). 
Figure 2. Risk of bias summary: review authors' judgements about each risk of bias item for each included study.

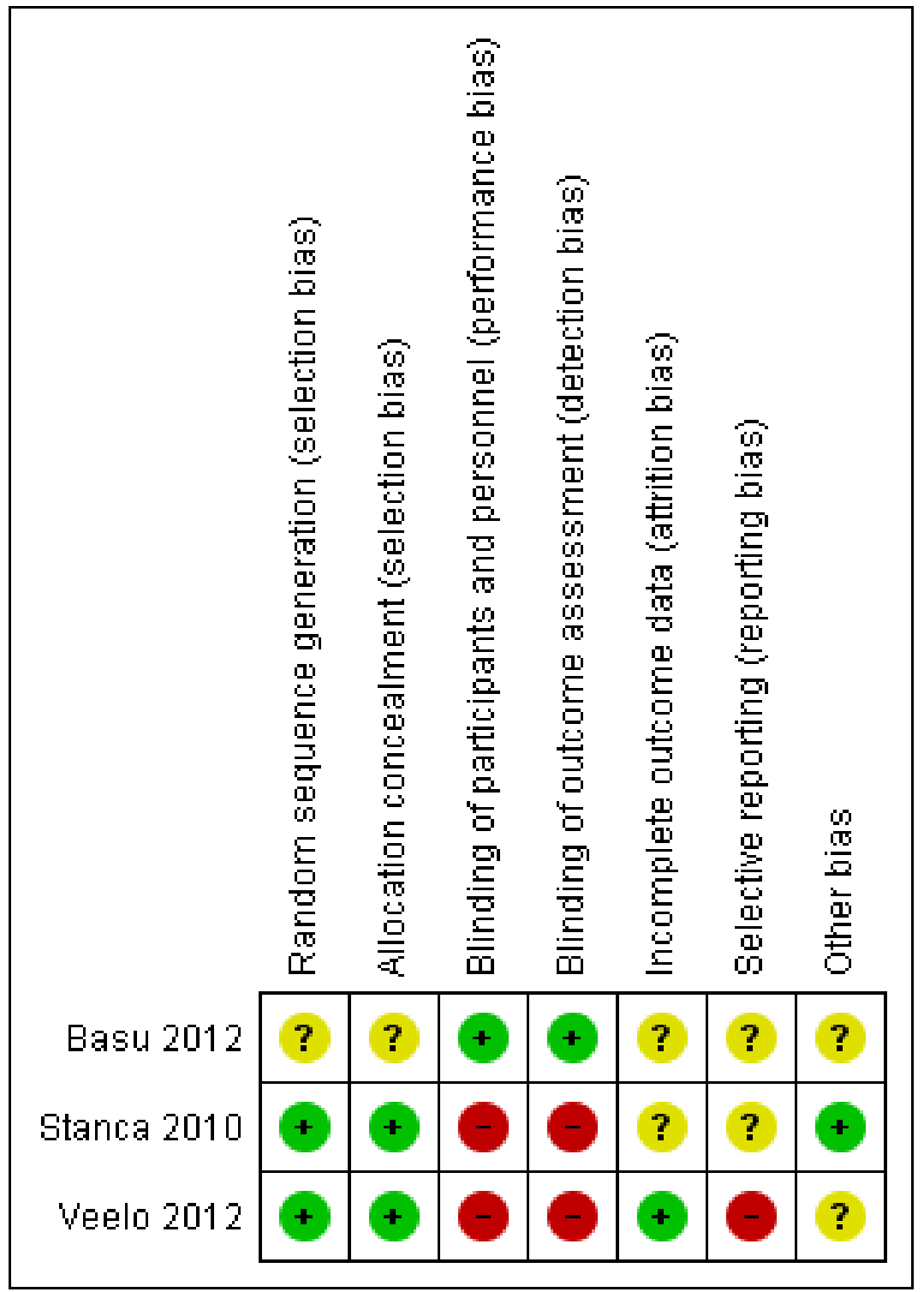

\section{Potential biases in the review process}

We conducted a comprehensive search of multiple databases and clinical trial registries to capture all relevant studies. We did not limit the search by language or publication status. There are two ongoing studies. Two review authors carefully screened all papers identified by the search and performed data extraction and quality assessment evaluations. We prespecified all outcomes prior to undertaking the search. We were unable to undertake a metaanalysis or assess publication bias as the review included only three studies and there were significant clinical differences between the studies (comparing different interventions).

\section{Agreements and disagreements with other studies or reviews}

To our knowledge this review is the first to systematically assess the evidence related to prophylactic platelet transfusion before surgery for people with thrombocytopenia. Two reviews have assessed the evidence for prophylactic platelet transfusions prior to lumbar punctures and epidural anaesthesia (Estcourt 2016b), and prior to central line insertion (Estcourt 2015). Neither of these reviews included non-randomised studies. Estcourt 2015 identified one of the ongoing studies identified in this review (Rocha 2017), and Estcourt 2016b did not identify any relevant studies. These other reviews highlight the lack of evidence regarding this question.

\section{AUTHORS' CONCLUSIONS}

\section{Implications for practice}

Based on only three small trials included in this review, there is insufficient evidence to determine whether prophylactic platelet transfusions before surgical procedures could reduce the risk of death and bleeding among people with a low platelet count.

\section{Implications for research}

An update of this review should consider including a platelet count threshold versus thrombelastography-based regimen as 
these study comparisons have been performed and have been excluded from this version of the review.

Further trials to examine the utility of prophylactic platelet transfusions among people with thrombocytopenia before surgical procedures are still required, there are no completed or ongoing trials that:

- include neonates or children;

- include major or emergency surgery;

- include an assessment of quality of life or other participantreported outcome measures;

- include adults with haematological disorders.

Further trials are required to assess the use of platelet transfusions versus no platelet transfusions in minor surgery, the use of alternatives to platelet transfusion and the use of different platelet count thresholds for all procedures.

\section{A C K N OWLEDGEMENTS}

We thank the editorial base of the Cochrane Haematological Malignancies Review Group.

We thank the peer and consumer reviewers Dr Julia Bohlius, Dr Sebastian Theurich, Dr Liat Vidal, Dr Olaf Weingart and Anne Lyddiatt of the protocol.

We thank NHS Blood and Transplant.

We thank the National Institute of Health Research (NIHR). This review is part of a series of reviews that have been funded by the NIHR Cochrane Programme Grant - Safe and Appropriate Use of Blood Components. This research was also supported by the NIHR Oxford Biomedical Research Centre Programme. The views expressed are those of the review authors and not necessarily those of the National Health Service, the NIHR or the Department of Health. 


\section{R E F E R E N C E S}

\section{References to studies included in this review}

\section{Basu 2012 \{published data only\}}

Basu P, Nair T, Farhat S, Shah NJ, Krishnaswamy N. Single use of romiplostim thrombopoietin analogue in thrombocytopenia for liver biopsy in chronic liver disease-randomized clinical trial. Asian Pacific Digestive Week 2012;27:207-8. [DOI: dx.doi.org/10.1111/jgh.12006]

Basu PP, Nair T, Farhat S, James Shah N, Jafri M, Foustin S. Single use of romiplostim thrombopoietin analogue in severe thrombocytopenia for outpatient percutaneous liver biopsy in patients with chronic liver disease-a randomized double blinded prospective trial. Journal of Hepatology 2012;56:S38. [DOI: dx.doi.org/10.1016/S0168-8278\%2812\%2960101-9]

Basu PP, Nair T, Jafri M, Krishnaswamy NV, Farhat S, Shah NJ, Brown R. Single use of romiplostim thrombopoietin analogue (TPO) in severe thrombocytopenia for outpatient percutaneous liver biopsy in patients with chronic liver disease (CLD) - a randomized double blinded prospective clinical pilot trial. 18th Annual International Congress of the International Liver Transplantation Society, ILTS; 2012 May 15-19; San Francisco (CA). 2012; Vol. 18:S271. [DOI: dx.doi.org/10.1002/lt.23435]

Basu PP, Nair T, Krishnaswamy N, James Shah N, Farhat S, Brown R. Single use of romiplostim thrombopoietin analogue (TPO) in severe thrombocytopenia for outpatient percutaneous liver biopsy in patients with chronic liver disease (CLD) - a randomized double blinded prospective clinical pilot trial. 76th Annual Scientific Meeting of the American College of Gastroenterology; 2011 Oct 28-Nov 2; Washington (DC). 2011, issue 106:S135-6. [DOI: dx.doi.org/10.1038/ajg.2011.336_5]

Basu PP, Nair TJ, Krishnaswamy N, Shah NJ, Farhat S. Single use of romiplostim thrombopoietin analogue (TPO) in severe thrombocytopenia for outpatient percutaneous liver biopsy in patients with chronic liver disease (CLD) - a randomized double blinded prospective clinical pilot trial. 62nd Annual Meeting of the American Association for the Study of Liver Diseases: The Liver Meeting; 2011 Nov 4-8; San Francisco (CA). 2011, issue 54:898A. [DOI: dx.doi.org/10.1002/hep.24666]

Basu PP, Nair TJ, Krishnaswamy NV, James Shah N, Brown RS. Single use of romiplostim thrombopoietin analogue (TPO) in severe thrombocytopenia for outpatient percutaneous liver biopsy in patients with chronic liver disease (CLD) a randomized double-blinded prospective clinical pilot trial. 43rd Nordic Gastroenterology Congress; 2012 Jun 12-15; Reykjavik Iceland. 2012, issue 47:45-46. [DOI: dx.doi.org/10.3109/00365521.2012.697267]

Basu PP, Nair TJ, Krishnaswamy NV, Shah NJ, Brown Jr RS. Single use of romiplostim thrombopoietin analogue (TPO) in severe thrombocytopenia for outpatient percutaneous liver biopsy in patients with chronic liver disease (CLD) - a randomized double blinded prospective clinical pilot trial. 2012 Scientific Session of the Society of American Gastrointestinal and Endoscopic Surgeons; 2012 Mar 7-10; San Diego (CA). 2012, issue 26:S333. [DOI: dx.doi.org/10.1007/s00464-012-2203-x]
Stanca 2010 \{published data only\}

NCT00816127. Prevention of bleeding in patient with cirrhosis undergoing dental extraction. clinicaltrials.gov/ct2/show/ NCT00816127 Date first received: 29 December 2008.

Stanca CM, Montazem AH, Lawal A, Zhang JX, Schiano TD. Intranasal desmopressin versus blood transfusion in cirrhotic patients with coagulopathy undergoing dental extraction: a randomized controlled trial. Journal of Oral and Maxillofacial Surgery 2010;68(1):138-43.

Stanca CM, Montazem AH, Zhang JH, Lawal A, Schiano TD. Intranasal desmopressin is effective in preventing bleeding after dental extraction in cirrhotic patients having moderate degrees of coagulopathy. Transfusion 2006;46(4, Suppl 1):568A.

\section{Veelo 2012 \{published data only\}}

Veelo DP, Vlaar AP, Dongelmans DA, Binnekade JM, Levi M, Paulus F, et al. Correction of subclinical coagulation disorders before percutaneous dilatational tracheotomy. Blood Transfusion 2012;10:213-20.

\section{References to studies excluded from this review}

Abdelfatah 2016 \{published data only\}

Abdelfatah M. Management of chronic subdural hematoma in patients with intractable thrombocytopenia. Turkish Neurosurgery Journal 2016;18825(16):1-5.

\section{Afdhal 2012 \{published data only\}}

Afdhal NH, Giannini EG, Tayyab G, Mohsin A, Lee JW, Andriulli A, et al. Eltrombopag before procedures in patients with cirrhosis and thrombocytopenia. New England Journal of Medicine 2012;367:716-24.

\section{Al-Zaabi 2014 \{published data only\}}

Al-Zaabi M, Clark S, Gomez K, Sekhar M. Assessing risk of bleeding in thrombocytopenic patients requiring platelet transfusion prior to invasive procedures. Haematologica 2014;99(S1):199.

\section{Backos 1999 \{published data only\}}

Backos M, Rai R, Baxter N, Chilcott IT, Cohen H, Regan L. Pregnancy complications in women with recurrent miscarriage associated with antiphospholipid antibodies treated with low dose aspirin and heparin. British Journal of Obstetrics and Gynaecology 1999;106(2):102-7.

\section{Barrera 1996 \{published data only\}}

Barrera R, Mina B, Huang Y, Groeger JS. Acute complications of central line placement in profoundly thrombocytopenic cancer patients. Cancer 1996;78:2025-30.

\section{Cai 2014 \{published data only\}}

Cai Y, Liu X, Peng B. Should we routinely transfuse platelet for immune thrombocytopenia patients with platelet count less than $10 \times 109 / \mathrm{L}$ who underwent laparoscopic splenectomy?. World Journal of Surgery 2014;38:2267-72. 
Chantarangkul 2013 \{published data only\}

Chantarangkul V, Primignani M, Lemma L, Clerici M, Jovani M, Rebulla P, et al. Global hemostasis tests in patients with cirrhosis before and after prophylactic platelet transfusion. 58th Annual Meeting of the Scientific and Standardization Committee of the International Society on Thrombosis and Haemostasis; 2012 Jun 27-30; Liverpool, UK. 2013, issue 11:73. [DOI: dx.doi.org/10.1111/jth.12443]

\section{Chen 2011 \{published data only\}}

Chen X, Peng B, Cai Y, Zhou J, Wang Y, Wu Z, et al. Laparoscopic splenectomy for patients with immune thrombocytopenia and very low platelet count: is platelet transfusion necessary?. Journal of Surgical Research 2011;170(2):e225-32.

\section{De Pietri 2016 \{published data only\}}

De Pietri L, Bianchini M, Montalti R, De Maria N, Di Maira T, Begliomini B, et al. Thrombelastography-guided blood product use before invasive procedures in cirrhosis with severe coagulopathy: a randomized, controlled trial. Hepatology 2016;63:566-73.

\section{Embrey 2006 \{published data only\}}

Embrey KK, Davis CL, Rey MA, Lumb PD, Gold ME. Perioperative transfusion practices in women versus men. American Association of Nurse Anesthetists Journal 2006;74(5):393-4.

\section{EudraCT 2007-005851-40 \{published data only\}}

EudraCT 2007-005851-40. A randomised, double-blind, placebo-controlled, multi-centre study to evaluate the safety and efficacy of eltrombopag to reduce the need for platelet transfusion in thrombocytopenic subjects with chronic liver disease undergoing elective invasive procedures. www.clinicaltrialsregister.eu/ctr-search/trial/2007-005851-40/ ES Date first registered: 3 December 2008.

\section{Fayed 2014 \{published data only\}}

Fayed NA, Abdallah AR, Khalil MK, Marwan IK. Therapeutic rather than prophylactic platelet transfusion policy for severe thrombocytopenia during liver transplantation. Platelets 2014;25(8):576-86.

\section{Harding 1975 \{published data only\}}

Harding SA, Shakoor MA, Grindon AJ. Platelet support for cardiopulmonary bypass surgery. Journal of Thoracic and Cardiovascular Surgery 1975;70(2):350-3.

\section{Hess 2015 \{published data only\}}

Hess R. Results of the pragmatic randomized optimal plasma and platelet ratios trial (PROPPR). British Blood Transfusion Society 2015;109:72.

\section{Hibbert 2013 \{published data only\}}

Hibbert RM, Atwell TD, Lekah A, Patel MD, Carter RE, McDonald JS, et al. Safety of ultrasound-guided thoracentesis in patients with abnormal preprocedural coagulation parameters. Chest 2013;44(2):456-63.

\section{Holcomb 2015 \{published data only\}}

Holcomb JB, Tilley BC, Baraniuk S, Fox EE, Wade CE, Podbielski JM, et al. Transfusion of plasma, platelets, and red blood cells in a 1:1:1 vs a 1:1:2 ratio and mortality in patients with severe trauma: the PROPPR randomized clinical trial. JAMA 2015;3;313(5):471-82

\section{Karkouti 2016 \{published data only\}}

Karkouti K, Callum J, Wijeysundera D, Rao V, Crowther M, Grocott $\mathrm{H}$, et al. Point-of-care hemostatic testing in cardiac surgery a stepped-wedge clustered randomized controlled trial. Circulation 2016;134:1152-62.

Khair 2015 \{published data only\}

Khair T, El-Haddad D, Srujal P, Marmagiolis K, Cilingiroglu M, Iliescu G, et al. Triple jeopardy: Heart disease, cancer and thrombocytopenia-fluoroscopic and echocardiographic guided pericardiocentesis in cancer patients with cardiac tamponade and thrombocytopenia. Catheterization and Cardiovascular Interventions 2015;85:S82-3. [DOI: dx.doi.org/10.1002/ ccd.25910]

\section{Kultufan 2006 \{published data only\}}

Kultufan, Turan S, Aydinli B, Ayik I, Yagar S, Kazanci D, et al. The role of rotational thromboelastgraphy on decision of blood transfusion in open heart surgery [Acik kalp cerrahisinde tromboelastografinin transfuzyon karari Uzerine etkisi]. Gogus-Kalp-Damar Anestezi ve Yogun Bakim Dernegi Dergisi 2006;12(4):154-9

\section{Napolitano 2017 \{published data only\}}

Napolitano G, lacobellis A, Merla A, Niro G, Valvano MR, Terracciano $\mathrm{F}$, et al. Bleeding after invasive procedures is rare and unpredicted by platelet counts in cirrhotic patients with thrombocytopenia. European Journal of Internal Medicine 2017;38:79-82.

\section{NCT00521664 \{published data only\}}

NCT00521664. A trial comparing a prophylactic with a therapeutic platelet transfusion strategy in two groups. clinicaltrials.gov/ct2/show/NCT00521664 Date first received: 27 August 2007.

\section{NCT00549484 \{published data only\}}

NCT00549484. Thrombopoietin levels and platelet transfusion in neonates. clinicaltrials.gov/ct2/show/NCT00549484 Date first received: 24 October 2007.

\section{NCT00678587 \{published data only\}}

NCT00678587. Eltrombopagto reduce the need for platelet transfusion in subjects with chronic liver disease and thrombocytopenia undergoing elective invasive procedures (ELEVATE). clinicaltrials.gov/ct2/show/NCT00678587 First submitted 13 May 2008

\section{NCT01291290 \{published data only\}}

NCT01291290. START - early thrombocyte administration to patients with ruptured abdominal aortic aneurism (rAAA). clinicaltrials.gov/ct2/show/NCT01291290 Date first received: 7 February 2011.

NCT01402739 \{published data only\}

NCT01402739. Monocentric pilot study of algorithm-guided transfusions in cardiac surgery patients for reduction of 
drainage blood losses. clinicaltrials.gov/ct2/show/NCT01402739 Date first received: 25 July 2011.

\section{NCT01919840 \{published data only\}}

NCT01919840. Blood products transfusion in cardiac surgery after the implementation of a coagulation monitoring system at patient bedside: thromboelastometry versus standard transfusion protocol (ROTEM-2010). clinicaltrials.gov/ct2/show/ NCT01919840 Date first received: 12 April 2013.

\section{NCT02042898 \{published data only\}}

NCT02042898. Transfusion Requirements In Cardiac Surgery III (TRICS-III). clinicaltrials.gov/ct2/show/NCT02042898 Date first received: 17 January 2014.

\section{NCT02074436 \{published data only\}}

NCT02074436. Prevention of bleeding in hematological malignancies with antifibrinolytic (epsilon aminocaproic acid) (PROBLEMA). clinicaltrials.gov/ct2/show/NCT02074436 Date first received: 26 February 2014.

\section{NCT02200419 \{published data only\}}

NCT02200419. POC - Transfusion Algorithm Cardiac Study (TACS). clinicaltrials.gov/ct2/show/NCT02200419 Date first received: 20 June 2014 .

\section{NCT02352181 \{published data only\}}

NCT02352181. Management of coagulopathy during orthotopic liver transplantation. Comparison between ROTEMbased management and standard biological assessment. clinicaltrials.gov/ct2/show/NCT02352181 Date first received: 18 December 2014

\section{NCT02987712 \{published data only\}}

NCT02987712. Management of coagulopathy in cirrhotic patients undergoing invasive procedures. clinicaltrials.gov/ct2/ show/NCT02987712 Date first received: 6 December 2016.

\section{NCT02990273 \{published data only\}}

NCT02990273. The utility of thromboelastography in cirrhotic patients undergoing endoscopic procedures. clinicaltrials.gov/ ct2/show/NCT02990273 Date first received: 14 October 2016.

\section{NCT03011827 \{published data only\}}

NCT03011827. Transfusion prediction model in orthotopic liver transplantation based on thromboelastometry: prospective validation study. clinicaltrials.gov/ct2/show/NCT03011827 Date first received: 4 January 2017.

\section{NCT03022253 \{published data only\}}

NCT03022253. Platelet transfusion for treatment of patent ductus arteriosus in thrombocytopenic preterm neonates. clinicaltrials.gov/ct2/show/NCT03022253 Date first received: 25 June 2016

\section{Park 2016 \{published data only\}}

Park JM, Oh HJ, Cho YK, Lee B-I, Cho YS, Choi M-G. Risk factor analysis of bleeding after endoscopic interventions in patients with chronic thrombocytopenia. Gastrointestinal Endoscopy 2016;83(1):AB205

\section{Pereboom 2009 \{published data only\}}

Pereboom IT, de Boer MT, Haagsma EB, Hendriks HG, Lisman T, Porte RJ. Platelet transfusion during liver transplantation is associated with increased postoperative mortality due to acute lung injury. Anesthesia and Analgesia 2009;108(4):1083-91.

Perek 2016 \{published data only\}

Perek B, Stefaniak S, Komosa A, Perek A, Katynska I, Jemielity M. Routine transfusion of platelet concentrates effectively reduces reoperation rate for bleeding and pericardial effusion after elective operations for ascending aortic aneurysm. Platelets 2016;27(8):764-70.

\section{Perl 2016 \{published data only\}}

Perl VJ, Leroux B, Cook MR, Watson J, Fair K, Martin D, et al. Damage-control resuscitation and emergency laparotomy: findings from the PROPPR study. Journal of Trauma and Acute Care Surgery 2016;80(4):568-75. [DOI: dx.doi.org/10.1097/ TA.0000000000000960]

\section{Pietri 2014 \{published data only\}}

Pietri L, Bianchini M, Montalti R, Maria N, Maira T, Begliomini B, et al. Thrombelastography (TEG) decreases blood products requirement before invasive procedures in cirrhotic patients with coagulation tests derangement. A randomized controlled trial. Digestive and Liver Disease 2014;46(1):e5-e6.

\section{Ray 1997 \{published data only\}}

Ray CE Jr, Shenoy SS. Patients with thrombocytopenia: outcome of radiologic placement of central venous access devices. Radiology 1997;204(1):97-9.

\section{Simon 1982 \{published data only\}}

Simon TL, Akl B, Murphy W. Controlled trial of platelet concentrates in patients undergoing cardiopulmonary bypass. Transfusion 1982;22(5, S3):423.

\section{Simon 1984 \{published data only\}}

Simon TL, Akl BF, Murphy W. Controlled trial of routine administration of platelet concentrates in cardiopulmonary bypass surgery. Annals of Thoracic Surgery 1984;37(5):359-64.

\section{Smart 2017 \{published data only\}}

Smart L, Wellner M, Gray NA, Michaels A, Kirkpatrick RB, Conteh $\mathrm{L}$, et al. A prospective, randomized clinical trial comparing blood product use, bleeding events, and cost during and after endoscopic procedures in patients with cirrhosis and coagulopathy: rotational thromboelastrometry (ROTEM) versus conventional therapy. Hepatology 2017;66(1):243A-4A.

\section{Tanaka 2014 \{published data only\}}

Tanaka KA, Egan K, Szlam F, Ogawa S, Roback JD, Sreeram G, et al. Transfusion and hematologic variables after fibrinogen or platelet transfusion in valve replacement surgery: preliminary data of purified lyophilized human fibrinogen concentrate versus conventional transfusion. Transfusion 2014;54(1):109-18.

\section{Titano 2016 \{published data only\}}

Titano JJ, Biederman DM, Marinelli BS, Patel RS, Kim E, Tabori NE, et al. Safety and feasibility of transradial access 
for visceral interventions in patients with thrombocytopenia. Cardiovascular and Interventional Radiology 2016;39(5):676-82.

Tripodi 2013 \{published data only\}

Tripodi A, Primignani M, Chantarangkul V, Lemma L, Jovani M, Rebulla $P$, et al. Global hemostasis tests in patients with cirrhosis before and after prophylactic platelet transfusion. Cirrhosis and Liver Failure 2013;33:362-7.

\section{References to ongoing studies}

NTR5653 \{published data only\}

NTR5653. Prophylactic platelet transfusion prior to central venous catheter placement in patients with thrombocytopenia [Onderzoek naar de noodzaak van correctie van bloedplaatjestekort voor het plaatsen van een centraal veneuze lijn]. www.trialregister.nl/trialreg/admin/ rctview.asp?TC=5653 Date first received: 27 January 2016. [www.trialregister.nl/trialreg/admin/rctview.asp?TC=5653]

\section{Rocha 2017 \{published data only\}}

NCT02311985. Comparison of three transfusion strategies for central venous catheterization in cirrhotics (POCKET). clinicaltrials.gov/ct2/show/NCT02311985 Date first received: 9 December 2014

Rocha LL, Pessoa CMS, Neto AS, do Prado RR, Silva E, de Almeida MD, et al. Thromboelastometry versus standard coagulation tests versus restrictive protocol to guide blood transfusion prior to central venous catheterization in cirrhosis: study protocol for a randomized controlled trial. Trials 2017;18:85. [DOI: 10.1186/s13063-017-1835-5]

\section{Additional references}

\section{Afdhal 2008}

Afdhal N, McHutchison J, Brown R, Jacobson I, Manns M, Poordad F, et al. Thrombocytopenia associated with chronic liver disease. Journal of Hepatology 2008;48(6):1000-7.

\section{BCSH 2003}

British Committee for Standards in Haematology. Guidelines for the use of platelet transfusions. British Journal of Haematology 2003;122(1):10-23.

\section{Birchall 2015}

Birchall J, Tinegate H, Regan F. Chapter 14 Acute transfusion reactions (ATR). In: Bolton-Maggs PHB, Poles D, et al. on behalf of the Serious Hazards of Transfusion (SHOT) Steering Group, editor(s). The 2014 Annual SHOT Report. Manchester, UK: SHOT, 2015:106-12.

\section{Blumberg 2010}

Blumberg N, Heal JM, Phillips GL. Platelet transfusions: trigger, dose, benefits and risks. F1000 Medicine Reports 2010;2:1-5.

\section{Bolliger 2012}

Bolliger D, Seeberger MD, Tanaka KA. Principles and practice of thromboelastography in clinical coagulation management and transfusion practice. Transfusion Medicine Reviews 2012;26(1):1-13.

\section{Bolton-Maggs 2016}

Bolton-Maggs $\mathrm{PH}$, on behalf of the Serious Hazards of Transfusion (SHOT) Steering Group. The 2015 Annual SHOT Report. SHOT 2016.

\section{Burrows 1990}

Burrows RF, Kelton JG. Thrombocytopenia at delivery: a prospective survey of 6715 deliveries. American Journal of Obstetrics and Gynecology 1990;162:731-4.

\section{Cameron 2007}

Cameron B, Rock G, Olberg B, Neurath D. Evaluation of platelet transfusion triggers in a tertiary-care hospital. Transfusion 2007;47(2):206-11.

\section{Carless 2004}

Carless PA, Stokes BJ, Moxey AJ, Henry DA. Desmopressin use for minimising perioperative allogeneic blood transfusion. Cochrane Database of Systematic Reviews 2004, Issue 1. [DOI: 10.1002/14651858.CD001884.pub2]

\section{Chapman 2015}

Chapman C. Transfusion-related lung injury (TRALI), 2015. www.shotuk.org/wp-content/uploads/SHOT-2014-AnnualReport_v11-Web-Edition.pdf (accessed 26 November 2015).

\section{Covidence 2016 [Computer program]}

Veritas Health Innovation. Covidence systematic review software. Melbourne: Veritas Health Innovation, 2016.

\section{Deeks 2011}

Deeks JJ, Higgins JPT, Altman DG. Chapter 9: Analysing data and undertaking meta-analyses. In: Higgins JP, Green S, editor(s). Cochrane Handbook for Systematic Reviews of Interventions Version 5.1.0 (updated March 2011). The Cochrane Collaboration, 2011. Available from handbook.cochrane.org.

\section{Desborough 2016}

Desborough MJ, Smethurst PA, Estcourt LJ, Stanworth SJ. Alternatives to allogeneic platelet transfusion. British Journal of Haematology 2016;175:381-92.

\section{Desborough 2017}

Desborough MJ, Oakland K, Brierley C, Bennett S, Doree C, Trivella $\mathrm{M}$, et al. Desmopressin use for minimising perioperative blood transfusion. Cochrane Database of Systematic Reviews 2017, Issue 7. [DOI: 10.1002/14651858.CD001884.pub3]

\section{Engele 2016}

Engele LJ, Straat M, van Rooijen IH, de Vooght KM, Cremer OL, Schultz M, et al. Transfusion of platelets, but not of red blood cells, is independently associated with nosocomial infections in the critically ill. Annals of Intensive Care 2016;6:67. [DOI: 10.1186/s13613-016-0173-1.]

\section{EPOC 2015}

Effective Practice, Organisation of Care (EPOC). EPOC Resources for review authors. Oslo: Norwegian Knowledge Centre for 
the Health Services 2015. epoc.cochrane.org/epoc-specificresources-review-authors (accessed prior to 23 August 2018).

\section{Estcourt 2012}

Estcourt LJ, Birchall J, Lowe D, Grant-Casey J, Rowley M, Murphy MF. Platelet transfusions in haematology patients: are we using them appropriately?. Vox Sanguinis 2012;103(4):284-93.

\section{Estcourt 2015}

Estcourt LJ, Desborough M, Hopewell S, Doree C, Stanworth SJ. Comparison of different platelet transfusion thresholds prior to insertion of central lines in patients with thrombocytopenia. Cochrane Database of Systematic Reviews 2015, Issue 12. [DOI: 10.1002/14651858.CD011771.pub2]

\section{Estcourt 2016a}

Estcourt LJ, Desborough M, Brunskill SJ, Doree C, Hopewell S, Murphy MF, et al. Antifibrinolytics (lysine analogues) for the prevention of bleeding in people with haematological disorders. Cochrane Database of Systematic Reviews 2016, Issue 3. [DOI: 10.1002/14651858.CD009733.pub3]

\section{Estcourt 2016b}

Estcourt LJ, Ingram C, Doree C, Trivella M, Stanworth SJ. Use of platelet transfusions prior to lumbar punctures or epidural anaesthesia for the prevention of complications in people with thrombocytopenia. Cochrane Database of Systematic Reviews 2016, Issue 5. [DOI: 10.1002/14651858.CD011980.pub2]

\section{Estcourt 2017a}

Estcourt LJ, Birchall J, Allard S, Bassey SJ, Hersey P, Kerr JP, et al. and the British Committee for Standards in Haematology. Guidelines for the use of platelet transfusions. British Journal of Haematology 2017;176:365-94. [DOI: 10.1111/bjh.14423]

\section{Fabes 2013}

Fabes J, Barker G, Simons G, Curry N, Brunskill SJ, Doree C, et al. Pro-coagulant haemostatic factors for the prevention and treatment of bleeding in patients without haemophilia. Cochrane Database of Systematic Reviews 2013, Issue 7. [DOI: 10.1002/14651858.CD010649]

\section{Fuller 2011}

Fuller AK, Uglik KM, Braine HG, King KE. A comprehensive program to minimize platelet outdating. Transfusion 2011;51:1469-76. [DOI: 10.1111/j.1537-2995.2010.03039.x]

\section{Gordon 1995}

Gordon MS, Nemunaitis J, Hoffman R, Paquette RL, Rosenfeld C, Manfreda S, et al. A phase I trial of recombinant human interleukin- 6 in patients with myelodysplastic syndromes and thrombocytopenia. Blood 1995;85:3066-76.

\section{Greeno 2007}

Greeno E, McCullough J, Weisdorf D. Platelet utilization and the transfusion trigger: a prospective analysis. Transfusion 2007;47:201-5. [DOI: 10.1111/j.1537-2995.2007.01089.x]

\section{Henry 2011}

Henry DA, Carless PA, Moxey AJ, O'Connell D, Stokes BJ, Fergusson DA, et al. Anti-fibrinolytic use for minimising perioperative allogeneic blood transfusion. Cochrane Database of Systematic Reviews 2011, Issue 3. [DOI: 10.1002/14651858.CD001886.pub4]

\section{Higgins 2011a}

Higgins JP, Deeks JJ. Chapter 7: Selecting studies and collecting data. In: Higgins JP, Green S, editor(s). Cochrane Handbook for Systematic Reviews of Interventions Version 5.1.0 (updated March 2011). The Cochrane Collaboration, 2011. Available from handbook.cochrane.org.

\section{Higgins 2011b}

Higgins JP, Altman DG, Sterne JAC. Chapter 8: Assessing risk of bias in included studies. In: Higgins JP, Green S, editor(s). Cochrane Handbook for Systematic Reviews of Interventions Version 5.1.0 (updated March 2011). The Cochrane Collaboration, 2011. Available from handbook.cochrane.org.

\section{Higgins 2011c}

Higgins JP, Deeks JJ, Altman DG. Chapter 16: Special topics in Statistics. In: Higgins JP, Green S, editor(s). Cochrane Handbook for Systematic Reviews of Interventions Version 5.1.0 (updated March 2011). The Cochrane Collaboration, 2011. Available from handbook.cochrane.org.

\section{Hui 2011}

Hui P, Cook DJ, Lim W, Fraser GA, Arnold DM. The frequency and clinical significance of thrombocytopenia complicating critical illness: a systematic review. Chest 2011;139(2):271-8.

\section{Jacobs 2011}

Jacobs MR, Smith D, Heaton WA, Zantek ND, Good CE. Detection of bacterial contamination in prestorage culture-negative apheresis platelets on day of issue with the Pan Genera Detection test. Transfusion 2011;51(12):2573-82.

\section{Joint Formulary Committee 2016}

Joint Formulary Committee. British National Formulary, 2016. www.medicinescomplete.com/mc/bnf/current. Online. London: BMJ Group and Pharmaceutical Press, (accessed 17 March 2016).

\section{Kaufman 2015}

Kaufman RM, Djulbegovic B, Gernsheimer T, Kleinman S, Tinmouth AT, Capocelli KE, et al. Platelet transfusion: a clinical practice guideline from the AABB. Annals of Internal Medicine 2015;162(3):205-13.

\section{Kurzrock 2011}

Kurzrock R, Cortes J, Thomas DA, Jeha S, Pilat S, Talpaz M. Pilot study of low-dose interleukin-11 in patients with bone marrow failure. Journal of Clinical Oncology 2011;19(21):4165-72.

\section{Kuter 2014}

Kuter DJ. Milestones in understanding platelet production: a historical overview. British Journal of Haematology 2014;165(2):248-58. 


\section{Leguit 2010}

Leguit RJ, van den Tweel JG. The pathology of bone marrow failure. Histopathology 2010;57(5):655-70.

\section{Levi 2009}

Levi M, Toh CH, Thachil J, Watson HG. Guidelines for the diagnosis and management of disseminated intravascular coagulation. British Journal of Haematology 2009;145(1):24-33.

\section{McNicol 2016}

McNicol ED, Tzortzopoulou A, Schumann R, Carr DB, Kalra A. Antifibrinolytic agents for reducing blood loss in scoliosis surgery in children. Cochrane Database of Systematic Reviews 2016, Issue 9. [DOI: 10.1002/14651858.CD006883.pub3]

\section{Moher 2009}

Moher D, Liberati A, Tetzlaff J, Altman DG. Preferred reporting items for systematic reviews and meta-analyses: the PRISMA statement. Annals of Internal Medicine 2009;151(4):264-9.

\section{Neunert 2013}

Neunert CE. Current management of immune thrombocytopenia. Hematology 2013;2013:276-82.

\section{NICE 2011}

National Institute of Health and Care Excellence. Romiplostim for the treatment of chronic immune (idiopathic) thrombocytopenic purpura, 2011. www.nice.org.uk/guidance/ ta221 (accessed prior to 23 August 2018).

\section{NICE 2013}

National Institute of Health and Care Excellence. Eltrombopag for treating chronic immune (idiopathic) thrombocytopenic purpura (review of technology appraisal 205). www.nice.org.uk/ guidance/ta293/documents/thrombocytopenic-purpuraeltrombopag-rev-ta205-final-appraisal-determination3 (accessed prior to 23 August 2018).

\section{NICE 2015}

National Institute for Health and Care Excellence. Blood transfusion. www.nice.org.uk/guidance/ng24 (accessed 10 November 2016).

\section{Nisha 2012}

Nisha S, Amita D, Uma S, Tripathi AK, Pushplata S. Prevalence and characterization of thrombocytopenia in pregnancy in Indian women. Indian Journal of Hematology and Blood Transfusion 2012;28(2):77-81.

\section{Pacheco 2011}

Pacheco LD, Berkowitz RL, Moise KJ, Bussel JB, McFarland JG, Saade GR. Fetal and neonatal alloimmune thrombocytopenia: a management algorithm based on risk stratification. Obstetrics and Gynecology 2011;118(5):1157-63.

\section{Parmar 1998}

Parmar M, Torri V, Stewart L. Extracting summary statistics to perform meta-analyses of the published literature for survival endpoints. Statistics in Medicine 1998;17(24):2815-34.

\section{Pendry 2011}

Pendry K, Davies T. An audit of use and wastage in the north west of England and North Wales: where have all the platelets gone?. Blood and Transplant Matters 2011;34:17-9.

\section{Perdigão 2012}

Perdigão JP, de Almeida PC, Rocha TD, Mota MR, Soares EC, Alves AP, et al. Postoperative bleeding after dental extraction in liver pretransplant patients. Journal of Oral and Maxillofacial Surgery 2012;70:e177-84.

\section{Provan 2010}

Provan D, Stasi R, Newland AC, Blanchette VS, BoltonMaggs P, Bussel JB, et al. International consensus report on the investigation and management of primary immune thrombocytopenia. Blood 2010;115(2):168-86.

\section{Reeves 2011}

Reeves BC, Deeks JJ, Higgins JP, Wells GA. Chapter 13: Including non-randomised studies. In: Higgins JP, Green S editor(s). Cochrane Handbook for Systematic Reviews of Interventions Version 5.1.0 (updated March 2011). The Cochrane Collaboration, 2011. Available from handbook.cochrane.org.

\section{Review Manager 2014 [Computer program]}

Nordic Cochrane Centre, The Cochrane Collaboration. Review Manager (RevMan). Version 5.3. Copenhagen: Nordic Cochrane Centre, The Cochrane Collaboration, 2014.

\section{Sainio 2000}

Sainio S, Kekomäki R, Riikonen S, Teramo K. Maternal thrombocytopenia at term: a population-based study. Acta Obstetricia et Gynecologica Scandinavica 2000;79:744-9.

\section{Schünemann 2011a}

Schünemann HJ, Oxman AD, Higgins JP, Vist GE, Glasziou P, Guyatt GH. Chapter 11: Presenting results and 'Summary of findings' tables. In: Higgins JP, Green S editor(s), Cochrane Handbook for Systematic Reviews of Interventions Version 5.1.0 (updated March 2011). The Cochrane Collaboration, 2011. Available from handbook.cochrane.org.

\section{Schünemann 2011b}

Schünemann HJ, Oxman AD, Vist GE, Higgins JP, Deeks JJ, Glasziou P, et al. Chapter 12: Interpreting results and drawing conclusions. In: Higgins JPT, Green S, editor(s). Cochrane Handbook for Systematic Reviews of Interventions Version 5.1.0 (updated March 2011). The Cochrane Collaboration, 2011. Available from handbook.cochrane.org.

\section{Simpson 2012}

Simpson E, Lin Y, Stanworth S, Birchall J, Doree C, Hyde C. Recombinant factor VIla for the prevention and treatment of bleeding in patients without haemophilia. Cochrane Database of Systematic Reviews 2012, Issue 3. [DOI: 10.1002/14651858.CD005011.pub4]

\section{Slichter 2007}

Slichter SJ. Evidence-based platelet transfusion guidelines. Hematology 2007;1520:172-8. 


\section{Spiess 2004}

Spiess BD, Royston D, Levy JH, Fitch J, Dietrich W, Body S, et al. Platelet transfusions during coronary artery bypass graft surgery are associated with serious adverse outcomes. Transfusion 2004;44(8):1143-8.

\section{Stanworth 2013}

Stanworth SJ, Walsh TS, Prescott RJ, Lee RJ, Watson DM, Wyncoll DLA. Thrombocytopenia and platelet transfusion in UK critical care: a multicenter observational study. Transfusion 2013;53(5):1050-8.

\section{Sterne 2011}

Sterne JA, Egger M, Moher D. Chapter 10: Addressing reporting biases. In: Higgins JP, Green S, editor(s). Cochrane Handbook for Systematic Reviews of Interventions Version 5.1.0 (updated March 2011). The Cochrane Collaboration, 2011. Available from handbook cochrane.org.

\section{Sterne 2016}

Sterne JA, Hernán MA, Reeves C, Savović J, Berkman ND, Viswanathan $\mathrm{M}$, et al. ROBINS-I: a tool for assessing risk of bias in non-randomised studies of interventions. BMJ 2016;355:i4919.

\section{Tierney 2007}

Tierney JF, Stewart LA, Ghersi D, Burdett S, Sydes MR. Practical methods for incorporating summary time-to-event data into meta-analysis. Trials 2007;8:16. [DOI: 10.1186/1745-6215-8-16]

\section{Tsimberidou 2005}

Tsimberidou AM, Giles FJ, Khouri I, Bueso-Ramos C, Pilat S, Thomas DA, et al. Low-dose interleukin-11 in patients with bone

\section{CHARACTERISTICS OF STUDIES}

Characteristics of included studies [ordered by study ID] marrow failure: update of the M. D. Anderson Cancer Center Experience. Annals of Oncology 2005;16(1):139-45.

\section{Vlaar 2013}

Vlaar AP, Juffermans NP. Transfusion-related acute lung injury: a clinical review. Lancet 2013;382(9896):984-94.

\section{Weinzierl 2013}

Weinzierl EP, Arber DA. The differential diagnosis and bone marrow evaluation of new-onset pancytopenia. American Journal of Clinical Pathology 2013;139(1):9-29.

\section{Whitaker 2013}

Whitaker BI. National blood collection and utilization survey report. Washington, DC: U.S. Department of Health and Human Services; 2013. www.hhs.gov/ash/bloodsafety/2011-nbcus.pdf (accessed 1 December 2016).

\section{Zeng 2011}

Zeng Y, Duan X, Xu J, Ni X. TPO receptor agonist for chronic idiopathic thrombocytopenic purpura. Cochrane Database of Systematic Reviews 2011, Issue 7. [DOI: 10.1002/14651858.CD008235.pub2]

\section{References to other published versions of this review \\ Estcourt 2017b}

Estcourt LJ, Malouf R, Doree C, Trivella M, Hopewell S, Birchall J. Prophylactic platelet transfusions prior to surgery for people with a low platelet count. Cochrane Database of Systematic Reviews 2017, Issue 9. [DOI: 10.1002/14651858.CD012779]

Basu 2012

Study design: randomised, double-blind, parallel-group controlled trial
Setting and country: outpatient university hospital, USA
Number of centres: 1
Study duration (start to end): unclear
Follow-up duration: 4 weeks
Power calculation: unclear
Publication type: abstract

Exclusion criteria: ITP, drug-induced thrombocytopenia, HIV, hepatocellular carcinoma, haemangioma, autoimmune thrombocytopenia, use of steroids, MDS

Number screened: unclear

Number randomised: 65 
Basu 2012 (Continued)

\section{Number analysed: unclear}

Number excluded: unclear

\section{Baseline characteristics}

- Number of participants: 18 in the platelet transfusion group, 23 in the romiplostim group, 24 in the eltrombopag group

- Age (years): mean 56

- Gender (male/female): 43/22

- Platelet count (× 109/L): mean 77

- Creatinine (mg/L): not reported

- Total bilirubin (mg/dL): not reported

- ALT: not reported

- Albumin: not reported

- INR: not reported

- PT: not reported

- Primary diagnosis: hepatitis C 37/65 (57\%); hepatitis B 7 (15.5\%), alcoholic cirrhosis 10 (15\%); nonalcoholic steatohepatitis $3(5 \%)$, primary biliary cirrhosis $6(9 \%)$

- Antiplatelet agents: not reported

- Anticoagulants: exclusion criterion

- Coagulopathy: not reported

Interventions

Procedure: liver biopsy

\section{Platelet transfusion $(n=18)$}

- Dose: 7 units of platelets

- Frequency: once at night for the morning liver biopsy

- Administration route: IV

\section{Romiplostim ( $n=23$ )}

- Dose: $500 \mu \mathrm{g}$

- Frequency: given once 2 weeks before the liver biopsy

- Administration route: subcutaneous

\section{Eltrombopag $(n=24)$}

- Dose: $57 \mathrm{mg} /$ day

- Frequency: for 2 weeks before the liver biopsy

- Administration route: by mouth

Outcomes

Review outcomes

- Bleeding and haematoma

\section{Other outcomes}

- adverse effects of the eltrombopag and romiplostim: nausea, vomiting, dry mouth, headache, insomnia, irritability, local skin rash, shortness of breath, myalgia, arthralgia, erythema in postbiopsy and postinjection site

- cost effectiveness

\section{Notes}

\section{Trial registration: none found}

Sources of funding: not reported

Conflicts of interest: unclear 
Basu 2012 (Continued)

Ethical approval: unclear

\section{Risk of bias}

\begin{tabular}{lll}
\hline Bias & Authors' judgement & Support for judgement \\
\hline $\begin{array}{l}\text { Random sequence genera- } \\
\text { tion (selection bias) }\end{array}$ & Unclear risk & Published as an abstract, no information available \\
\hline $\begin{array}{l}\text { Allocation concealment } \\
\text { (selection bias) }\end{array}$ & Unclear risk & Published as an abstract, no information available \\
\hline $\begin{array}{l}\text { Blinding of participants } \\
\text { and personnel (perfor- } \\
\text { mance bias) }\end{array}$ & Low risk & Double-blind trial \\
All outcomes & \\
\hline $\begin{array}{l}\text { Blinding of outcome as- } \\
\text { sessment (detection bias) }\end{array}$ & Low risk & Double-blind trial \\
All outcomes & & \\
\hline $\begin{array}{l}\text { Incomplete outcome data } \\
\text { (attrition bias) } \\
\text { All outcomes }\end{array}$ & Unclear risk & Published as an abstract, no information available \\
\hline $\begin{array}{l}\text { Selective reporting (re- } \\
\text { porting bias) }\end{array}$ & Unclear risk & Published as an abstract, no information available \\
\hline \begin{tabular}{l} 
Other bias \\
\hline
\end{tabular} & Unclear risk & Published as an abstract, no information available \\
\hline
\end{tabular}

Stanca 2010

Methods Study design: randomised, open-label, parallel-controlled trial

Setting and country: dental clinic, Mount Sinai Hospital, USA

Number of centres: 1

Study duration (start to end): study enrolment occurred between October 2005 and May 2007

Follow-up duration: 24 hours after surgery

Study power calculation: no

Publication type: full

Participants

Inclusion criteria: adults with biopsy-confirmed liver cirrhosis or clinical/radiological evidence of cirrhosis, requiring dental extraction, having a platelet count of $30 \times 10^{9} / \mathrm{L}$ to $50 \times 10^{9} / \mathrm{L}$, INR of 2.0 to 3.0 , or a combination of these

Exclusion criteria: presence of other bleeding disorders besides cirrhosis such as renal dysfunction (creatinine $2.0 \mathrm{mg} / \mathrm{dL}$ ) or HIV, receipt of blood transfusion within 2 weeks before the study, recent acute decompensation of liver cirrhosis, malignancy excluding hepatocellular carcinoma in the absence of portal vein thrombosis, treatment with antiplatelet medications (aspirin, non-steroidal anti-inflammatory drugs or clopidogrel) within 10 days before the extraction and documented allergy to desmopressin

Pretreatment: no difference between groups with regard to the age, gender, the severity of liver disease as reflected by MELD score, number of teeth removed and percentage of surgical extractions 
Number screened: 43 enrolled. 2 participants assigned to the blood transfusion group withdrew their consent for the study; 1 participant wanted to be assigned to the desmopressin group, and the other participant changed his mind about having the dental extraction done at that time. 5 participants, 4 in the desmopressin group and 1 in the transfusion group, had blood drawn after being enrolled in the study but before their surgical procedure that resulted in laboratory values outside of the study parameters. These 5 participants underwent the surgical procedure but were not included in the analysis.

Number excluded: 5 participants underwent the surgical procedure but were not included in the analysis.

\section{Baseline characteristics}

\section{Platelet transfusion group}

- Number of participants: 19

- Age (years): mean 50 (range 28 to 65)

- Gender (male/female): $13 / 6$

- Platelet count ( $\times 10^{9} / \mathrm{L}$ ): mean 45 (range 22 to 103 ), 11 out of 19 participants had low platelets

- Creatinine $(\mathrm{mg} / \mathrm{dL}$ ): mean 0.8 (range 0.5 to 1.8 )

- Total bilirubin (mg/dL): mean 2.7 (range 1.5 to 24.9 )

- ALT (IU/L): mean 46 (range 17 to 188)

- Albumin (g/dL): mean 2.5 (range 1.4 to 3.5 )

- INR: mean 2.1 (range 1.4 to 2.9 )

- PT: not reported

- Procedure: dental extraction: simple 10; surgical 7; unknown 2

- Primary diagnosis: liver cirrhosis

- Antiplatelet agents: exclusion criterion

- Anticoagulants: exclusion criteria included the presence of other bleeding disorders

- Coagulopathy: exclusion criteria included the presence of other bleeding disorders

- Platelet dysfunction: exclusion criteria included the presence of other bleeding disorders

\section{Alternatives to platelet transfusions group}

- Number of participants: 17

- Age (years): mean 51 (range 34 to 63)

- Gender (male/female): $12 / 5$

- Platelet count ( $\times 109 / \mathrm{L}$ ): mean 48 (range 30 to 147 ), 11 out of 17 participants had low platelets

- Creatinine (mg/dL): mean 0.9 (range 0.5 to 1.9 )

- Total bilirubin (mg/dL): mean 2.7 (range 1.1 to 15.4)

- ALT (IU/L): mean 30 (range 13 to 491)

- Albumin (g/dL): mean 2.7 (range 1.9 to 4.1 )

- INR: mean 2.0 (range 1.0 to 3.0 )

- PT: NR

- Procedure: dental extraction: simple 9; surgical 7; unknown 1

- Primary diagnosis: liver cirrhosis

- Antiplatelet agents: exclusion criterion

- Anticoagulants: exclusion criteria included the presence of other bleeding disorders

- Coagulopathy: exclusion criteria included the presence of other bleeding disorders

- Platelet dysfunction: exclusion criteria included the presence of other bleeding disorders

\footnotetext{
Interventions
}

Surgical procedure: dental extraction

\section{Platelet transfusion}

- Dose: FFP $10 \mathrm{~mL} / \mathrm{kg}$ for INR of 2.0 to 3.0 or 1 unit of single donor platelets if the platelet count was in the range of $30,000 / \mathrm{L}$ to $50,000 / \mathrm{L}$ (or both) 
Stanca 2010 (Continued)

- Frequency: additional transfusions if bleeding post procedure

- Administration route: IV

\section{Alternatives to platelet transfusions}

- Dose: desmopressin acetate, nasal spray, $1.5 \mathrm{mg} / \mathrm{mL} ; 25$ doses in 1 container) provided by CSL Behring, Kankakee, IL

- Frequency: both nostrils, prior to surgery and after surgery if bleeding or evening after procedure if bleeding

- Administration route: intranasal

Primary outcome:
- necessity of rescue blood transfusion in participants who received desmopressin or blood transfusion
prior to dental extraction (time frame: 48 hours)
Secondary outcomes:
- number of participants with major procedure-related bleeding within 7 days of surgery
- number of participants with minor procedure-related bleeding within 7 days of surgery
- number of platelet transfusions per participant and number of platelet components per participant
- number of red cell transfusions per participant and number of red cell components per participant
- serious adverse events
- cost

Notes

Trial registration number: NCT00816127

Source of funding: Icahn School of Medicine at Mount Sinai, New York City, NY

Conflicts of interest: unclear

Ethical approval: yes, "The study protocol conformed to the ethical guidelines of the 1975 Declaration of Helsinki as reflected in the approval by the Mount Sinai Institutional Review Board."

\section{Risk of bias}

Bias Authors' judgement Support for judgement

Random sequence genera- Low risk tion (selection bias)

\section{Allocation concealment Low risk} (selection bias)
Quote: "randomization list was generated by one member of the biomathematics team using computer software for randomization."

Quote: "same member of the biomathematics team, not involved in patient enrollment, prepared sealed white randomization envelopes prelabeled with an ID number. The content of the envelope (patient's assignment to the DDAVP [desmopressin] or blood transfusion group) matched the information in the randomization plan for that particular ID number (DDAVP or blood transfusion group). The content of the envelope was not accessible to the research coordinator who enrolled patients or to any member of the team at the time of enrollment."

Judgement comment: sealed white envelopes

Blinding of participants High risk $\quad$ Open-label design, no blinding
and personnel (perfor-
mance bias)
All outcomes

\begin{tabular}{|c|c|c|}
\hline $\begin{array}{l}\text { Blinding of outcome as- } \\
\text { sessment (detection bias) } \\
\text { All outcomes }\end{array}$ & High risk & No blinding \\
\hline
\end{tabular}


Stanca 2010 (Continued)

Incomplete outcome data Unclear risk (attrition bias)

All outcomes
In all, 43 participants were enrolled in the study and randomised: 21 in desmopressin group and 22 in transfusion group. 36 participants (17 in desmopressin group and 19 in transfusion group) completed the study procedures. 2 participants assigned to the blood transfusion group withdrew their consent for the study; 1 participant wanted to be assigned to the desmopressin group, and the other participant changed his mind about having the dental extraction done at that time. 5 participants, 4 in desmopressin group and 1 in transfusion group, had blood drawn after being enrolled in the study but before their surgical procedure that resulted in laboratory values outside of the study parameters. These 5 participants underwent the surgical procedure but were not included in the analysis. None of these participants experienced bleeding after the procedure. 7 participants randomised were not included in the analysis. 3 in transfusion arm and 4 in desmopressin arm. This is a relative large (up to 19\%) number of participants randomised who were not included in the analysis.
Selective reporting (re- Unclear risk porting bias)
Only outcome listed on clinical trials.gov was: "Necessity of rescue blood transfusion in patients who received DDAVP [desmopressin] or blood transfusion prior to dental extraction."

No other secondary outcomes listed. This outcome was reported. However, no protocol to assess if other outcomes was planned.

Other bias Low risk No other biases found

Veelo 2012

Methods

Study design: parallel-group, open-label, RCT

Setting and country: ICU University hospital, the Netherlands

Number of centres: 1

Study duration (start to end): July 2007 to October 2009

Follow-up duration: Not reported

Power calculation: yes, "Although a sample size of 152 patients was considered necessary to find a difference of $15 \%$ in bleeding between groups, the study was prematurely terminated."

Publication type: full

Participants

Inclusion criteria: participants planned for bedside PDT with mild coagulation disorders defined as PT $14.7-20.0$ seconds or platelet counts $40-100 \times 10^{9} / \mathrm{L}$ or active treatment with aspirin at any dose, or a combination of these

Exclusion criteria: aged < 18 years; need for surgical tracheotomy; contraindications to transfusion of blood products and use of clopidogrel. Participant would also be excluded from participation if the attending physician insisted on the need for transfusion of FFP or platelets (or both) before the procedure.

Number screened: 355

Number randomised: 72

Number analysed: 64, 4 in each arm did not undergo PDT

Number excluded: 283 (refused consent 27, surgical procedure 53, clopidogrel 13, PT > 20 seconds, 11, normal coagulation 179)

\section{Baseline characteristics}




\section{Platelet transfusion group}

- Number of participants: 35

- Age (years): median 64 (IQR 56-72)

- Gender (male/female): 22/13

- Platelet count (× 109/L): median 81 (IQR 63-85), low platelet count 13

- Creatinine: not reported

- Total bilirubin: not reported

- ALT: not reported

- Albumin: not reported

- INR: not reported

- PT (secs): mean 16.0 (SD 1.2)

- Primary diagnosis: 9 acute renal failure, 2 chronic renal failure, 7 sepsis, 5 massive transfusion, 2 haematological malignancy, 0 liver cirrhosis

- Antiplatelet agents: 11 (aspirin)

- Anticoagulants: exclusion criterion

- Coagulopathy: 8 had $>1$ coagulation disorder present

- Platelet dysfunction: not reported

\section{No platelet transfusion group}

- Number of participants: 37

- Age (years): median 68 (IQR 60-76)

- Gender (male/female): 16/21

- Platelet count (× 109/L): median 56 (IQR 47-70), low platelet count 10

- Creatinine: not reported

- Total bilirubin: not reported

- ALT: not reported

- Albumin: not reported

- INR: not reported

- PT (secs): mean 16.6 (SD 1.1)

- Primary diagnosis: 3 acute renal failure, 2 chronic renal failure, 9 sepsis, 5 massive transfusion, 3 haematological malignancy, 0 liver cirrhosis

- Antiplatelet agents: 12 participants were on aspirin

- Anticoagulants: excluded criterion

- Coagulopathy: 7 had $>1$ coagulation disorder present

- Platelet dysfunction: not reported

\section{Procedure: PDT}

\section{Platelet transfusion group}

- Dose: participants with a prolonged PT (normal values 11.0-14.7 seconds) assigned to the "correction group" received 1 or 2 units of FFP ( 1 unit contained $300 \mathrm{~mL}$ of FFP: if the PT was between 14.7 and 18.0 seconds the participant received 1 unit of FFP; if the PT was between 18.0 and 20.0 seconds the participant received 2 units of FFP). Participants with a low platelet count or active use of aspirin (or both) assigned to the correction group received 5 units of platelet concentrates prepared from 5 pooled buffy coats.

- Frequency: before procedure

- Administration route: IV

\section{No platelet transfusion group}

- Dose: participants assigned to the "no correction" group received neither plasma nor platelets. However, FFP or platelets (or both) were made available for immediate transfusion in case bleeding occurred during or after PDT 
Veelo 2012 (Continued)

Primary outcomes
- Volume of blood loss during PDT
- Intensity of intra-tracheal bleeding
- Time until no blood is visible in tracheal aspirates
Secondary outcome
- Amount of blood products used during and after tracheotomy
Review outcomes reported by the trial
- All-cause mortality within 30 days of surgery
- Major bleeding within 7 days of surgery
- Minor bleeding within 7 days of surgery
- Number of participants received platelet transfusions
- Number of participants received red blood cells transfusions
- Proportion of participants requiring additional interventions to stop bleeding within 7 days of surgery
- Serious adverse effects

Source of funding: Academic Medical Centre (AMC) (The Netherlands), Department of Intensive Care

Conflicts of interest: authors declared no conflicts of interest

Ethical approval: yes. "The study was approved by the local ethics committee."

\section{Risk of bias}

\begin{tabular}{|c|c|c|}
\hline Bias & Authors' judgement & Support for judgement \\
\hline $\begin{array}{l}\text { Random sequence genera- } \\
\text { tion (selection bias) }\end{array}$ & Low risk & Quote: "computer-generated randomisation scheme was used." \\
\hline $\begin{array}{l}\text { Allocation concealment } \\
\text { (selection bias) }\end{array}$ & Low risk & $\begin{array}{l}\text { Quote: "Each assignment ("correction" or "no correction") was recorded on a } \\
\text { piece of paper folded three times and enclosed in a consecutively numbered, } \\
\text { opaque, sealed envelope." }\end{array}$ \\
\hline $\begin{array}{l}\text { Blinding of participants } \\
\text { and personnel (perfor- } \\
\text { mance bias) } \\
\text { All outcomes }\end{array}$ & High risk & Open-label design RCT \\
\hline $\begin{array}{l}\text { Blinding of outcome as- } \\
\text { sessment (detection bias) } \\
\text { All outcomes }\end{array}$ & High risk & Open-label design RCT \\
\hline $\begin{array}{l}\text { Incomplete outcome data } \\
\text { (attrition bias) } \\
\text { All outcomes }\end{array}$ & Low risk & $\begin{array}{l}\text { CONSORT flow diagram clearly reported. All participants who underwent the } \\
\text { procedure were included in the analysis. } 4 \text { in each arm did not undergo the } \\
\text { procedure. }\end{array}$ \\
\hline $\begin{array}{l}\text { Selective reporting (re- } \\
\text { porting bias) }\end{array}$ & High risk & $\begin{array}{l}\text { No protocol available, but registered ISRCTN31808827. } \\
\text { Primary outcome measures: volume of blood loss during PDT2; intensity of } \\
\text { intratracheal bleeding; time until no blood is visible in tracheal aspirates. All } \\
\text { these were all reported in the published paper. Secondary outcome measures: } \\
\text { amount of blood products used during and after tracheotomy - not clearly re- } \\
\text { ported in the published paper }\end{array}$ \\
\hline
\end{tabular}


Veelo 2012 (Continued)

Other bias
Trial stopped early due to increase resistance to recruitment and low rate of bleeding in either arm of the study.

Quote: "Although a sample size of 152 patients was considered necessary to find a difference of $15 \%$ in bleeding between groups, the study was prematurely terminated."

ALT: alanine transaminase; CLD: chronic liver disease; FFP: fresh frozen plasma; ICU: intensive care unit; INR: international normalised ratio; IQR: interquartile range; ITP: immune thrombocytopenia; IV: intravenous; MDS: myelodysplastic syndrome; MELD: Model for End-Stage Liver Disease; n: number of participants; PDT: percutaneous dilational tracheotomy; PT: prothrombin time; RCT: randomised controlled trial; SD: standard deviation.

Characteristics of excluded studies [ordered by study ID]

\begin{tabular}{|c|c|}
\hline Study & Reason for exclusion \\
\hline Abdelfatah 2016 & Wrong study design, observational retrospective cohort \\
\hline Afdhal 2012 & Wrong intervention, no platelet transfusions \\
\hline Al-Zaabi 2014 & Wrong study design, single-centre observational cohort \\
\hline Backos 1999 & Wrong participant population, not receiving surgery or a procedure \\
\hline Barrera 1996 & Wrong study design, observational retrospective cohort \\
\hline Cai 2014 & Wrong study design, single-centre observational cohort \\
\hline Chantarangkul 2013 & Wrong study design, single-centre observational cohort \\
\hline Chen 2011 & Wrong study design, single-centre observational cohort \\
\hline De Pietri 2016 & wrong intervention, thrombelastography-guided blood product use \\
\hline Embrey 2006 & Wrong study design, observational retrospective cohort \\
\hline EudraCT 2007-005851-40 & Wrong intervention, no platelet transfusions \\
\hline Fayed 2014 & Wrong study design, observational cohort \\
\hline Harding 1975 & Wrong participant population (not thrombocytopenic prior to surgery) \\
\hline Hess 2015 & Wrong participant population (bleeding) \\
\hline Hibbert 2013 & Wrong study design, observational cohort \\
\hline Holcomb 2015 & Wrong participant population (bleeding) \\
\hline Karkouti 2016 & Wrong intervention, thrombelastography-guided blood product use \\
\hline Khair 2015 & Wrong study design, case series \\
\hline Kultufan 2006 & Wrong intervention, thrombelastography-guided blood product use \\
\hline Napolitano 2017 & Wrong study design, case series \\
\hline
\end{tabular}




\begin{tabular}{|c|c|}
\hline Study & Reason for exclusion \\
\hline NCT00521664 & Wrong participant population, not receiving surgery or a procedure \\
\hline NCT00549484 & Wrong study setting, measuring thrombopoietin levels \\
\hline NCT00678587 & Wrong intervention, no platelet transfusions \\
\hline NCT01291290 & Wrong participant population (bleeding) \\
\hline NCT01402739 & Wrong participant population (not thrombocytopenic prior to surgery) \\
\hline NCT01919840 & Wrong intervention, thrombelastography-guided blood product use \\
\hline NCT02042898 & Wrong intervention, no platelet transfusions \\
\hline NCT02074436 & Wrong participant population, not receiving surgery or a procedure \\
\hline NCT02200419 & Wrong study design, observational study \\
\hline NCT02352181 & Wrong intervention, thrombelastography-guided blood product use \\
\hline NCT02987712 & Wrong study design, single-centre non-randomised study \\
\hline NCT02990273 & Wrong intervention, thrombelastography-guided blood product use \\
\hline NCT03011827 & Wrong study design, observational cohort study \\
\hline NCT03022253 & Wrong participant population, not receiving surgery or a procedure \\
\hline Park 2016 & Wrong study design, observational cohort \\
\hline Pereboom 2009 & Wrong study design, case series \\
\hline Perek 2016 & Wrong study design, retrospective cohort \\
\hline Perl 2016 & Wrong intervention, blood transfusion ratios in trauma (PROPPR study) \\
\hline Pietri 2014 & Wrong intervention, thrombelastography-guided blood product use \\
\hline Ray 1997 & Wrong study design, observational cohort \\
\hline Simon 1982 & Wrong participant population (not thrombocytopenic prior to surgery) \\
\hline Simon 1984 & Wrong participant population (not thrombocytopenic prior to surgery) \\
\hline Smart 2017 & Wrong intervention, thrombelastography-guided blood product use \\
\hline Tanaka 2014 & Wrong participant population (not thrombocytopenic prior to surgery) \\
\hline Titano 2016 & Wrong intervention, no platelet transfusions \\
\hline Tripodi 2013 & Wrong study design, observational cohort study \\
\hline
\end{tabular}


Characteristics of ongoing studies [ordered by study ID]

\section{NTR5653}

\section{Trial name or title}

Prophylactic platelet transfusion prior to central venous catheter placement in patients with thrombocytopenia

Methods

Study design: parallel-group, single-blind, randomised controlled trial

Country: the Netherlands

Number of centres: multicentre

Planned starting date: February 2016

Planned completion date: October 2019

Follow-up points: directly after CVC insertion, 1 hour, 24 hours

Target number of participants: 462
Inclusion criteria:
- Aged $>18$ years
- Need for CVC placement at the clinician's discretion
- Platelet count $10-50 \times 109 / \mathrm{L}$
- INR $<1.5$
- Informed consent
Exclusion criteria:
- Use of therapeutic anticoagulant therapy, except single antiplatelet therapy
- Contraindication for platelet transfusion, such as thrombotic thrombocytopenic purpura, or con-
- genital IgA deficiency
- Previous randomisation in the current trial

Interventions

Intervention arm: 1 unit of platelets

Control arm: no platelets or placebo treatment

Outcomes Primary outcome:

- A procedure-related relevant bleeding, occurring within 24 hours after the procedure. A WHO grade $2-4$ bleed up to 24 hours from randomisation was defined as relevant bleeding.

\section{Secondary outcomes:}

- WHO grade 1 bleeding within 24 hours of CVC placement

- Adjusted WHO bleeding score, HEmorrhage MEasurement (HEME)-bleeding score

- Allergic transfusion reaction within 24 hours

- Onset of acute lung injury within 48 hours

- Length of hospital stay

- Number of RBC and platelet transfusions within 24 hours

- Costs

\begin{tabular}{ll}
\hline Starting date & February 2016 \\
\hline Contact information & APJ Vlaar \\
\hline
\end{tabular}


NTR5653 (Continued)

\title{
Methods
}

\author{
Allocation: randomised \\ Endpoint classification: safety/efficacy study \\ Intervention model: parallel assignment ( 3 arms) \\ Masking: double-blind (participant, caregiver) \\ Primary purpose: treatment
}

Participants

\section{Inclusion criteria:}

- adults (aged $\geq 18$ years) with chronic liver failure (cirrhosis or chronic liver graft dysfunction or both) admitted to ICU and requiring insertion of a central line.

\section{Exclusion criteria:}

- acute liver failure

- use of therapeutic doses of oral or parenteral anticoagulants (unfractionated heparin or low molecular weight heparin or oral anticoagulants)

- use of oral or parenteral platelet aggregation inhibitors

- people with von Willebrand disease

- over-the-guidewire CVC changing

- people previously included in this study protocol during the same hospital stay

\section{Arm 1: coagulogram-based protocol}

Arm based on standard coagulation tests protocol to guide blood transfusion before central venous catheterisation. The possible components to be used include fresh frozen plasma, platelets (random or apheresis), cryoprecipitate (or a combination of these), based on INR), PTT, platelet count, fibrinogen (or a combination of these).

- $\quad$ INR $>1.5$ or PTT $>50$ seconds, fresh frozen plasma is administered (dose: $10 \mathrm{~mL} / \mathrm{kg}$ )

- Platelets $<50 \times 109 / \mathrm{L}$, platelet transfusion is administered (random or apheresis)

- Fibrinogen $<1.5 \mathrm{~g} / \mathrm{L}$, cryoprecipitate is administered

\section{Arm 2: thromboelastometry-based protocol}

The interventions for this protocol included transfusion of fresh frozen plasma, platelets (random or aphaeresis) cryoprecipitate (or a combination of these), based on rotational thromboelastometry.

- Coagulation time (extrinsically activated) $<80$ seconds and $\mathrm{A} 10$ (extrinsically activated) $>40 \mathrm{~mm}$, then no blood transfusion is performed

- Coagulation time (extrinsically activated) $>80$ seconds then fresh frozen plasma is administered (dose: $10 \mathrm{~mL} / \mathrm{kg}$ )

- A10 (extrinsically activated) $<40 \mathrm{~mm}$ or A10 (fibrinogen polymerisation) $>10 \mathrm{~mm}$ platelet transfusion is administered (random or apheresis)

- $\mathrm{A} 10$ (extrinsically activated) $<40 \mathrm{~mm}$ or $\mathrm{A} 10$ (fibrinogen polymerisation) $<10 \mathrm{~mm}$ cryoprecipitate is administered 
Rocha 2017 (Continued)

\section{Arm 3: restrictive strategy}

The interventions for this protocol include transfusion of fresh frozen plasma or platelets (random or aphaeresis), or both, based on INR and platelet count.

- INR $>5$, fresh frozen plasma is administered (dose: $10 \mathrm{~mL} / \mathrm{kg}$ )

- Platelets $<25 \times 109 / \mathrm{L}$, platelet transfusion is administered (random or apheresis)

\begin{tabular}{|c|c|}
\hline Outcomes & $\begin{array}{l}\text { Primary outcome: } \\
\text { - proportion of participants receiving a blood component transfusion, i.e. fresh frozen plasma, } \\
\text { platelets, cryoprecipitate (or a combination of these) before central venous catheterisation (on } \\
\text { day of randomisation) } \\
\text { Secondary outcomes: } \\
\text { - incidence of haemorrhagic complications associated with central venous catheterisation proce- } \\
\text { dure (up to } 24 \text { hours) } \\
\text { - incidence of acute immunological and non-immunological adverse effects of blood transfusion } \\
\text { (up to } 24 \text { hours) } \\
\text { - cost assessments (laboratory and blood transfusion) between the } 3 \text { strategies (up to } 24 \text { hours) } \\
\text { - length of stay in ICU (up to } 90 \text { days) } \\
\text { - mortality rate (up to } 28 \text { days) }\end{array}$ \\
\hline
\end{tabular}

\begin{tabular}{ll}
\hline Starting date & September 2014 \\
\hline Contact information & Leonardo L Rocha, MD +55-11-21511500, Irocha23@gmail.com \\
& Thiago D Correa, MD, PhD +55-11-21511500, thiagodct@gmail.com \\
\hline
\end{tabular}

Notes

Estimated enrolment: 165

Estimated study completion date: January 2019

Estimated primary completion date: December 2018 (final data collection date for primary outcome measure)

Trial registration: NCT02311985

Location of trial: Hospital Israelita Albert Einstein, Sao Paulo, Brazil

CVC: central venous catheter; ICU: intensive care unit; IgA: immunoglobulin A; INR: international normalised ratio; PTT: partial thromboplastin time; RBC: red blood cell; WHO: World Health Organization.

\section{DATA AND ANALYSES}

\section{Comparison 1. Prophylactic platelet transfusion prior to surgery versus no prophylactic platelet transfusion prior to surgery}

\begin{tabular}{lllll}
\hline Outcome or subgroup title & No. of studies & $\begin{array}{l}\text { No. of partici- } \\
\text { pants }\end{array}$ & Statistical method & Effect size \\
\hline 1 All-cause mortality within 30 days of surgery & 1 & & $\begin{array}{l}\text { Risk Ratio (M-H, Ran- } \\
\text { dom, 95\% Cl) }\end{array}$ & $\begin{array}{l}\text { Totals not select- } \\
\text { ed }\end{array}$ \\
\hline
\end{tabular}




\begin{tabular}{|c|c|c|c|c|}
\hline Outcome or subgroup title & No. of studies & $\begin{array}{l}\text { No. of partici- } \\
\text { pants }\end{array}$ & Statistical method & Effect size \\
\hline $\begin{array}{l}2 \text { Number of participants with major proce- } \\
\text { dure-related bleeding within } 7 \text { days of surgery }\end{array}$ & 1 & & $\begin{array}{l}\text { Risk Ratio (M-H, Ran- } \\
\text { dom, } 95 \% \mathrm{Cl})\end{array}$ & $\begin{array}{l}\text { Totals not select- } \\
\text { ed }\end{array}$ \\
\hline $\begin{array}{l}3 \text { Number of participants with minor proce- } \\
\text { dure-related bleeding within } 7 \text { days of surgery }\end{array}$ & 1 & & $\begin{array}{l}\text { Risk Ratio (M-H, Ran- } \\
\text { dom, } 95 \% \mathrm{Cl})\end{array}$ & $\begin{array}{l}\text { Totals not select- } \\
\text { ed }\end{array}$ \\
\hline $\begin{array}{l}4 \text { Proportion of participants requiring addi- } \\
\text { tional interventions to stop bleeding within } 7 \\
\text { days of surgery }\end{array}$ & 1 & & $\begin{array}{l}\text { Risk Ratio (M-H, Ran- } \\
\text { dom, } 95 \% \mathrm{Cl})\end{array}$ & $\begin{array}{l}\text { Totals not select- } \\
\text { ed }\end{array}$ \\
\hline
\end{tabular}

Analysis 1.1. Comparison 1 Prophylactic platelet transfusion prior to surgery versus no prophylactic platelet transfusion prior to surgery, Outcome 1 All-cause mortality within $\mathbf{3 0}$ days of surgery.

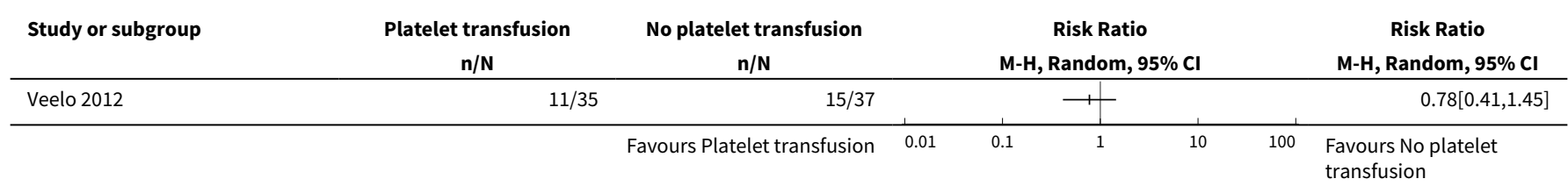

Analysis 1.2. Comparison 1 Prophylactic platelet transfusion prior to surgery versus no prophylactic platelet transfusion prior to surgery, Outcome 2 Number of participants with major procedure-related bleeding within 7 days of surgery.

\begin{tabular}{|c|c|c|c|c|c|c|c|}
\hline Study or subgroup & $\begin{array}{c}\text { Platelet transfusion } \\
\mathrm{n} / \mathrm{N}\end{array}$ & $\begin{array}{c}\text { No platelet transfusion } \\
n / N\end{array}$ & & & Ratio & & $\begin{array}{c}\text { Risk Ratio } \\
\text { M-H, Random, } 95 \% \mathrm{Cl}\end{array}$ \\
\hline Veelo 2012 & $3 / 31$ & $2 / 33$ & & & - & & $1.6[0.29,8.92]$ \\
\hline
\end{tabular}

Analysis 1.3. Comparison 1 Prophylactic platelet transfusion prior to surgery versus no prophylactic platelet transfusion prior to surgery, Outcome 3 Number of participants with minor procedure-related bleeding within 7 days of surgery.

\begin{tabular}{|c|c|c|c|c|c|c|c|}
\hline \multirow{2}{*}{$\begin{array}{l}\text { Study or subgroup } \\
\text { Veelo } 2012\end{array}$} & $\begin{array}{l}\text { Platelet transfusion } \\
\qquad \mathrm{n} / \mathrm{N} \\
\end{array}$ & $\begin{array}{l}\text { No platelet transfusion } \\
\mathrm{n} / \mathrm{N} \\
\end{array}$ & \multicolumn{3}{|c|}{$\begin{array}{c}\text { Risk Ratio } \\
\text { M-H, Random, } 95 \% \mathrm{Cl} \\
\end{array}$} & & \multirow{2}{*}{\begin{tabular}{c}
\multicolumn{1}{c}{ Risk Ratio } \\
M-H, Random, 95\% Cl \\
$1.29[0.9,1.85$
\end{tabular}} \\
\hline & $23 / 31$ & $19 / 33$ & & & + & & \\
\hline & & Favours Platelet transfusion & 0.01 & 0.1 & 10 & 100 & $\begin{array}{l}\text { Favours No platelet } \\
\text { transfusion }\end{array}$ \\
\hline
\end{tabular}


Analysis 1.4. Comparison 1 Prophylactic platelet transfusion prior to surgery versus

no prophylactic platelet transfusion prior to surgery, Outcome 4 Proportion of participants requiring additional interventions to stop bleeding within 7 days of surgery.

\begin{tabular}{|c|c|c|c|c|c|c|c|}
\hline \multirow{2}{*}{$\begin{array}{l}\text { Study or subgroup } \\
\text { Veelo } 2012\end{array}$} & $\begin{array}{l}\text { Platelet transfusion } \\
\mathrm{n} / \mathrm{N} \\
\end{array}$ & $\begin{array}{c}\text { No platelet transfusion } \\
\mathrm{n} / \mathrm{N}\end{array}$ & \multicolumn{3}{|c|}{$\begin{array}{c}\text { Risk Ratio } \\
\text { M-H, Random, } 95 \% \mathrm{Cl} \\
\end{array}$} & & \multirow{2}{*}{$\begin{array}{c}\text { Risk Ratio } \\
\text { M-H, Random, 95\% Cl } \\
0.35[0.01,8.38]\end{array}$} \\
\hline & $0 / 31$ & $1 / 33$ & & 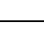 & + & & \\
\hline
\end{tabular}

Comparison 2. Prophylactic platelet transfusion prior to surgery versus alternative treatments

\begin{tabular}{|c|c|c|c|c|}
\hline Outcome or subgroup title & No. of studies & $\begin{array}{l}\text { No. of partici- } \\
\text { pants }\end{array}$ & Statistical method & Effect size \\
\hline $\begin{array}{l}1 \text { Number of participants with minor pro- } \\
\text { cedure-related bleeding within } 7 \text { days of } \\
\text { surgery }\end{array}$ & 2 & & $\begin{array}{l}\text { Risk Ratio (M-H, Ran- } \\
\text { dom, } 95 \% \mathrm{Cl})\end{array}$ & $\begin{array}{l}\text { Totals not select- } \\
\text { ed }\end{array}$ \\
\hline 1.1 Desmopressin vs platelet transfusion & 1 & & $\begin{array}{l}\text { Risk Ratio (M-H, Ran- } \\
\text { dom, } 95 \% \mathrm{Cl} \text { ) }\end{array}$ & $0.0[0.0,0.0]$ \\
\hline $\begin{array}{l}1.2 \text { Thrombopoietin mimetics vs platelet } \\
\text { transfusion }\end{array}$ & 1 & & $\begin{array}{l}\text { Risk Ratio (M-H, Ran- } \\
\text { dom, } 95 \% \mathrm{Cl})\end{array}$ & $0.0[0.0,0.0]$ \\
\hline $\begin{array}{l}2 \text { Proportion of participants requiring addi- } \\
\text { tional interventions to stop bleeding within } \\
7 \text { days of surgery }\end{array}$ & 1 & & $\begin{array}{l}\text { Risk Ratio (M-H, Ran- } \\
\text { dom, } 95 \% \mathrm{Cl})\end{array}$ & $\begin{array}{l}\text { Totals not select- } \\
\text { ed }\end{array}$ \\
\hline 2.1 Desmopressin vs platelet transfusion & 1 & & $\begin{array}{l}\text { Risk Ratio (M-H, Ran- } \\
\text { dom, } 95 \% \mathrm{Cl} \text { ) }\end{array}$ & $0.0[0.0,0.0]$ \\
\hline $\begin{array}{l}3 \text { Serious adverse events (transfusion re- } \\
\text { lated adverse effects within } 24 \text { hours of the } \\
\text { transfusion) }\end{array}$ & 1 & & $\begin{array}{l}\text { Risk Ratio (M-H, Ran- } \\
\text { dom, } 95 \% \mathrm{Cl})\end{array}$ & $\begin{array}{l}\text { Totals not select- } \\
\text { ed }\end{array}$ \\
\hline 3.1 Desmopressin vs platelet transfusion & 1 & & $\begin{array}{l}\text { Risk Ratio (M-H, Ran- } \\
\text { dom, } 95 \% \mathrm{Cl} \text { ) }\end{array}$ & $0.0[0.0,0.0]$ \\
\hline
\end{tabular}

\section{Analysis 2.1. Comparison 2 Prophylactic platelet transfusion prior to surgery versus alternative treatments, Outcome 1 Number of participants with minor procedure-related bleeding within 7 days of surgery.}

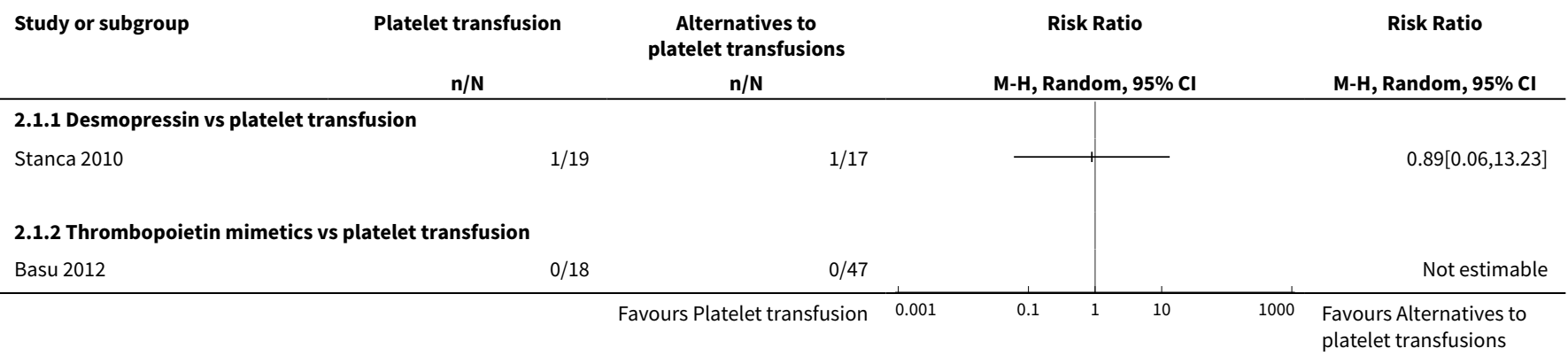


Analysis 2.2. Comparison 2 Prophylactic platelet transfusion prior to surgery versus alternative treatments, Outcome 2 Proportion of participants requiring additional interventions to stop bleeding within $\mathbf{7}$ days of surgery.

\begin{tabular}{|c|c|c|c|c|c|c|c|}
\hline \multirow[t]{2}{*}{ Study or subgroup } & Platelet transfusion & $\begin{array}{c}\text { Alternatives to } \\
\text { platelet transfusions }\end{array}$ & \multicolumn{4}{|c|}{ Risk Ratio } & \multirow{2}{*}{$\begin{array}{c}\text { Risk Ratio } \\
\text { M-H, Random, } 95 \% \mathrm{CI} \\
\end{array}$} \\
\hline & $\mathrm{n} / \mathrm{N}$ & $n / N$ & \multicolumn{3}{|c|}{ M-H, Random, $95 \% \mathrm{Cl}$} & & \\
\hline Stanca 2010 & $1 / 19$ & $4 / 17$ & & & - & & $0.22[0.03,1.81]$ \\
\hline
\end{tabular}

Analysis 2.3. Comparison 2 Prophylactic platelet transfusion prior to surgery versus alternative treatments, Outcome 3 Serious adverse events (transfusion related adverse effects within 24 hours of the transfusion).

\begin{tabular}{|c|c|c|c|c|c|c|c|}
\hline \multirow[t]{2}{*}{ Study or subgroup } & Platelet transfusion & $\begin{array}{c}\text { Alternatives to } \\
\text { platelet transfusions }\end{array}$ & \multicolumn{4}{|c|}{ Risk Ratio } & \multirow{2}{*}{$\begin{array}{c}\text { Risk Ratio } \\
\text { M-H, Random, } 95 \% \mathrm{Cl}\end{array}$} \\
\hline & $n / N$ & $n / N$ & & $M-H, R$ & dom, $95 \% \mathrm{Cl}$ & & \\
\hline \multicolumn{8}{|c|}{ 2.3.1 Desmopressin vs platelet transfusion } \\
\hline \multirow[t]{2}{*}{ Stanca 2010} & $1 / 19$ & $0 / 17$ & & & 1 & & $2.7[0.12,62.17]$ \\
\hline & & Favours Platelet transfusion & 0.001 & $\frac{1}{0.1}$ & 10 & 1000 & $\begin{array}{l}\text { Favours Alternatives to } \\
\text { platelet transfusions }\end{array}$ \\
\hline
\end{tabular}

\section{APPENDICES}

\section{Appendix 1. CENTRAL (the Cochrane Library)}

$\# 1$ MeSH descriptor: [Blood Platelets] explode all trees

\#2 transfus*

$\# 3 \# 1$ and \#2

\#4 MeSH descriptor: [Platelet Transfusion] explode all trees

\#5 MeSH descriptor: [Plateletpheresis] explode all trees

\#6 ((platelet* or thrombocyte*) near/5 (prophyla* or transfus* or infus* ${ }^{*}$ or administ* or requir* or need* or product or products or component ${ }^{\star}$ or concentrate ${ }^{\star}$ or apheres* or pooled or single donor ${ }^{\star}$ or random donor $\left.\left.{ }^{\star}\right)\right)$

$\# 7$ thrombo?ytopheres* or plateletpheres*

\#8 ((platelet ${ }^{\star}$ or thrombocyte ${ }^{\star}$ ) near/5 (protocol ${ }^{*}$ or trigger ${ }^{*}$ or threshold* or schedul ${ }^{\star}$ or dose* or dosing or usage or utilisation or utilization))

\#9 \#3 or \#4 or \#5 or \#6 or \#7 or \#8

\#10 MeSH descriptor: [Specialties, Surgical] explode all trees

\#11 MeSH descriptor: [Surgical Procedures, Operative] explode all trees

$\# 12$ MeSH descriptor: [Perioperative Care] explode all trees

\#13 MeSH descriptor: [Perioperative Period] explode all trees

\#14 surg* or presurg* $^{*}$ or postsurg* or operat $^{\star}$ or preoperat ${ }^{\star}$ or perioperat ${ }^{\star}$ or postoperat ${ }^{\star}$ or transplant ${ }^{\star}$ or bypass ${ }^{\star}$ or

arthroplasty or neurosurg*

$\# 15 \# 10$ or \#11 or \#12 or \#13 or \#14

$\# 16 \# 9$ and \#15

\section{Appendix 2. MEDLINE (OvidSP)}

1. Platelet Transfusion/

2. Plateletpheresis/

3. Blood Platelets/ and transfus*.mp.

4. ((platelet ${ }^{\star}$ or thrombocyte*) adj5 (prophyla* or transfus or infus $^{\star}$ or administ ${ }^{\star}$ or requir ${ }^{\star}$ or need ${ }^{\star}$ or product or component $^{\star}$ or concentrate* or apheres* or pooled or single donor or random donor)).tw,kf.

5. (thromboc?topheres* ${ }^{*}$ or plateletpheres*).tw,kf.

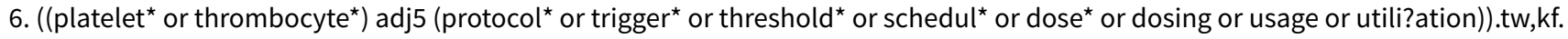

7. 1 or 2 or 3 or 4 or 5 or 6 
8. exp Perioperative Care/

9. exp Surgical Procedures, Operative/

10. exp Perioperative Period/

11. exp Specialties, Surgical/

12. (preoperat ${ }^{\star}$ or postoperat ${ }^{\star}$ or perioperat ${ }^{\star}$ or operat ${ }^{\star}$ or surg ${ }^{\star}$ or presurg* or postsurg ${ }^{\star}$ or perisurg ${ }^{\star}$ or transplant ${ }^{\star}$ or bypass or $^{\star}$ arthroplasty or neurosurg $\left.{ }^{\star}\right) . \mathrm{mp}$.

13. 8 or 9 or 10 or 11 or 12

14. 7 and 13

15. Meta-Analysis.pt.

16. ((meta analy* or metaanaly*) and (trials or studies)).ab.

17. (meta analy* or metaanaly* or evidence-based).ti.

18. ((systematic ${ }^{\star}$ or evidence-based) adj2 (review ${ }^{\star}$ or overview $\left.\left.{ }^{\star}\right)\right)$.tw.

19. (cochrane or medline or pubmed or embase or cinahl or cinhal or lilacs or "web of science" or science citation index or scopus or search terms or literature search or electronic search* or comprehensive search* or systematic search* or published articles or search strateg* or reference list* or bibliograph* or handsearch* or hand search* or manual ${ }^{\star}$ search $\left.^{\star}\right)$.ab.

20. Cochrane Database of systematic reviews.jn.

21. (additional adj (papers or articles or sources)).ab.

22. ((electronic* or online) adj (sources or resources or databases)).ab.

23. (relevant adj (journals or articles)).ab.

24. or/15-23

25. Review.pt.

26. RANDOMIZED CONTROLLED TRIALS AS TOPIC/

27. selection criteria.ab. or critical appraisal.ti.

28. (data adj (abstraction or extraction or analys $\left.\left.{ }^{\star}\right)\right)$.ab.

29. RANDOMIZED CONTROLLED TRIAL/

30. or/26-29

31.25 and 30

32. 24 or 31

33. $\exp$ CONTROLLED CLINICAL TRIAL/

34. $\operatorname{exp~CONTROLLED~CLINICAL~TRIALS~AS~TOPIC/~}$

35. (randomi ${ }^{\star}$ or trial).tw,kf.

36. (placebo or randomly or groups).ab.

37. or/33-36

38. CONTROLLED BEFORE-AFTER STUDIES/

39. INTERRUPTED TIME SERIES ANALYSIS/

40. (nonrandom ${ }^{\star}$ or non random ${ }^{\star}$ ).tw,kf.

41. (pre-post or pre-test* or pretest $^{\star}$ or posttest ${ }^{\star}$ or post-test ${ }^{\star}$ or (pre adj5 post)).tw,kf.

42. (controlled clinical study or controlled study or control group $\left.{ }^{\star}\right)$.tw,kf.

43. ((before adj3 after) or "before-after" or interrupted time series or time point ${ }^{\star}$ or repeated measur $\left.{ }^{\star}\right)$.tw,kf.

44.37 or 38 or 39 or 40 or 41 or 42 or 43

45. 32 or 37 or 44

46. (ANIMALS/ or exp ANIMAL EXPERIMENTATION/ or exp MODELS, ANIMAL/) not HUMANS/

47. Editorial.pt.

48.46 or 47

49. 45 not 48

50.14 and 49

\section{Appendix 3. PubMed (epublications ahead of print only)}

\#1 ((platelet ${ }^{\star}$ OR thrombocyte ${ }^{\star}$ ) AND (prophyla* OR transfus* OR infus ${ }^{\star}$ OR administ ${ }^{\star}$ OR requir ${ }^{\star}$ OR need ${ }^{\star}$ OR product ${ }^{\star}$ OR component ${ }^{\star}$ OR concentrate* OR apheres ${ }^{\star}$ OR pooled OR single donor OR "random donor" OR "random donors" OR protocol ${ }^{\star}$ OR trigger ${ }^{\star}$ OR threshold* OR schedul ${ }^{\star}$ OR dose* OR dosing OR usage OR utilisation OR utilization))

\#2 (thrombo?ytopheres* OR plateletpheres ${ }^{\star}$ )

\#3 \#1 OR \#2

\#4 (preoperat*[TI] OR postoperat* $\left.{ }^{*} \mathrm{TI}\right]$ OR perioperat* $[\mathrm{TI}]$ OR operation[TI] OR operations[TI] OR operating[TI] OR operated[TI] OR surgery[TI] OR surgical* $[\mathrm{TI}]$ OR presurg* $[\mathrm{TI}]$ OR postsurg* $[\mathrm{TI}]$ OR perisurg* $[\mathrm{TI}]$ OR transplant[TI] OR transplants[TI] OR transplanted[TI] OR transplanting $[\mathrm{TI}]$ OR transplantation ${ }^{\star}[\mathrm{TI}]$ OR bypass* $[\mathrm{TI}]$ OR arthroplasty*[TI] OR neurosurg* $\left.[\mathrm{TI}]\right)$

\#5 \#3 AND \#4

\#6 ((random* OR blind* OR "control group" OR placebo OR "controlled trial" OR "controlled study" OR groups OR trials OR "systematic review" OR "systematic overview" OR "meta-analysis" OR metaanalysis OR "literature search" OR medline OR cochrane OR embase OR "time series" OR "repeated measures" OR "before and after" OR "before-after" OR "pre-test" OR "post-test" OR pretest ${ }^{\star}$ OR posttest ${ }^{\star}$ ) AND (publisher[sb] OR inprocess[sb] OR pubmednotmedline[sb])) 
\#7 \#5 AND \#6

\section{Appendix 4. Embase (OvidSP)}

1. Thrombocyte Transfusion/

2. Thrombocyte/ and transfus*.mp.

3. *Thrombocyte/

4. Thrombo?ytopheresis/

5. ((platelet ${ }^{\star}$ or thrombocyte $)$ adj5 (prophyla* or transfus ${ }^{\star}$ or infus ${ }^{\star}$ or administ ${ }^{\star}$ or requir ${ }^{\star}$ or need or product $^{\star}$ or component ${ }^{\star}$ or concentrate* or apheres* or pooled or single donor or random donor)).tw.

6. (thrombo?ytopheres ${ }^{\star}$ or plateletpheres $\left.{ }^{\star}\right)$.tw.

7. ((platelet ${ }^{\star}$ or thrombocyte ${ }^{\star}$ adj5 (protocol ${ }^{\star}$ or trigger $^{\star}$ or threshold ${ }^{\star}$ or schedul* or dose ${ }^{\star}$ or dosing or usage or utili?ation)).tw.

8. or/1-7

9. exp Surgery/

10. preoperat $^{\star}$ or postoperat ${ }^{\star}$ or perioperat ${ }^{\star}$ or operati ${ }^{\star}$ or surg ${ }^{\star}$ or presurg ${ }^{\star}$ or postsurg ${ }^{\star}$ or perisurg ${ }^{\star}$ or transplant $^{\star}$ or bypass $^{\star}$ or arthroplasty or neurosurg $\left.{ }^{\star}\right) . \mathrm{mp}$.

11.9 or 10

12. 8 and 11

13. Meta Analysis/

14. Systematic Review/

15. (meta analy ${ }^{\star}$ or metaanalys $\left.{ }^{\star}\right)$.tw.

16. ((systematic ${ }^{\star}$ or literature) $\operatorname{adj2}\left(\right.$ review $^{\star}$ or overview ${ }^{\star}$ or search $\left.\left.{ }^{\star}\right)\right)$.tw.

17. (cochrane or embase or cinahl or cinhal or lilacs or BIDS or science citation index or psyclit or psychlit or psycinfo or psychinfo or cancerlit).ti,ab.

18. ((electronic ${ }^{\star}$ or online) adj (sources or resources or databases)).ab.

19. (additional adj (articles or papers or sources)).ab.

20. (reference lists or bibliograph* or handsearch* or hand search* or manual ${ }^{\star}$ search $^{\star}$ ).ab.

21. (relevant adj (journals or articles)).ab.

22. (search term* or published articles or search strateg*).ab.

23. or/13-22

24. (data extraction or selection criteria).ab.

25. review.pt.

26. 23 or (24 and 25)

27. editorial.pt.

28. 26 not 27

29. randomized controlled trial/ or crossover-procedure/ or single-blind procedure/ or double-blind procedure/ or triple-blind procedure/ 30. (random ${ }^{\star}$ or factorial ${ }^{\star}$ or crossover ${ }^{\star}$ or cross over ${ }^{\star}$ or cross-over ${ }^{\star}$ or placebo* or doubl ${ }^{\star}$ blind $^{\star}$ or singl ${ }^{\star}$ blind $^{\star}$ or tripl ${ }^{\star}$ blind $^{\star}$ or assign $^{\star}$ or allocat*).tw.

31. (nonrandom ${ }^{\star}$ or non random $\left.{ }^{\star}\right)$.tw.

32. (controlled clinical study or controlled study or control group* or trial).tw.

33. controlled clinical trial/

34. time series analysis/

35. epidemiology/

36. pretest posttest control group design/ or pretest posttest design/

37. (pre-post or pre-test ${ }^{\star}$ or pretest ${ }^{\star}$ or posttest* or post-test $^{\star}$ or (pre adj5 post)).tw.

38. ((before adj3 after) or "before-after" or interrupted time series or time point ${ }^{\star}$ or repeated measur $\left.{ }^{\star}\right)$.tw.

39. or $/ 28-38$

40. 12 and 39

41. Animal experiment/ not (human experiment/ or human/)

42. 40 not 41

43. limit 42 to embase

\section{Appendix 5. CINAHL (EBSCOHost)}

S1 (MH "Blood Platelets")

S2 TX transfus*

S3 S1 AND S2

S4 (MH "Platelet Transfusion")

S5 (MH "Plateletpheresis")

S6 TX ((platelet* or thrombocyte*) N5 (prophyla* or transfus* or infus* or administ* or requir ${ }^{\star}$ or need ${ }^{\star}$ or product or products or component $^{\star}$ or concentrate* or apheres* or pooled or single donor ${ }^{\star}$ or random donor $\left.{ }^{\star}\right)$ )

S7 TX thrombocytopheres* or plateletpheres* 
S8 TX ((platelet* or thrombocyte*) N5 (protocol* or trigger* or threshold* or schedul* or dose* or dosing or usage or utilisation or utilization))

S9 S3 OR S4 OR S5 OR S6 OR S7 OR S8

S10 (MH "Specialties, Surgical+")

S11 (MH "Surgery, Operative+")

S12 (MH "Perioperative Care+")

S13 TX (surg* or presurg* or postsurg* or operat ${ }^{\star}$ or preoperat* or perioperat ${ }^{\star}$ or postoperat ${ }^{\star}$ or transplant* or bypass ${ }^{\star}$ or arthroplasty or neurosurg*)

S14 S10 OR S11 OR S12 OR S13

S15 S9 AND S14

S16 (MH Clinical Trials+)

S17 PT Clinical Trial

S18 TI ((controlled trial*) or (clinical trial $\left.\left.{ }^{*}\right)\right)$ OR AB ((controlled trial $\left.{ }^{\star}\right)$ or (clinical trial $\left.\left.{ }^{\star}\right)\right)$

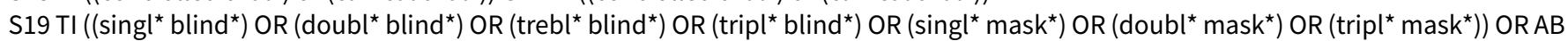

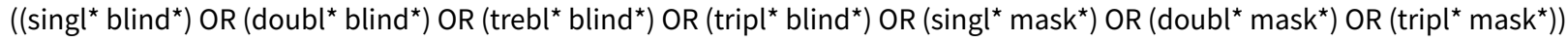

S20 TI randomi* OR AB randomi*

S21 MH RANDOM ASSIGNMENT

S22 TI ((phase three) or (phase III)) or AB ((phase three) or (phase III) or (phase three))

S23 ( TI (random* N2 (assign* or allocat $\left.\left.{ }^{\star}\right)\right)$ ) OR ( AB (random* N2 (assign* or allocat $\left.\left.{ }^{\star}\right)\right)$ )

S24 MH PLACEBOS

S25 MH META ANALYSIS

S26 MH SYSTEMATIC REVIEW

S27 TI ("meta analys " OR metaanalys* OR "systematic review" OR "systematic overview" OR "systematic search*") OR AB ("meta analys OR metaanalys* OR "systematic review" OR "systematic overview" OR "systematic search*")

S28 TI ("literature review" OR "literature overview" OR "literature search") OR AB ("literature review" OR "literature overview" OR "literature search*")

S29 TI (cochrane OR embase OR cinahl OR cinhal OR lilacs OR BIDS OR science AND citation AND index OR cancerlit) OR AB (cochrane OR embase OR cinahl OR cinhal OR lilacs OR BIDS OR science AND citation AND index OR cancerlit)

S30 TI placebo* OR AB placebo*

S31 MH QUANTITATIVE STUDIES

$\mathrm{S} 32 \mathrm{~S} 16$ or S17 or S18 or S19 or S20 or S21 or S22 or S23 or S24 or S25 or S26 or S27 or S28 or S29 or S30 or S31

S33 (MH "Controlled Before-After Studies") OR (MH "Interrupted Time Series Analysis") OR (MH "Nonrandomized Trials") OR (MH "PretestPosttest Design+")

S34 (MH "Quasi-Experimental Studies+") OR (MH "Repeated Measures")

S35 TX (nonrandom* or non random*)

S36 TX (pre-post or pre-test ${ }^{\star}$ or pretest ${ }^{\star}$ or posttest ${ }^{\star}$ or post-test ${ }^{\star}$ or (pre N5 post))

S37 TX (controlled clinical study or controlled study or control group ${ }^{\star}$ )

S38 TX ((before N3 after) or "before-after" or interrupted time series or time point* or repeated measur*)

S39 S32 OR S33 OR S34 OR S35 OR S36 OR S37 OR S38

S40 S15 AND S39

\section{Appendix 6. Transfusion Evidence Library}

Clinical Specialty: Surgery

Subject Area: Blood Components/Platelets

\section{Appendix 7. LILACS}

tw:((platelet OR platelets) AND (prophylactic OR prophylaxis OR transfusion OR transfused OR transfusing OR infused OR infusion OR administered OR required OR needed OR product OR component OR concentrate OR concentrates OR apheresis OR pooled OR donor OR donors OR protocol OR trigger OR threshold OR schedule OR dose OR doses OR dosing OR usage OR utilisation OR utilization)) AND (instance:"regional") AND ( db:("LILACS") AND type_of_study:("clinical_trials"))

\section{Appendix 8. Web of Science CPC-IS}

\#1 TS=((platelet ${ }^{\star}$ or thrombocyte $\left.{ }^{\star}\right)$ NEAR/5 (prophyla* or transfus ${ }^{\star}$ or infus ${ }^{\star}$ or administ* or requir $^{\star}$ or need* or product or products or component ${ }^{\star}$ or concentrate* or apheres* or pooled or donor $\left.\left.{ }^{\star}\right)\right)$

\#2 TS=(thrombocytopheres* or plateletpheres*)

\#3 TS=((platelet* or thrombocyte $\left.{ }^{\star}\right)$ NEAR/5 (protocol $^{\star}$ or trigger* or threshold* or schedul* or dose* or dosing or usage or utilisation or utilization))

\#4 \#3 OR \#2 OR \#1

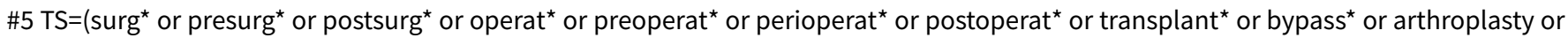
neurosurg*) 
\#6 \#5 AND \#4

\#7 TS=(random* OR blind* OR "control group" OR placebo OR "controlled trial" OR "controlled study" OR groups OR trials OR "systematic review" OR "systematic overview" OR "meta-analysis" OR metaanalysis OR "literature search" OR medline OR cochrane OR embase OR "time series" OR "repeated measures" OR "before and after" OR "before-after" OR "pre-test" OR "post-test" OR pretest* OR posttest ${ }^{\star}$ ) \#8 \#7 AND \#6

\section{Appendix 9. ClinicalTrials.gov}

Search Terms: (preoperative OR postoperative OR perioperative OR operation OR surgery OR presurgery OR postsurgery OR presurgical OR postsurgical OR transplantation OR bypass OR arthroplasty OR neurosurgery) AND (platelet transfusion OR platelet concentrate) OR

Search Terms: (preoperative OR postoperative OR perioperative OR operation OR surgery OR presurgery OR postsurgery OR presurgical OR postsurgical OR transplantation OR bypass OR arthroplasty OR neurosurgery)

Interventions: platelet transfusion OR platelet concentrate OR prophylactic platelets

\section{Appendix 10. WHO ICTRP}

Title: platelet transfusion OR platelet concentrate

Recruitment Status: ALL

OR

Title: preoperative OR postoperative OR perioperative OR operation OR surgery OR surgical OR presurgery OR postsurgery OR presurgical OR postsurgical OR perisurgical OR transplant OR transplantation OR bypass OR arthroplasty OR neurosurgery

Intervention: platelets OR platelet transfusion OR platelet concentrate OR platelet concentrates

Recruitment Status: ALL

Appendix 11. ROBINS-I

ROBINS-I tool (Stage I)

Specify the review question

\begin{tabular}{|c|c|}
\hline Participants & People of all ages with a low platelet count who are due to have surgery \\
\hline Experimental intervention 1 & Prophylactic platelet transfusion before surgery \\
\hline Control intervention 1 & No prophylactic platelet transfusion before surgery \\
\hline Control intervention 2 & $\begin{array}{l}\text { Artificial platelet substitutes, e.g. lyophilised platelets, infusible plasma membranes and liposomes } \\
\text { with inserted platelet receptors }\end{array}$ \\
\hline Control intervention 3 & Cryosupernatant \\
\hline Control intervention 4 & Thrombopoietin mimetics \\
\hline Control intervention 5 & Antifibrinolytic drugs \\
\hline Outcomes & $\begin{array}{l}\text { Primary outcomes } \\
\text { - Mortality (all-causes, secondary to bleeding, secondary to thromboembolism and secondary to } \\
\text { infection) within } 30 \text { days and } 90 \text { days of surgery. } \\
\text { - Number of participants with major procedure-related bleeding within } 7 \text { days of surgery, defined } \\
\text { as: } \\
\text { - surgical site bleeding requiring a second intervention or reoperation or surgical site bleeding } \\
\text { that causes a haematoma or haemarthrosis of sufficient size to delay mobilisation or wound } \\
\text { healing; } \\
\text { - bleeding of sufficient size to cause delayed wound healing, or wound infection or surgical site } \\
\text { bleeding that is unexpected and prolonged or causes haemodynamic instability (as defined by } \\
\text { the study) that is associated with a } 20 \text { g/L drop in haemoglobin; } \\
\text { - bleeding that requires } \geq 2 \text { units of whole blood/red cells within } 24 \text { hours of the bleeding; } \\
\text { - bleeding that is defined by the study with no further details. }\end{array}$ \\
\hline
\end{tabular}




\section{Secondary outcomes}

- Number of participants with minor procedure-related bleeding within 7 days of surgery (e.g. haematoma, prolonged bleeding at surgical site that does not fulfil the definition for major bleeding).

- Number of platelet transfusions per participant and number of platelet components per participant.

- Number of red cell transfusions per participant and number of red cell components per participant.

- Proportion of participants requiring additional interventions to stop bleeding (surgical; medical, e.g. tranexamic acid; other blood products, e.g. fresh frozen plasma, cryoprecipitate, fibrinogen) within 7 days of surgery.

- Quality of life assessment using validated tools.

- Serious adverse events due to: transfusion (transfusion reactions, transfusion-related acute lung injury, transfusion-related infection, transfusion-associated circulatory overload, transfusion-related dyspnoea) within 24 hours of transfusion.

- Surgery (e.g. delayed wound healing, infection) within 30 days after the operation; length of hospital stay and length of intensive care unit stay.

- Venous and arterial thromboembolism (including deep vein thrombosis, pulmonary embolism, stroke, myocardial infarction).

\section{List the confounding areas relevant to all or most studies}

We prespecified the main potential confounding factors.

- Age (neonate, child (aged 1-15 years), adult (aged $\geq 16$ years)).

- Gender: male/female ratio.

- Underlying conditions which caused thrombocytopenia.

- Minor surgery or major surgery.

- Severity of thrombocytopaenia.

- Haemodynamic status at baseline.

- Participants with clotting abnormalities, such as disseminated intravascular coagulation, or concomitant use of anticoagulant or antiplatelet agents.

- Previous severe bleeding (e.g. World Health Organization grade 3 or 4 or equivalent).

\section{List the possible cointerventions that could be different between intervention groups and could have an impact on outcomes}

We prespecified the possible cointerventions that could be different between intervention groups and could have an impact on outcomes.

- Receiving corticosteroids.

- Intravenous immunoglobulin which usually is given when thrombocytopenia is caused by autoimmune disease.

- People with immune thrombocytopenia and who had their spleen removed (splenectomy).

- Transfusion of red blood cells.

- Transfusion of platelets.

The ROBINS-I tool (Stage II): for each study

Specify a target trial specific to the study

\begin{tabular}{ll}
\hline Design & Individually randomised/cluster-randomised/matched \\
\hline Participants & People of all ages with a low platelet count who are due to have surgery \\
\hline Experimental intervention & Prophylactic platelet transfusion prior to surgery \\
\hline
\end{tabular}


(Continued)

\section{Control intervention}

No prophylactic platelet transfusion prior to surgery (placebo or no treatment)

\author{
Is your aim for this study...? \\ $\square$ To assess the effect of initiating intervention (as in an intention-to-treat analysis) \\ $\square$ To assess the effect of initiating and adhering to intervention (as in a per-protocol analysis)
}

\title{
Specify the outcome
}

Specify which outcome is being assessed for risk of bias (typically from among those earmarked for the 'Summary of findings' table). Specify whether this is a proposed benefit or harm of intervention.

\section{Specify the numerical result being assessed}

In case of multiple alternative analyses being presented, specify the numeric result (e.g. risk ratio $(\mathrm{RR})=1.52(95 \%$ confidence interval $(\mathrm{Cl})$ 0.83 to 2.77 ) or a reference (e.g. to a table, figure or paragraph) (or both) that uniquely defines the result being assessed.

\section{Preliminary consideration of confounders}

Complete a row for each important confounding area:

- listed in the review protocol; and

- relevant to the setting of this particular study, or which the study authors identified as potentially important. 'Important' confounding areas are those for which, in the context of this study, adjustment is expected to lead to a clinically important change in the estimated effect of the intervention. 'Validity' refers to whether the confounding variable or variables fully measure the area, while 'reliability' refers to the precision of the measurement (more measurement error means less reliability).

\section{Confounding areas listed in the review protocol}

\begin{tabular}{lllll}
\hline $\begin{array}{l}\text { Confounding } \\
\text { area }\end{array}$ & $\begin{array}{l}\text { Measured vari- } \\
\text { able (s) }\end{array}$ & $\begin{array}{l}\text { Is there evidence } \\
\text { that controlling } \\
\text { for this variable } \\
\text { was unneces- } \\
\text { sary?* }\end{array}$ & $\begin{array}{l}\text { Is the confounding area } \\
\text { measured validly and re- } \\
\text { liably by this variable (or } \\
\text { these variables)? }\end{array}$ & $\begin{array}{l}\text { Optional: is adjusting for this vari- } \\
\text { able (alone) expected to favour the } \\
\text { experimental or the control group? }\end{array}$ \\
\hline & & Yes / no / no information & $\begin{array}{l}\text { Favour intervention / favour control / } \\
\text { no information }\end{array}$ \\
\hline
\end{tabular}

\section{Additional confounding areas relevant to the setting of this particular study, or which the study authors identified as impor-} tant

$\begin{array}{lllll}\begin{array}{l}\text { Confounding } \\ \text { area }\end{array} & \begin{array}{l}\text { Measured vari- } \\ \text { able (s) }\end{array} & \begin{array}{l}\text { Is there evidence } \\ \text { that controlling } \\ \text { for this variable } \\ \text { was unneces- } \\ \text { sary?* }\end{array} & \begin{array}{l}\text { Is the confounding area mea- } \\ \text { sured validly and reliably by } \\ \text { this variable (or these vari- } \\ \text { ables)? }\end{array} & \begin{array}{l}\text { Optional: is adjusting for this variable } \\ \text { (alone) expected to favour the experi- } \\ \text { mental or the control group? }\end{array} \\ & & \end{array}$


* In the context of a particular study, variables can be demonstrated not to be confounders and so not included in the analysis:

- if they are not predictive of the outcome;

- if they are not predictive of intervention; or

- because adjustment makes no or minimal difference to the estimated effect of the primary parameter. Note that 'no statistically significant association' is not the same as 'not predictive.'

\section{Preliminary consideration of cointerventions}

Complete a row for each important cointervention listed in the review protocol; and relevant to the setting of this particular study, or which the study authors identified as important.

'Important' cointerventions are those for which, in the context of this study, adjustment is expected to lead to a clinically important change in the estimated effect of the intervention.

\section{Cointerventions listed in the review protocol}

\begin{tabular}{ll}
\hline Cointervention & $\begin{array}{l}\text { Is there evidence that control- } \\
\text { ling for this cointervention was } \\
\text { unnecessary (e.g. because it } \\
\text { was not administered)? }\end{array}$
\end{tabular}

Favour experimental / favour comparator / no information

Favour experimental / favour comparator / no information

Favour experimental / favour comparator / no information

\section{Additional cointerventions relevant to the setting of this particular study, or which the study authors identified as important}

$\begin{array}{lll}\text { Cointervention } & \begin{array}{l}\text { Is there evidence that control- } \\ \text { ling for this cointervention was } \\ \text { unnecessary (e.g. because it } \\ \text { was not administered)? }\end{array} & \begin{array}{l}\text { Is presence of this cointervention likely to favour outcomes in the ex- } \\ \text { perimental or the control group? }\end{array}\end{array}$

Favour experimental / favour comparator / no information

Favour experimental / favour comparator / no information

Favour experimental / favour comparator / no information 
'Risk of bias' assessment (cohort-type studies)

\begin{tabular}{llll}
\hline Bias domain & $\begin{array}{l}\text { Signalling ques- } \\
\text { tions }\end{array}$ & Elaboration & Response options \\
\hline $\begin{array}{l}\text { Bias due to con- } \\
\text { founding }\end{array}$ & $\begin{array}{l}\text { 1.1. Is there poten- } \\
\text { tial for confound- } \\
\text { ing of the effect of } \\
\text { intervention in this } \\
\text { study? }\end{array}$ & $\begin{array}{l}\text { In rare situations, such as when studying harms that are very } \\
\text { unlikely to be related to factors that influence treatment deci- } \\
\text { sions, no confounding is expected and the study can be consid- } \\
\text { ered to be at low risk of bias due to confounding, equivalent to } \\
\text { a fully randomised trial. }\end{array}$ & Y PY / PN / N \\
& $\begin{array}{l}\text { If } \text { or PN to 1.1.: } \\
\text { the study can be } \\
\text { considered to be } \\
\text { at low risk of bias } \\
\text { due to confounding } \\
\text { and no further sig- } \\
\text { nalling questions } \\
\text { need be considered }\end{array}$ & \\
\hline
\end{tabular}

If $\mathrm{Y}$ or $\mathrm{PY}$ to 1.1.: determine whether there is a need to assess time-varying confounding

\begin{tabular}{|c|c|c|}
\hline $\begin{array}{l}\text { 1.2. Was the analy- } \\
\text { sis based on split- } \\
\text { ting participants' } \\
\text { follow-up time ac- } \\
\text { cording to interven- } \\
\text { tion received? } \\
\text { If } \mathbf{N} \text { or PN, answer } \\
\text { questions relating } \\
\text { to baseline con- } \\
\text { founding (1.4. to } \\
\text { 1.6.) } \\
\text { If } \mathbf{Y} \text { or PY, proceed } \\
\text { to question } 1.3 \text {. }\end{array}$ & $\begin{array}{l}\text { If participants could switch between intervention groups then } \\
\text { associations between intervention and outcome may be biased } \\
\text { by time-varying confounding. This occurs when prognostic fac- } \\
\text { tors influence switches between intended interventions. }\end{array}$ & $\begin{array}{l}\mathrm{NA} / \mathrm{Y} / \mathrm{PY} / \mathrm{PN} / \mathrm{N} / \\
\mathrm{NI}\end{array}$ \\
\hline $\begin{array}{l}\text { 1.3. Were interven- } \\
\text { tion discontinua- } \\
\text { tions or switches } \\
\text { likely to be related } \\
\text { to factors that are } \\
\text { prognostic for the } \\
\text { outcome? } \\
\text { If } \mathbf{N} \text { or PN, answer } \\
\text { questions relating } \\
\text { to baseline con- } \\
\text { founding (1.4. to } \\
\text { 1.6.) } \\
\text { If Y or PY, answer } \\
\text { questions relating } \\
\text { to both baseline } \\
\text { and time-varying } \\
\text { confounding (1.7. } \\
\text { and } 1.8 . \text { ) }\end{array}$ & $\begin{array}{l}\text { If intervention switches are unrelated to the outcome, for ex- } \\
\text { ample when the outcome is an unexpected harm, then time- } \\
\text { varying confounding will not be present and only control for } \\
\text { baseline confounding is required. }\end{array}$ & $\begin{array}{l}\mathrm{NA} / \mathrm{Y} / \mathrm{PY} / \mathrm{PN} / \mathrm{N} / \\
\mathrm{NI}\end{array}$ \\
\hline
\end{tabular}




\section{Questions relating to baseline confounding only}

1.4. Did the authors use an appropriate analysis method that controlled for all the important confounding areas?
Appropriate methods to control for measured confounders include stratification, regression, matching, standardisation, and inverse probability weighting. They may control for individual variables or for the estimated propensity score. Inverse probability weighting is based on a function of the propensity score. Each method depends on the assumption that there is no unmeasured or residual confounding.

\begin{tabular}{|c|c|c|}
\hline $\begin{array}{l}\text { 1.5. If } Y \text { or PY to } \\
\text { 1.4.: were con- } \\
\text { founding areas that } \\
\text { were controlled for } \\
\text { measured validly } \\
\text { and reliably by the } \\
\text { variables available } \\
\text { in this study? }\end{array}$ & $\begin{array}{l}\text { Appropriate control of confounding requires that the variables } \\
\text { adjusted for are valid and reliable measures of the confounding } \\
\text { domains. For some topics, a list of valid and reliable measures } \\
\text { of confounding domains will be specified in the review protocol } \\
\text { but for others such a list may not be available. Study authors } \\
\text { may cite references to support the use of a particular measure. } \\
\text { If authors control for confounding variables with no indication } \\
\text { of their validity or reliability pay attention to the subjectivity of } \\
\text { the measure. Subjective measures (e.g. based on self-report) } \\
\text { may have lower validity and reliability than objective measures } \\
\text { such as lab findings. }\end{array}$ & $\begin{array}{l}\mathrm{NA} / \mathrm{Y} / \mathrm{PY} / \mathrm{PN} / \mathrm{N} / \\
\mathrm{NI}\end{array}$ \\
\hline $\begin{array}{l}\text { 1.6. Did the au- } \\
\text { thors control for } \\
\text { any postinterven- } \\
\text { tion variables? }\end{array}$ & $\begin{array}{l}\text { Controlling for postintervention variables is not appropriate. } \\
\text { Controlling for mediating variables estimates the direct effect } \\
\text { of intervention and may introduce confounding. Controlling for } \\
\text { common effects of intervention and outcome causes bias. }\end{array}$ & $\begin{array}{l}\mathrm{NA} / \mathrm{Y} / \mathrm{PY} / \mathrm{PN} / \mathrm{N} / \\
\mathrm{NI}\end{array}$ \\
\hline
\end{tabular}

\section{Questions relating to baseline and time-varying confounding}

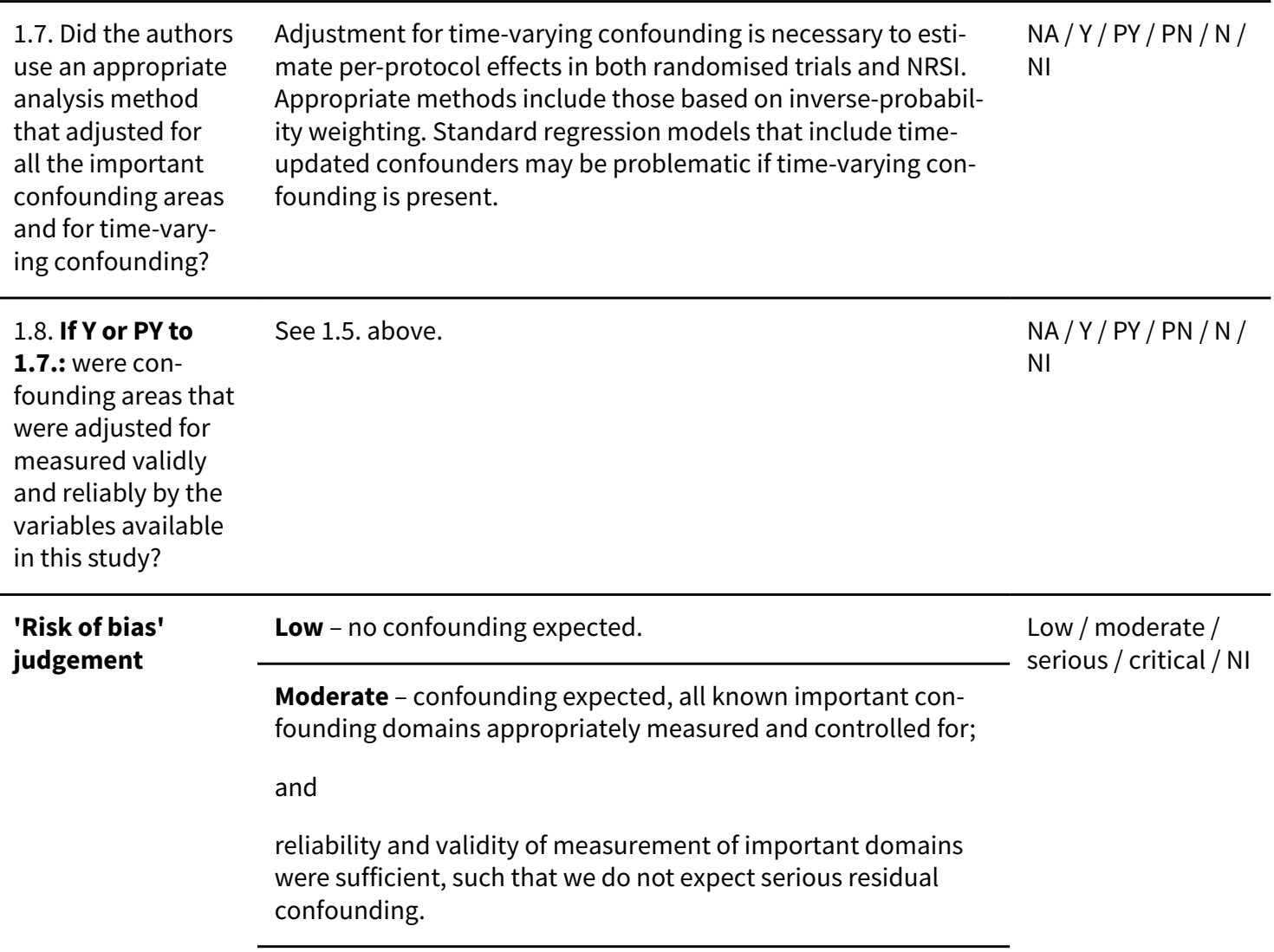


Serious - $\geq 1$ known important domain was not appropriately measured, or not controlled for;

or

reliability or validity of measurement of an important domain was low enough that we expect serious residual confounding.

Critical - confounding inherently not controllable, or the use of negative controls strongly suggests unmeasured confounding.
Optional: what is the predicted direction of bias due to confounding?
Can the true effect estimate be predicted to be greater or less than the estimated effect in the study because $\geq 1$ of the important confounding domains was not controlled for? Answering this question will be based on expert knowledge and results in other studies and therefore can only be completed after all of the studies in the body of evidence have been reviewed. Consider the potential effect of each of the unmeasured domains and whether all important confounding domains not controlled for in the analysis would be likely to change the estimate in the same direction, or if 1 important confounding domain that was not controlled for in the analysis is likely to have a dominant impact.

\section{Bias in selection of participants into the study}

\subsection{Was selection of participants in- to the study (or into the analysis) based on participant char- acteristics observed after the start of in- tervention?}

Favours experimental / favours comparator / unpredictable
This domain is concerned only with selection into the study based on participant characteristics observed after the start of intervention. Selection based on characteristics observed before the start of intervention can be addressed by controlling for imbalances between intervention and control groups in baseline characteristics that are prognostic for the outcome (baseline confounding).
If $\mathbf{N}$ or $\mathbf{P N}$ to 2.1.: go to 2.4.

\begin{tabular}{lll}
\hline $\begin{array}{l}\text { 2.2. If Y or PY to } \\
\text { 2.1.: were the }\end{array}$ & $\begin{array}{l}\text { Selection bias occurs when selection is related to an effect of } \\
\text { either intervention or a cause of intervention and an effect of } \\
\text { postintervention }\end{array}$ & $\begin{array}{l}\mathrm{NA} / \mathrm{Y} / \mathrm{PY} / \mathrm{PN} / \mathrm{N} / \\
\text { variables that in- } \\
\text { fluenced selection } \\
\text { result is at risk of selection bias if selection into the study is re- } \\
\text { likely to be associ- } \\
\text { ated with interven- }\end{array}$ \\
$\begin{array}{l}\text { lated to both the intervention and the outcome. } \\
\text { tion }\end{array}$ & $\mathrm{NA} / \mathrm{Y} / \mathrm{PY} / \mathrm{PN} / \mathrm{N} /$ \\
\hline $\begin{array}{l}\text { 2.3. If Y or PY to } \\
\text { 2.2.: were the }\end{array}$ & $\mathrm{NI}$ \\
postintervention \\
variables that in- \\
fluenced selection \\
likely to be influ- \\
enced by the out- \\
come or cause of \\
the outcome?
\end{tabular}

2.4. Do start of follow-up and start of intervention coincide for most participants?
If participants are not followed from the start of the interven-

$\mathrm{Y} / \mathrm{PY} / \mathrm{PN} / \mathrm{N} / \mathrm{NI}$
$\mathrm{Y} / \mathrm{PY} / \mathrm{PN} / \mathrm{N} / \mathrm{NI}$ tion then a period of follow-up has been excluded, and participants who experienced the outcome soon after intervention will be missing from analyses. This problem may occur when 
prevalent, rather than new (incident), users of the intervention are included in analyses.
2.5.If $\mathrm{Y}$ or $\mathrm{PY}$ to 2.2. It is in principle possible to correct for selection biases, e.g. by and 2.3., or $\mathrm{N}$ or PN to 2.4.: were adjustment techniques used that are likely to correct for the presence of selection biases? using inverse probability weights to create a pseudo-population in which the selection bias has been removed, or by modelling the distributions of the missing participants or follow-up times and outcome events and including them using missing data methodology. However, such methods are rarely used and the answer to this question will usually be 'N.'
'Risk of bias' judgement
Low - all participants who would have been eligible for the target trial were included in the study and start of follow-up and start of intervention coincide for all participants.
NA / Y / PY / PN / N /

NI

Low / moderate / serious / critical / NI

Moderate - selection into the study may have been related to intervention and outcome, but the authors used appropriate methods to adjust for the selection bias; or Start of follow-up and start of intervention do not coincide for all participants, but the proportion of participants for which this was the case was too low to induce important bias; the authors used appropriate methods to adjust for the selection bias or the review authors are confident that the rate (hazard) ratio for the effect of intervention remains constant over time.

Serious - selection into the study was related to intervention and outcome;

or

start of follow-up and start of intervention do not coincide, and a potentially important amount of follow-up time is missing from analyses, and the rate ratio is not constant over time.

Critical - selection into the study was strongly related to intervention and outcome;

or

a substantial amount of follow-up time is likely to be missing from analyses, and the rate ratio is not constant over time.

Optional: what is the predicted direction of bias due to selection of participants into the study?
If the likely direction of bias can be predicted, it is helpful to state this. The direction might be characterised either as being towards (or away from) the null, or as being in favour of 1 of the interventions.
Favours experimental / favours comparator / towards null / away from null / unpredictable

\section{Bias in classifica- tion of interven- tions}

3.1. Were intervention groups clearly defined?

\begin{abstract}
A prerequisite for an appropriate comparison of interventions is that the interventions are well-defined. Ambiguity in the definition may lead to bias in the classification of participants. For individual-level interventions, criteria for considering individuals to have received each intervention should be clear and explicit, covering issues such as type, setting, dose, frequency, intensity, timing of intervention, or a combination of these. For population-level interventions (e.g. measures to control air pollution), the question relates to whether the population is clearly defined, and the answer is likely to be 'Yes.'
\end{abstract}

$\mathrm{Y} / \mathrm{PY} / \mathrm{PN} / \mathrm{N} / \mathrm{NI}$ 
3.2. Was the information used to define intervention groups recorded at the start of the intervention?
In general, if information about interventions received is available from sources that could not have been affected by subsequent outcomes, then differential misclassification of intervention status is unlikely. Collection of the information at the time of the intervention makes it easier to avoid such misclassification. For population-level interventions (e.g. measures to control air pollution), the answer to this question is likely to be 'Yes.'

\subsection{Could classifi- cation of interven- tion status have been affected by knowledge of the outcome or risk of the outcome?}

Collection of the information at the time of the intervention may not be sufficient to avoid bias. The way in which the data are collected for the purposes of the NRSI should also avoid misclassification.
$\mathrm{Y} / \mathrm{PY} / \mathrm{PN} / \mathrm{N} / \mathrm{NI}$

Y/ PY / PN / N / NI

\begin{tabular}{lll}
\hline 'Risk of bias' & Low - intervention status is well-defined and based solely on & Low / moderate / \\
judgement & information collected at the time of intervention. & serious / critical / NI
\end{tabular}

Low - intervention status is well-defined and based
information collected at the time of intervention.

\section{serious / critical / N}

Moderate - intervention status is well-defined but some aspects of the assignments of intervention status were determined retrospectively

Serious - intervention status is not well-defined, or major aspects of the assignments of intervention status were determined in a way that could have been affected by knowledge of the outcome.

Critical - (unusual) an extremely high amount of misclassification of intervention status, e.g. because of unusually strong recall biases.

Optional: what is the predicted direction of bias due to measurement of outcomes or interventions?
If the likely direction of bias can be predicted, it is helpful to state this. The direction might be characterised either as being towards (or away from) the null, or as being in favour of 1 of the interventions.
Favours experimental / favours comparator / towards null / away from null / unpredictable
Bias due to departures from intended interventions

\subsection{Was the inter-} vention implemented successfully for most participants?
Consider the success of implementation of the intervention in the context of its complexity. Was recommended practice followed by those administering the intervention?
Y / PY / PN / N / NI

\section{If your aim for this study is to assess the effect of initiating and adhering to intervention (as in a per-pro-} tocol analysis), answer questions 4.2. to 4.4.

$\begin{array}{ll}\begin{array}{l}\text { 4.2. Did study par- } \\ \text { ticipants adhere to } \\ \text { the assigned inter- } \\ \text { vention regimen? }\end{array} & \begin{array}{l}\text { Lack of adherence to assigned intervention includes cessation } \\ \text { of intervention, cross-overs to the comparator intervention } \\ \text { and switches to another active intervention. We distinguish be- } \\ \text { tween analyses where: }\end{array} \\ & \begin{array}{l}\text { intervention switches led to follow-up time being assigned to } \\ \text { the new intervention, and } \\ \text { - intervention switches (including cessation of intervention) } \\ \text { where follow-up time remained allocated to the original in- } \\ \text { tervention, }\end{array}\end{array}$

NA / Y / PY / PN / N / $\mathrm{NI}$ 
- is addressed under time-varying confounding, and should not be considered further here.

Consider available information on the proportion of study participants who continued with their assigned intervention throughout follow-up. Was lack of adherence sufficient to impact the intervention effect estimate?

4.3. Were important cointerventions balanced across intervention groups?

4.4. If $\mathrm{N}$ or $\mathrm{PN}$ to 4.1., 4.2. or 4.3.: were adjustment techniques used that are likely to correct for these issues?
Consider the cointerventions that are likely to affect the outcome and to have been administered in the context of this study, based on the preliminary consideration of cointerventions and available literature. Consider whether these cointerventions are balanced between intervention groups.
NA / Y / PY / PN / N /

$\mathrm{NI}$

Such adjustment techniques include inverse-probability weighting to adjust for censoring at deviation from intended intervention, or inverse probability weighting of marginal structural models to adjust for time-varying confounding. Specialist advice may be needed to assess studies that used these approaches.
NA / Y / PY / PN / N /

$\mathrm{NI}$

\section{'Risk of bias' judgement}

Low - no bias due to deviation from the intended intervention is expected, for example if both the intervention and comparator are implemented over a short time period, and subsequent interventions are part of routine medical care, or if the specified comparison relates to initiation of intervention regardless of whether it is continued.
Low / moderate / serious / critical / NI

Moderate - bias due to deviation from the intended intervention is expected, and switches, cointerventions and some problems with intervention fidelity are appropriately measured and adjusted for in the analyses. Alternatively, most (but not all) deviations from intended intervention reflect the natural course of events after initiation of intervention.

Serious - switches in treatment, cointerventions, or problems with implementation fidelity are apparent and are not adjusted for in the analyses.

Critical - substantial deviations from the intended intervention are present and are not adjusted for in the analysis.

Optional: what is the predicted direction of bias due to departures from the intended interventions?
If the likely direction of bias can be predicted, it is helpful to state this. The direction might be characterised either as being towards (or away from) the null, or as being in favour of 1 of the interventions.
Favours experimental / favours comparator / towards null / away from null / unpredictable

\section{Bias due to miss- ing data}

\subsection{Were there missing outcome data?}

This aims to elicit whether the proportion of missing observations is likely to result in missing information that could substantially impact our ability to answer the question being addressed. Guidance will be needed on what is meant by 'reasonably complete.' One aspect of this is that review authors would ideally try and locate an analysis plan for the study.
5.2. Were partici-
pants excluded due
Missing intervention status may be a problem. This requires that the intended study sample is clear, which it may not be in practice.
$\mathrm{Y} / \mathrm{PY} / \mathrm{PN} / \mathrm{N} / \mathrm{NI}$

$\mathrm{Y} / \mathrm{PY} / \mathrm{PN} / \mathrm{N} / \mathrm{NI}$ 
to missing data on

intervention status?

\begin{tabular}{|c|c|c|}
\hline $\begin{array}{l}\text { 5.3. Were partic- } \\
\text { ipants excluded } \\
\text { due to missing da- } \\
\text { ta on other vari- } \\
\text { ables needed for } \\
\text { the analysis? }\end{array}$ & $\begin{array}{l}\text { This question relates particularly to participants excluded from } \\
\text { the analysis because of missing information on confounders } \\
\text { that were controlled for in the analysis. }\end{array}$ & $\mathrm{Y} / \mathrm{PY} / \mathrm{PN} / \mathrm{N} / \mathrm{NI}$ \\
\hline
\end{tabular}

\subsection{If $Y$ or $P Y$ to \\ 5.1., 5.2. or 5.3.: are the proportion of participants and reasons for missing data similar across interventions?}

This aims to elicit whether either differential proportion of missing observations or differences in reasons for missing observations could substantially impact on our ability to answer the question being addressed.
NA / Y / PY / PN / N /

$\mathrm{NI}$

\subsection{If $\mathrm{Y}$ or $\mathrm{PY}$ to}

5.1., 5.2. or 5.3.: were appropriate statistical methods used to account for missing data?
It is important to assess whether assumptions employed in analyses are clear and plausible. Both content knowledge and statistical expertise will often be required for this. For instance, use of a statistical method such as multiple imputation does not guarantee an appropriate answer. Review authors should seek naïve (complete-case) analyses for comparison, and clear differences between complete-case and multiple imputation-based findings should lead to careful assessment of the validity of the methods used.

\begin{tabular}{ll}
\hline 'Risk of bias' & Low - data were reasonably complete; or proportions of and \\
judgement & $\begin{array}{l}\text { reasons for missing participants were similar across interven- } \\
\text { tion groups; or analyses that addressed missing data are likely } \\
\text { to have removed any risk of bias. }\end{array}$ \\
& $\begin{array}{l}\text { Moderate - proportions of missing participants differ across in- } \\
\text { terventions; or reasons for missingness differ minimally across } \\
\text { interventions; and missing data were not addressed in the } \\
\text { analysis. }\end{array}$ \\
\hline
\end{tabular}
NA / Y / PY / PN / N /
NI

Low / moderate / serious / critical / NI

Serious - proportions of missing participants differ substantially across interventions; or reasons for missingness differ substantially across interventions; and missing data were addressed inappropriately in the analysis; or the nature of the missing data means that the risk of bias cannot be removed through appropriate analysis.

Critical - (unusual) there were critical differences between interventions in participants with missing data that were not, or could not, be addressed through appropriate analysis.
Optional: what is the predicted direction of bias due to missing data?
If the likely direction of bias can be predicted, it is helpful to state this. The direction might be characterised either as being towards (or away from) the null, or as being in favour of 1 of the interventions.
Favours experimental / favours comparator / towards null / away from null / unpredictable

\section{Bias in measure- ment of outcomes}

\subsection{Could the out-} come measure have been influenced by knowledge of
Some outcome measures involve negligible assessor judgement, e.g. all-cause mortality or non-repeatable automated laboratory assessments. Risk of bias due to measurement of these outcomes would be expected to be low. 
6.2. Were outcome assessors aware of the intervention received by study participants?
If outcome assessors were blinded to intervention status, the answer to this question would be 'no.' In other situations, outcome assessors may be unaware of the interventions being received by participants despite there being no active blinding by the study investigators; the answer to this question would then also be 'no.' In studies where participants report their outcomes themselves, e.g. in a questionnaire, the outcome assessor is the study participant. In an observational study, the answer to this question will usually be 'Yes' when the participants report their outcomes themselves.
$\mathrm{Y} / \mathrm{PY} / \mathrm{PN} / \mathrm{N} / \mathrm{NI}$

$\mathrm{Y} / \mathrm{PY} / \mathrm{PN} / \mathrm{N} / \mathrm{NI}$

6.3. Were the methods of outcome assessment comparable across intervention groups?

Comparable assessment methods (i.e. data collection) would involve the same outcome detection methods and thresholds, same time point, same definition and same measurements

6.4. Were any systematic errors in measurement of the outcome related to intervention received?

This question refers to differential misclassification of outY / PY / PN / N / NI comes. Systematic errors in measuring the outcome, if present, could cause bias if they are related to intervention or to a confounder of the intervention-outcome relationship. This will usually be due either to outcome assessors being aware of the intervention received or to non-comparability of outcome assessment methods, but there are examples of differential misclassification arising despite these controls being in place.

\section{'Risk of bias'} judgement

Low - the methods of outcome assessment were comparable
Low / moderate / serious / critical / NI across intervention groups;

and

the outcome measure was unlikely to be influenced by knowledge of the intervention received by study participants (i.e. is objective) or the outcome assessors were unaware of the intervention received by study participants;

and

any error in measuring the outcome is unrelated to intervention status.

Moderate - the methods of outcome assessment were comparable across intervention groups;

and

the outcome measure is only minimally influenced by knowledge of the intervention received by study participants;

and

any error in measuring the outcome is only minimally related to intervention status.

Serious - the methods of outcome assessment were not comparable across intervention groups;

or 
the outcome measure was subjective (i.e. likely to be influenced by knowledge of the intervention received by study participants) and was assessed by outcome assessors aware of the intervention received by study participants;

or

error in measuring the outcome was related to intervention status.

Critical - the methods of outcome assessment were so different that they cannot reasonably be compared across intervention groups.

Optional: what is the predicted direction of bias due to measurement of outcomes?
If the likely direction of bias can be predicted, it is helpful to state this. The direction might be characterised either as being towards (or away from) the null, or as being in favour of 1 of the interventions.
Favours experimental / favours comparator / towards null / away from null / unpredictable
Bias in selection of the reported result

Is the reported effect estimate unlikely to be selected, on the basis of the results, from...

7.1.... multiple out- For a specified outcome domain, it is possible to generate mul- $\quad$ Y / PY / PN / N / NI come measurements within the outcome domain? tiple effect estimates for different measurements. If multiple measurements were made, but only 1 or a subset is reported, there is a risk of selective reporting on the basis of results.

7.2. ... multiple analyses of the intervention-outcome relationship?
Because of the limitations of using data from non-randomised studies for analyses of effectiveness (need to control confounding, substantial missing data, etc.), analysts may implement different analytic methods to address these limitations. Examples include unadjusted and adjusted models; use of final value vs change from baseline vs analysis of covariance; different transformations of variables; a continuously scaled outcome converted to categorical data with different cut-points; different sets of covariates used for adjustment; and different analytic strategies for dealing with missing data. Application of such methods generates multiple effect estimates for a specific outcome metric. If the analyst does not prespecify the methods to be applied, and multiple estimates are generated but only 1 or a subset is reported, there is a risk of selective reporting on the basis of results.

\begin{abstract}
7.3. ... different subgroups?

Particularly with large cohorts often available from routine data sources, it is possible to generate multiple effect estimates for different subgroups or simply to omit varying proportions of the original cohort. If multiple estimates are generated but only 1 or a subset is reported, there is a risk of selective reporting on the basis of results.
\end{abstract}

$\mathrm{Y} / \mathrm{PY} / \mathrm{PN} / \mathrm{N} / \mathrm{NI}$
$\mathrm{Y} / \mathrm{PY} / \mathrm{PN} / \mathrm{N} / \mathrm{NI}$
Low - there is clear evidence (usually through examination of a preregistered protocol or statistical analysis plan) that all reported results correspond to all intended outcomes, analyses and subcohorts.
'Risk of bias' judgement
Moderate - the outcome measurements and analyses are consistent with an a priori plan;
Low / moderate / serious / critical / NI

or 
are clearly defined and both internally and externally consistent;

and

there is no indication of selection of the reported analysis from among multiple analyses;

and

there is no indication of selection of the cohort or subgroups for analysis and reporting on the basis of the results.

Serious - outcome measurements or analyses are internally or externally inconsistent; or there is a high risk of selective reporting from among multiple analyses; or the cohort or subgroup is selected from a larger study for analysis and appears to be reported on the basis of the results.

Critical - there is evidence or strong suspicion of selective reporting of results, and the unreported results are likely to be substantially different from the reported results.

Optional: what is the predicted direction of bias due to selection of the reported result?
If the likely direction of bias can be predicted, it is helpful to state this. The direction might be characterised either as being towards (or away from) the null, or as being in favour of 1 of the interventions.
Favours experimental / favours comparator / towards null / away from null / unpredictable

\section{Overall bias}

'Risk of bias'
judgement

Low - the study is judged to be at low risk of bias for all domains.

Low / moderate / serious / critical / NI

Moderate - the study is judged to be at low or moderate risk of bias for all domains.

Serious - the study is judged to be at serious risk of bias in $\geq 1$ domain, but not at critical risk of bias in any domain.

Critical - the study is judged to be at critical risk of bias in $\geq 1$ domain.

No information - there is no clear indication that the study is at serious or critical risk of bias and there is a lack of information in $\geq 1$ key domains of bias (a judgement is required for this).

Optional: what is the overall predicted direction of bias for this outcome?
Favours experimental / favours comparator / towards null / away from null / unpredictable

N: no; NA: not applicable; NI: no information; NRSI: ; PN: probably no; PY: probably yes; Y: yes.

\section{CONTRIBUTIONS OF AUTHORS}

LE: undertook the screening and selection of trials, data extraction, assessment of risk of bias, analysis of results and preparation of the protocol and final report in addition to being the content expert of the review. 
RM: undertook the screening and selection of trials, data extraction, assessment of risk of bias, analysis of results and drafted the final report.

CD: created the search strategies and contributed to the preparation of the protocol and final report.

MT: statistical expert for this review and provided support with data analysis and contributed to the preparation of the protocol and final report.

$\mathrm{SH}$ : methodological expert for this review and provided support with data analysis and contributed to the preparation of the protocol and final report.

JB: content expert for this review and contributed to the preparation of the protocol and final report.

\section{DECLARATIONSOF INTEREST}

LE: partly funded by the National Institute of Health Research (NIHR) Cochrane Programme Grant - Safe and Appropriate Use of Blood Components.

RM: partly funded by the National Institute of Health Research (NIHR) Cochrane Programme Grant- Safe and Appropriate Use of Blood Components.

CD: none known.

MT: none known.

$\mathrm{SH}$ : none known.

JB: none known.

\section{SOURCES OF SUPPORT}

\section{Internal sources}

- NHS Blood and Transplant, Research and Development, UK.

To fund the work of the Systematic Review Initiative (SRI)

\section{External sources}

- National Institute for Health Research (NIHR) Cochrane Programme Grant, UK, Other.

To provide funding for systematic reviewers and methodological support from the Centre for Statistics in Medicine, Oxford

\section{DIFFERENCES BETWEEN PROTOCOLANDREVIEW}

There were no changes between the protocol (Estcourt 2017b) and the completed review.

\section{N DEX TERMS}

\section{Medical Subject Headings (MeSH)}

Benzoates [therapeutic use]; Deamino Arginine Vasopressin [therapeutic use]; Hemostatics [therapeutic use]; Hydrazines [therapeutic use]; Plasma; Platelet Transfusion [ ${ }^{*}$ methods]; Postoperative Care [methods]; Postoperative Hemorrhage [ ${ }^{*}$ prevention \& control]; Pyrazoles [therapeutic use]; Randomized Controlled Trials as Topic; Receptors, Fc [therapeutic use]; Recombinant Fusion Proteins [therapeutic use]; Thrombocytopenia [complications] [*therapy]; Thrombopoietin [therapeutic use]

\section{MeSH check words}

Adult; Humans 